\title{
ANALYTICAL AND EXPERIMENTAL SOLUTION FOR HEAT SOURCE LOCATED UNDER SKIN: CHEST TUMOR DETECTION VIA IR CAMERA
}

\author{
By \\ Maryam Rastgar-Jazi \\ Bachelor of Biomedical Engineering, Ryerson University, 2015
}

A thesis presented to Ryerson University in partial fulfillment of the requirements for the degree of Master of Applied Science in the program of

Electrical and Computer Engineering

Toronto, Ontario, Canada, 2017

(C) Maryam Rastgar-Jazi 2017 


\section{AUTHOR'S DECLARATION FOR ELECTRONIC SUBMISSION OF A THESIS}

I hereby declare that I am the sole author of this thesis. This is a true copy of the thesis, including any required final versions, as accepted by my examiners. I authorize Ryerson University to lend this thesis to other institutions or individuals for the purpose of scholarly research. I further authorize Ryerson University to reproduce this thesis by photocopying or by other means, in total or in part, at the request of other institutions or individuals for the purpose of scholarly research. I understand that my thesis may be may be made electronically available to the public. 


\title{
ANALYTICAL AND EXPERIMENTAL SOLUTION FOR HEAT SOURCE LOCATED UNDER SKIN: CHEST TUMOR DETECTION VIA IR CAMERA
}

\author{
Maryam Rastgar-Jazi \\ Master of Applied Science in the program of \\ Department of Electrical and Computer Engineering \\ Ryerson University \\ Toronto, Ontario, Canada, 2017
}

\begin{abstract}
Infrared (IR) imaging could be used as both noninvasive and nonionizing technology. Utilizing IR camera, it is possible to measure skin temperature with the aim of finding any superficial tumors. Since tumors are highly vascular and usually have a higher temperature than the rest of the body, using thermograms, it is possible to assess various tumor parameters, such as depth, intensity, and radius. In this study, we have developed an analytical method to detect tumor parameters in both spherical and cubical tissues to represent female breast and male chest tissue. This includes development of analytical solution for solving inverse bio-heat problem as well as laboratory set up for further validation of the analytical achievements. The models were developed by solving Penne's Bioheat equation for each tissue under certain conditions and two main assumptions:
\end{abstract}

1. The tumor was assumed as separate heat source;

2. The developed model does not change with time (steady state condition).

Finally, the analytical findings were validated by utilizing a laboratory test set-up containing an IR camera, 1\% Agar solution (tissue phantom), and a heater of variable powers. The models were set to test by adjusting the heater $(0.9 \mathrm{~W})$ in various depth and imaging the tissue phantom. Comparing the analytically obtained results with the experimental results, it can be concluded that the method is able to detect superficial tumors of small size only by measuring the body surface temperature and ambient temperature. 


\section{Acknowledgments}

I would like to thank all the people who contributed in some way to the work described in this thesis. First and foremost, I would like to thank Dr. Farah Mohammadi for her unconditional help and guidance through my MASc studies. She has constantly shared me with her pearl of wisdom. I appreciate all her contributions of time, ideas, and funding.

I would also like to thank Health care management systems Inc. for providing me with findings to work and acquire experience in machine learning algorithms.

Finally, I would like to acknowledge friends and family who supported me during research. First and foremost, I would like to thank my parents and my fiancé for their constant love and support. Also, I would like to thank my lab mates for their emotional and intellectual support during the course of this study. 


\section{Table of Contents}

Acknowledgments $\quad$ iv

Table of Contents $v$ v

List of Tables

List of Figures

List of Nomenclature $\quad$ xii

Subscripts $\quad$ xii

$\begin{array}{ll}\text { Chapter } 1 & 1\end{array}$

1 Introduction 1

$\begin{array}{lll}1.1 & \text { Background } & 1\end{array}$

$1.2 \quad$ Current Imaging Technology 4

1.2.1 Mammography 4

1.2.2 MRI

1.2.3 Positron Emission Tomography (PET) 6

$\begin{array}{lll}\text { 1.2.4 Infrared thermograms } & 7\end{array}$

$\begin{array}{lll}1.3 & \text { Challenges and limitations } & 8\end{array}$

1.4 Thesis Contribution $\quad 9$

$\begin{array}{lll}1.5 & \text { Chapters summery } & 10\end{array}$

Chapter 2 Literature Review 12

2 Introduction $\quad 12$

$\begin{array}{lll}2.1 & \text { Background } & 12\end{array}$

$\begin{array}{lll}2.2 & \text { SUMMARY } & 17\end{array}$

$\begin{array}{ll}\text { Chapter } 3 \text { Analytical solution for breast tumor (spherical model) } & 18\end{array}$

3 Introduction $\quad 18$

$\begin{array}{lll}3.1 & \text { Breast tumor modeling } & 18\end{array}$

3.2 $\quad$ Breast tumor simulation $\quad 23$

3.3 ANN model $\quad 27$

3.4 Sensitivity of data analysis $\quad 31$

$\begin{array}{lll}3.4 .1 & \text { Parameter sensitivity } & 31\end{array}$

3.4.2 Temperature sensitivity

3.5 Application $\quad 34$

$\begin{array}{lll}3.6 & \text { Summary } & 36\end{array}$

Chapter 4 Analytical solution for chest tumor (cubical model) 37

$4 \quad$ Introduction $\quad 37$

$\begin{array}{lll}4.1 & \text { Analytical model } & 38\end{array}$

$\begin{array}{lll}\text { 4.2 Chest tumor simulation } & 41\end{array}$

4.2.1 Effect of the heat source parameters on the surface temperature 42

$\begin{array}{lll}\text { 4.2.2 } & \text { ANN model } & 46\end{array}$ 
$\begin{array}{lll}4.3 & \text { Data sensitivity analysais } & 48\end{array}$

$\begin{array}{lll}\text { 4.3.1 } & \text { Parameter sensitivity } & 48\end{array}$

$\begin{array}{lll}\text { 4.3.2 } & \text { Temperature sensitivity } & 49\end{array}$

$\begin{array}{lll}4.4 & \text { Summary } & \mathbf{5 0}\end{array}$

Chapter 5 Experimental results of the breast model

5 Introduction $\quad 51$

$\begin{array}{lll}5.1 & \text { Experimental tests } & 54\end{array}$

5.1.1 Experiment $1 \quad 54$

5.1.2 Experiment 2055

$\begin{array}{lll}5.1 .3 & \text { Experiment } 3 & 57\end{array}$

$\begin{array}{lll}\mathbf{5 . 2} & \text { Control experimental tests } & \mathbf{5 8}\end{array}$

$\begin{array}{lll}\text { 5.2.1 Control experiment } 1 & 58\end{array}$

$\begin{array}{lll}\text { 5.2.2 } & \text { Control experiment } 2 & 60\end{array}$

5.2.3 Control experiment $3 \quad 61$

$\begin{array}{lll}5.3 & \text { Summary } & 63\end{array}$

Chapter 6 Experimental results of the chest model $\quad 64$

6 Introduction $\quad 64$

$\begin{array}{lll}6.1 & \text { Experimental Tests } & 66\end{array}$

$\begin{array}{lll}6.1 .1 & \text { Experiment } 1 & 67\end{array}$

6.1.2 Experiment $2 \quad 69$

$\begin{array}{lll}6.1 .3 & \text { Experiment } 3 & 70\end{array}$

$\begin{array}{lll}6.2 & \text { Control experimental tests } & 72\end{array}$

$\begin{array}{lll}\text { 6.2.1 Control experiment } 1 & 72\end{array}$

$\begin{array}{lll}\text { 6.2.2 } & \text { Control experiment } 2 & 73\end{array}$

6.2.3 Control experiment $3 \quad 74$

$\begin{array}{lll}6.3 & \text { Heater with fixed temperature } & 76\end{array}$

$\begin{array}{lll}6.4 & \text { Summary } & 77\end{array}$

$\begin{array}{ll}\text { Chapter } 7 \text { General conclusions and future work } & 78\end{array}$

$\begin{array}{lll}7 & \text { Conclusion and future work } & 78\end{array}$

$\begin{array}{lll}7.1 & \text { Conclusions } & 78\end{array}$

$\begin{array}{lll}7.2 & \text { Summary of Contribution of this thesis } & 78\end{array}$

$\begin{array}{lll}7.3 & \text { Future work } & 79\end{array}$

$\begin{array}{ll}\text { Appendices } & 81\end{array}$

$\begin{array}{lc}\text { References } & 86\end{array}$

$\begin{array}{lc}\text { Glossary } & 93\end{array}$ 


\section{List of Tables}

\section{Table Caption}

Table 2-1 summery of various studies and along with results obtained from evaluation of 14 thermograms.

Table 3-1 Thermal and Biological Parameters of tissue.

Table 3-2: Thermal and Biological Parameters.

Table 3-3: Error analysis for optimization of the two cases.

Table4-1: Thermal and physical properties of chest (muscle) tissue.

Table 5-1: Thermal conductivity of various gelatinous materials.

Table 5-2: results of the 3 tests.

Table 5-3: comparison between the two different test sets.

Table 6-1: Thermal conductivity of various gelatinous materials. Agar $1.5 \%$ at $21{ }^{\circ} \mathrm{C}$ has the closest thermal conductivity to chest muscle.

Table 6-2: Results obtained through experiment 1-3.

Table 6-3: Results obtained through experiment 1-3 and control experiments 1-3. 


\section{List of Figures}

Figure 1-1 Breast Cancer diagnosis methods.

Figure 1-2 Typical mammogram imaging procedure. Compression of breast causes tissues substantially

Figure 1-3 A patient lying on the scanning taking MRI

6

Figure 1-4 Normal thermogram (left) V.S abnormal thermogram (right). Figure demonstrates increased temperature (metabolism) of the right breast. There are three suspicious areas of higher temperatures. Especially significant is the highly vascular area closest to the right nipple

Figure 3-1 the generated model including all the assumptions and parameters 22 namely: depth, intensity, and radius measurement model.

Figure 3-2 Fixed intensity and varying depth: Surface Temperature directly depends 24 on the depth wherein the heat source is located.

Figure 3-3 Fixed heat source depth and varying intensity: Variation in intensity 25 affects the area over which temperature rises.

Figure 3-4 Fixed intensity and varying depth for a spherical object with $\mathrm{R}=0.005$ : Temperature on the model surface directly depends on the depth wherein the heat source is located.

Figure 3-5 Fixed heat source depth and varying intensity for a spherical object with 26 $\mathrm{R}=0.005$ : Variation in intensity affects the area over which temperature rises.

Figure 3-6 Fixed heat source depth and fix intensity for spherical objects with 27 varying Rs.

Figure 3-7 Heat source model and ANN simulated model

Figure 3-8 Noisy model of analytical solution with and without ANN simulation. 29 Maximum temperature increases after optimization process to a more accurate temperature.

Figure 3-9 A comparison between the optimized and non-optimized parameters 31 (depth and radius) assuming a spherical breast of diameter $10 \mathrm{~cm}$.

The larger sphere illustrates the optimized location of the tumor with in the breast tissue.

Figure 3-10 Sensitivity studies with $20 \%$ change in data.

Figure 3 - 11 Sensitivity models with $\pm 5 \%$ change in surface temperature. There is 33 about $1.41^{\circ} \mathrm{C}$ difference between maximum temperatures.

Figure 3-12 Sensitivity models with $\pm 5 \%$ (of maximum and minimum points) 34 
change in surface temperature.

Figure 3-13 Thermal image of breast with an abnormal mass in the right breast.

Figure 3-14 Maximum temperature provided by the algorithm.

Figure 4-1 Chest structure and its tissue integrity as well as the assumed dimensions 39 as proposed by Md. S. Hossain et al.

Figure 4-2 Conditions and approximations for solving the inverse heat conduction 40 (IHCP) deducted according to conditions 1 to 5 stated in section 4.1.

Figure 4-3 Fixed core temperature at $37{ }^{\circ} \mathrm{C}$ and varying depth. Surface temperature 43 of the model is directly dependent on the depth of the heat source.

Figure 4-4 Fixed intensity and varying depth. Maximum temperature decreases as depth increase. In other words, depth and $\mathrm{T}_{\max }$ are inversely proportional.

Figure 4-5 Fixed core temperature of $37{ }^{\circ} \mathrm{C}$ and varying depth with $\mathrm{R}=0.008$. 44 Surface temperature of the model is directly dependent to the depth of the heat source.

Figure 4-6 Fixed intensity and varying depth. As the heat source radius increases, it 45 would be more applicable to use intensity as the basis of the calculation.

Figure 4-7 Fixed depth and varying radius. It could be seen that as the heat source 45 radius increases, the area of the temperature elevation increases as well.

Figure 4-8 Analytical Model and ANN simulated model. Using ANN optimization 46 technique, the heat source parameters were optimized to a more accurate value.

Figure 4-9 Analytical model and ANN simulated model with 5\% noise. The 47 temperature difference between the two maximum peaks increase due to the random noise added to the data.

Figure 4-10 Comparison between the optimized and non-optimized parameters in 47 chest tissue for analytical model.

Figure $4-11$ (a) Sensitivity analysis with $20 \%$ change in depth value.

Figure $4-11$ (b) Sensitivity analysis with $20 \%$ and $50 \%$ change in radius value.

Figure 4-12 Sensitivity analysis with 5\% error in measured surface temperature.

Figure 5-1 the two hemispheres inside each other to mold the layers of phantoms. 51 The red line is the gap between the two bowls that is $1 \mathrm{~cm}$.

Figure 5-2 The laboratory set-up.

Figure 5-3 Phantom model.

Figure 5-4 Thermal image of a heater located at $1.5 \mathrm{~cm}$ depth having diameter of 54

$3.1 \mathrm{~mm}$. The location of the maximum temperature is shown as opaque red in the 
image.

Figure 5-5 Analytical simulation for a heater located at $1.5 \mathrm{~cm}$ depth having $\quad 55$ diameter of $3.1 \mathrm{~mm}$.

Figure 5-6 Thermal image of a heater located at $2 \mathrm{~cm}$ depth having diameter of 56 $3.1 \mathrm{~mm}$. The location of the maximum temperature is shown as opaque red in the image.

\section{Figure 5-7 Analytical simulation for a heater located at $2 \mathrm{~cm}$ depth having diameter 56} of $3.1 \mathrm{~mm}$.

Figure 5-8 Thermal image of a heater located at $3 \mathrm{~cm}$ depth having diameter of 57 $3.1 \mathrm{~mm}$. The location of the maximum temperature is shown as opaque red in the image.

Figure 5-9 Analytical simulation for a heater located at $2 \mathrm{~cm}$ depth having diameter $\quad 57$ of $3.1 \mathrm{~mm}$.

Figure 5-10 The thermal image of a heater located at $1.5 \mathrm{~cm}$ depth having diameter 59 of $3.1 \mathrm{~mm}$. The heater was located at a random corner of the heater.

Figure 5-11 Temperature profile of the heater per pixel. Maximum temperature 59 happens somewhere around 74 pixels.

Figure 5-12 The thermal image of a heater located at $2 \mathrm{~cm}$ depth having diameter of $\quad 60$ $3.1 \mathrm{~mm}$. The heater was located at a random corner of the heater.

Figure 5-13 Temperature profile of the heater per pixel. Maximum temperature 60 happens somewhere around 250 pixels.

Figure 5-14 The thermal image of a heater located at $3 \mathrm{~cm}$ depth having diameter of

61

$3.1 \mathrm{~mm}$.

Figure 5-15 Temperature profile of the heater per pixel. Maximum temperature 62 happens somewhere around 98.

Figure 6-1 Experimental set-up.

Figure 6-2 Heater housing at different depth before and after pouring the Agar 66 solution in the container.

Figure 6-3 The thermal image of a phantom wit heater at off state. Maximum 67 temperature is very close to ambient temperature.

Figure 6-4 The thermal image of a heater located at $3.4 \mathrm{~cm}$ depth having diameter of 68 $3.1 \mathrm{~mm}$. The red arrow illustrates the location of the maximum temperature and hence the tip of the heater.

Figure 6-5 Analytical solution for a heater located at $3.4 \mathrm{~cm}$ depth having diameter 68 of $3.1 \mathrm{~mm}$.

Figure 6-6 The thermal image of a heater located at $2 \mathrm{~cm}$ depth having diameter of 69 $3.1 \mathrm{~mm}$. The red arrow illustrates the location of the maximum temperature and hence the tip of the heater. 
Figure 6-7 Analytical solution for a heater located at $2 \mathrm{~cm}$ depth having diameter of $3.1 \mathrm{~mm}$.

Figure 6-8 The thermal image of a heater located at $1 \mathrm{~cm}$ depth having diameter of $3.1 \mathrm{~mm}$. The red arrow illustrates the location of the maximum temperature and hence the tip of the heater.

Figure 6-9 Analytical solution for a heater located at $1 \mathrm{~cm}$ depth having diameter of 71 $3.1 \mathrm{~mm}$

Figure 6-10 The thermal image of a heater located at $3.4 \mathrm{~cm}$ depth having diameter 72 of $3.1 \mathrm{~mm}$. The red arrow illustrates the location of the maximum temperature and hence the tip of the heater.

Figure 6-11 Temperature profile of the heater per pixel. Maximum temperature 73 happens somewhere around 70 .

Figure 6-12 The thermal image of a heater located at $3.4 \mathrm{~cm}$ depth having diameter $\quad 73$ of $3.1 \mathrm{~mm}$. The red arrow illustrates the location of the maximum temperature and hence the tip of the heater.

Figure 6-13 Temperature profile of the heater per pixel. Maximum temperature 74 happens somewhere around 158.

Figure 6-14 The thermal image of a heater located at $1 \mathrm{~cm}$ depth having diameter of 74 $3.1 \mathrm{~mm}$. The red arrow illustrates the location of the maximum temperature and hence the tip of the heater.

Figure 6-15 Temperature profile of the heater per pixel. Maximum temperature 75 happens somewhere around 76. A summary of obtained results are listed in Table 6-3.

Figure 6-16 The thermal image of a heater located at $2 \mathrm{~cm}$ depth having diameter of 76 $3.1 \mathrm{~mm}$. 


\section{List of Nomenclature}

E Total emitted radiance, $\mathrm{W} / \mathrm{m}^{2}$

$h \quad$ Average convection coefficient, $\mathrm{W} / \mathrm{m}^{2}-\mathrm{K}$

k Thermal conductivity, W/m-K

Q Heat generation, $\mathrm{W} / \mathrm{m}^{3}$

t Time, $\mathrm{s}$

S Sum of squares

T Temperature, ${ }^{\circ} \mathrm{C}$

$\beta \quad$ Model parameter vector

$\rho \quad$ Density

$\sigma \quad$ Stefan-Boltzmann constant, $\mathrm{W} \mathrm{m}^{-2} \mathrm{~K}^{-4}$

$\omega \quad$ Blood perfusion term

\section{Subscripts}

$\begin{array}{ll}\text { a } & \text { Arterial } \\ \mathrm{b} & \text { Blood } \\ \mathrm{m} & \text { Metabolic } \\ \mathrm{T}_{\text {core }} & \text { Core temperature }\end{array}$




\section{Chapter 1}

\section{Introduction}

\subsection{Background}

Breast cancer is the most common cancer in developed and undeveloped countries of the world. Breast Cancer Incidence rates vary worldwide, i.e., 19.3 per 100,000 women in Eastern Africa and 89.7 per 100,000 women in Western Europe. Additionally, the rate of survival in diagnosed women varies from $80 \%$ or over in North America and Sweden to $60 \%$ in middle-income countries and below $40 \%$ in low-income countries in less developed countries. The low survival rates in less developed countries could be related to lack of early detection means and programs and lack adequate diagnosis and treatment facilities [1].

According to Breast Cancer Society of Canada, it is estimated that in 2016, 25,700 women and 230 men were diagnosed with breast cancer. Additionally, based on 2010 estimates, about 1 in 9 Canadian women is expected to develop breast cancer during her lifetime, and 1 in 30 will die from it [2].

Various modalities are currently employed to diagnose breast cancer among which Mammogram, X-rays, MRI (Magnetic Resonance Imaging), Ultrasound, SPECT (Single Photon Emission Tomography), Positron Emission Tomography (PET), CT-Scan, and Infrared thermography. These methods have successfully detected breast cancer over many years. However, each of them has certain advantages and limitations. For example, Mammography being one of the primary methods of detection is very accurate (80\%) diagnosing cancer in individuals over 50 years old. This sensitivity is less in the younger patient. Specifically, mammograms are known to be limited [3].

Methods measuring functional processes rather than anatomical changes show the greatest promise for future improvements [4]. However, MRI and PET do assess function, high cost and being invasive have prevented their widespread deployment in breast screening and diagnosis. 
Although, Ultrasound, Mammography measure at structural level of the human body. Oppositely, Infrared (IR) Thermography assess the human body function by detecting body temperatures such as any increase or decrease due to physiological or metabolic change [5]. Therefore, achieving an accurate functional representation of the tissues in any living organism without disturbing or damaging natural body structure or function, could be achieved by IR technique. This method is not ionizing, radiation or invasive. Therefore, it brings comfort to the patient and is a safe way of diagnosis and detection.

In warm-blooded living beings such as human, temperature plays an important role in the diagnosis of the many physiological conditions. Body temperature is affected by various factors such as blood perfusion rate underneath the skin, metabolism rate, and the heat exchange rate between the body surface and the surrounding environment. Any change in the mentioned above factor would change the body temperature [6].

Malignant cells major physiological characteristic is their abnormal division rate and growth. This would result in a higher metabolism rate. Additionally, cancerous tissues are characterizing by their higher temperature due to higher vascularity of blood and lymphatic vessels. Such tissues have a higher heat flux density as well. Although, body temperature varies in the healthy individual as well $\left(0.5^{\circ} \mathrm{C}\right)$, the variation in this cases of higher local temperature on the skin where the tumor is located by several degrees (around $5^{\circ} \mathrm{C}$ ). The abnormality in the temperature could be detected by an IR camera [6]. The modern IR camera or sensor can accurately measure the spontaneous Electromagnetic (EM) energy in IR frequency that is radiated from the human body as a function of skin temperature [7]. Figure 1-1 illustrates Breast Cancer diagnosis methods. 
Wave based methods

* X-ray: Mammography

* Gamma ray: Scinti-mammography

* Positrons: Positron Emission

Tomography

* Microwave: Microwave imaging

* Infrared: Optical imaging

Thermal Energy

Heat: Thermography

Electrical properties

* Impedance: Electrical impedance imaging

* Potential: Electrical potential imaging

Audio/Magnetic field

* Radio emission: Magnetic resonance imaging

* Radio emission: Magnetic resonance spectroscopy

* Sound wave: Ultrasound

* Sound + radio emission: Electrography

* Sound + RF energy: Thermoacoustic computed tomography

* Vibration to magnetic field: Hall-effect imaging

Figure 1-1 Breast Cancer diagnosis methods $[8,9]$ 


\subsection{Current Imaging Technology}

The most common forms of breast tumors form in epithelial cells, which are found along the terminal duct lobule unit as well as glands. If this growth is restricted, the tumor is classified as benign. However, if the growth is rapid with the ability to progress to other body parts, the tumor is classified as cancerous or malignant.

Current methods of cancer detection with an emphasis on screening are summarized in in this section. These methods are based on the underlying principles of wave theory, heat energy, audio/magnetic field and electric properties. A comparative study among Mammography, MRI, Positron Emission Tomography (PET), and Thermogram is discussed in the following sections while applied to breast cancer screening.

\subsubsection{Mammography}

Mammogram as a method of breast cancer detection utilizes a low dose X-ray to produce a 2D projected image of the breast. Since each type of tissue has different X-ray absorption level, the gray level of a pixel in a mammogram gives an indication of the proportion of various tissues in the column of the breast. In the regions of the breast that there was no absorption of X-ray the mammogram appears black, and where total absorption has occurred it will appear white. Since Fibro glandular tissue has high X-ray absorption, it appears brighter that adipose tissue (fat) in mammograms. Therefore, this method is mostly effective for women of age 50 or older. Younger subjects tend to have a lot of fibro-glandular tissue with denser breast which could cause their image to be very bright and unreadable.

As mentioned above, mammograms utilize a small dose of ionizing radiation in the form of Xray. For the small dose to penetrate through breast tissue, the machine will compress or flatten the breast to spread the tissue apart using two plates. The most common angles of X-ray imaging are craniocaudal (CC), where the direction of the X-ray photon travel is head-to-toe, and mediolateral oblique (MLO), which is shoulder-to-opposite-hip. However, there are less common views namely mediolateral (ML) which are taken from the center of the chest outwards to the side, and lateromedial (LM) which is taken in an opposite direction to ML. Mammography often involves imaging the breast from two different angles of $\mathrm{CC}$ and $\mathrm{MLO}$ which would provide the 
radiologist with more accurate information [10,11]. The main disadvantage of this method of cancer detection is the fact that it is restricted by the age of the subject. Discomfort and radiating waves are other drawbacks. Figure 1-2 illustrates the imaging modality.

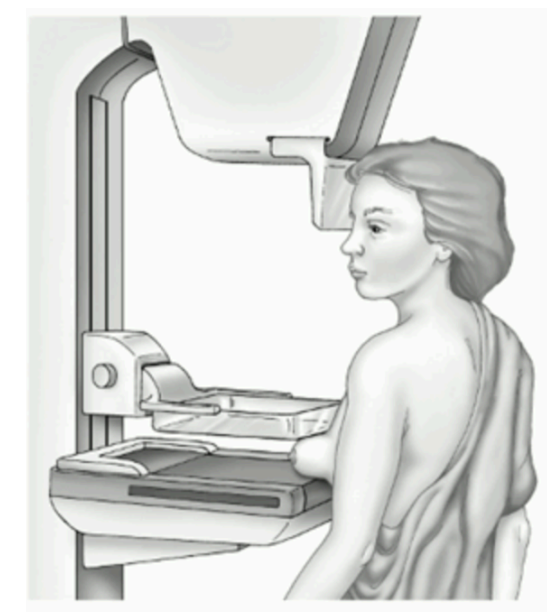

Figure 1-2 Typical mammogram imaging procedure. Compression of breast causes tissues substantially [11].

\subsubsection{MRI}

Magnetic resonance imaging (MRI) works on the basis of magnetic fields and radio waves to produce an image. The production of the picture is dependent on the distribution of hydrogen in the body. Hydrogen atoms are very magnetic due to the intrinsic spin of their nuclei, therefore, under the influence of the magnetic field the hydrogen nuclei become aligned with the field than against it, and the body acquires a net magnetization [12].

During the MRI procedure, the patient would lie face down on a special design platform while breasts will hand down. This process takes between 10 to 30 minutes taking $2 \mathrm{D}$ images of the different slices of the breast. Then a 3D image would be generated in any desired plane [12].

MRI scans have various advantages over X-ray mammograms. The main advantage is that they provide three-dimensional data on the breast. Additionally, MR imaging is not age restricted meaning that it is equally effective in younger patients as older ones. However, the resolution is a lot lower than mammograms and structures such as microcalcification cannot be resolved. 
One of the disadvantages of MR imaging is its cost. However, the main disadvantage is due to the huge magnetic fields. This would make the MR imaging not possible on patients with pacemakers or metallic implants. Additionally, images could be affected by blurring and other motion-related artefacts, motion due to both chest movements for breathing and shifts in position by the patient $[9,12]$. Figure $1-3$ shows MRI stetting.

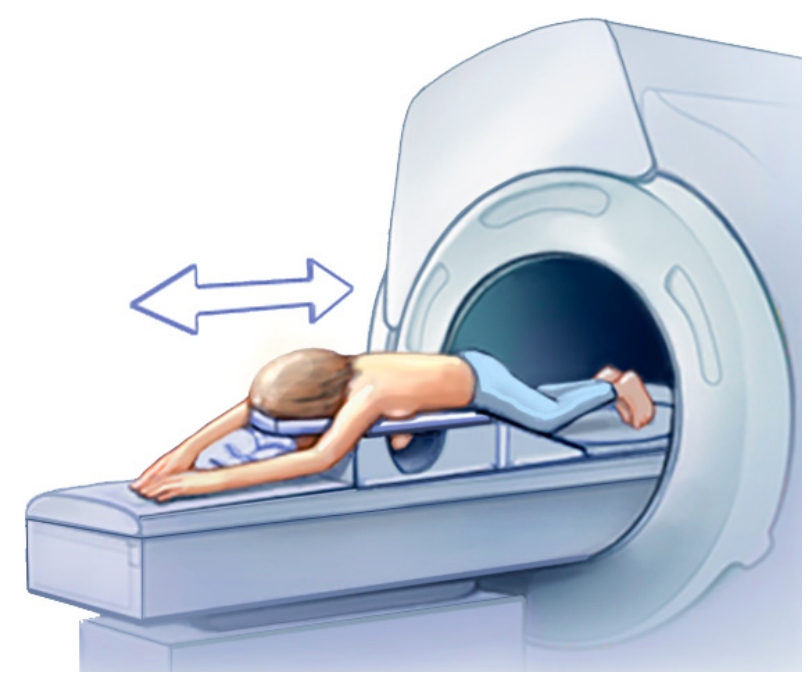

Figure 1-3 A patient lying on the scanning taking MRI [13]

\subsubsection{Positron Emission Tomography (PET)}

PET scans, short for Positron Emission Tomography, can detect areas of cancer by obtaining images of the body's cells as they work. Prior to the scan, the patient is injected with a substance made with sugar and radioactive material. Since cancer cells are more active than normal cells, they would absorb more of the radioactive substance. Scanning the patient, the areas of suspicious activity could be identified.

PET scans are not used to screen for breast cancer since they have limited ability to detect small and superficial tumors. This modality is rather used after the diagnosis of cancer to determine whether cancer has spread to the lymph nodes as well as to determine whether cancer has spread to other parts of the body (metastatic breast cancer). Additionally, PET scans could be used to evaluate whether metastatic breast cancer is responding to treatment. 
The main disadvantage of PET scans is the radiating procedure and limited ability to detect small tumors. Also, they are available in only very few centers, and the process tends to be expensive $[14,15]$.

\subsubsection{Infrared thermograms}

In warm blooded beings, the temperature could be an indication of some physiological changes during clinical diagnostics. IR thermography makes use of a thermal imager to detect the IR radiation and measure the heat pattern of the object surface or human skin $[8,16]$.

Human skin emits infrared radiation as a function of body temperature. The generated thermal energy is due to the metabolic process at the cell level as well as blood flow. Any object at room temperature having invisible radiation in infrared range could be detected by thermal imaging cameras to produce a visible image. From this image decision can be made in the medical application by $[8,9,17]$ :

- Absolute temperature

- Temperature fixture (abnormal temperature zone)

- Temperature irregularity between the left and right side of the body which is a good indication of abnormality.

The principle in thermography is that the metabolism rate and temperature in both pre-cancerous tissue and the area surrounding a developing breast cancer are almost always higher than in the healthy breast due to the greater number of blood and lymphatic vessels.

The main advantage of thermograms over mammograms is the fact that difficulties in reading mammograms can occur in women who are on hormone replacement, nursing or have fibrocystic, large, dense, or enhanced breasts. These types of breast differences do not cause difficulties in reading digital infrared scans. Additionally, scans could be performed on patients of any age without affecting the results $[18,19]$. Figure 1-4 illustrates the difference between 
thermograms obtained from normal and abnormal breast tissue.
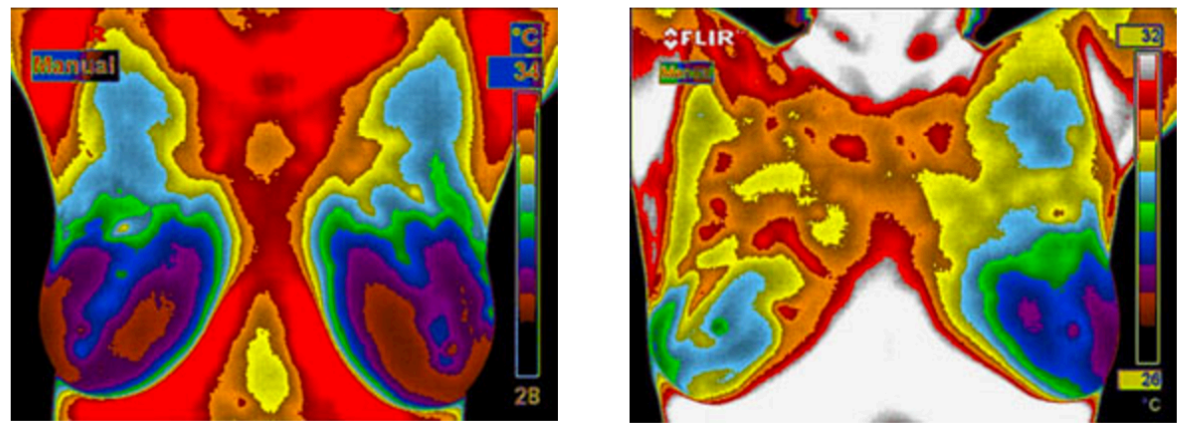

Figure 1-4 Normal thermogram (left) V.S abnormal thermogram (right). Figure demonstrates increased temperature (metabolism) of the right breast. There are three suspicious areas of higher temperatures. Especially significant is the highly vascular area closest to the right nipple [17].

\subsection{Challenges and limitations}

Presently, mammography is the most reliable mean of tumor detection. However, it associated with ionizing and frequent false positive. It is also limited by age and brings discomfort to the patient. MRI is very expensive and not always available. The same is with PET. PET is also associated with ionizing radiation.

Having drawbacks from all techniques above, we have investigated an alternative method. Thermography obtains skin surface temperatures. The temperature profile could be further studied to disclose any hidden abnormal tissue functions. Being incapable of exposing anatomical structure, thermograms could be used as a careening modality. Therefore, when used along with other imaging modalities, thermography may contribute to the best possible evaluation of breast health. Therefore, thermography could be utilized as a method of screening and detection due to the following reasons.

* There is no available test that can detect cancer with the accuracy of $99 \%$. Therefore, no test alone is sufficient for detection or screening of breast cancer.

* Thermography can not replace existing imaging process such as mammography since the two approaches search for completely different pathological process.

* Thermography is more sensitive than mammography in the case of slow-growing nonaggressive cancers that may not be detected by mammography. 
Breast thermography could be used as a complementary screening process in order to increase the sensitivity of detecting any abnormalities in breast tissue. As a unique physiological examination procedure, breast thermography is the only known test that can also serve as an early warning system by identifying women who have high-risk pre-cancerous infrared imaging markers [9].

\subsection{Thesis Contribution}

This study has developed a methodology with regards to finding the relation between surface temperatures with thermal, biological and physical parameters of tumors. By developing an analytical method, the depth, and radius of the tumor was estimated. The results were validated by a unique experimental set-up.

Penne's bioheat equation was utilized to drive an analytical method as well as optimizing the existing methods. A physically accurate model was developed for chest and breast tissue considering their thermal properties, the behavioral variation of tissues found in different layers, and physical shape of the above organs. Additionally, if any, bio-thermo-physical variations in embedded tumors or cancer tissues inside the bodies were considered. Assuming a uniform biothermal property within an entire organ, an approximate model has been developed. This model is called homogeneous or simplistic model, and the bio-heat transfer problem has been addressed analytically.

To optimize the obtained results, a 3-layer feed forward artificial neural network (ANN) was created using MATLAB tool box. ANN was trained by the data library created previously by solving the finite element model in multi-physic COMSOL [9]. Optimization algorithms have been tailored for each method to estimate tumor physio-bio-thermal parameters like the intensity, size, and depth.

Finally, a laboratory set-up was developed to measure the accuracy of the obtained results. This was carried out by mixing Agar powder with different concentration according to thermal properties of each tissue. A heater was embedded inside the phantom at various depth and imaging the system. During the testing, it was important to monitor the room temperature so we 
could input it in the algorithm for validation of our results. Inputting the size, depth, and the room temperature in the algorithm, the analytical and experimental results were compared and validated.

\subsection{Chapters summery}

\section{Chapter 2}

Chapter 2 will describe the literature review. In this chapter, some studies along with their results have been discussed. Studies, conducted before 2000, had investigated the efficacy of thermograms for early cancer detection regarding Sensitivity (False-negative rate) and Specificity (False-positive rate). However, recent studies have been using thermal information obtained from the skin surface and correlated it to physiological changes. The chapter summarizes major studies and their shortcomings relating to thermogram.

\section{Chapter 3 and Chapter 4}

These chapters will cover the analytical solution for breast and chest tumor respectively. In each chapter, an analytical model was developed by solving for Penne's bioheat equation under the particular assumption. Model parameters were obtained by step by step solving of bioheat problems in homogeneous tissues. Finally, the effect of each parameter on surface temperature was studied, and parameters were optimized using Artificial Neural Network for each tissue type.

\section{Chapter 5 and Chapter 6}

The two models were tested by developing a laboratory set-up. Agar solution was used a tissue phantom, and a small cartridge heater was embedded inside it to act as a tumor. The heater $0.9 \mathrm{~W}$ was located at different depths inside the phantom and was imaged using an infrared camera. The experimental findings were compared to analytical ones. Therefore, the mathematical model was validated by conducting the test. 


\section{Chapter 7}

This chapter will present the conclusion, summary of the contributions of the thesis, and future works. Finally, the reference section will cover all the sources used in this study. 


\section{Chapter 2 \\ Literature Review}

\section{Introduction}

Thermography measures the heat radiated from the skin surface. The energy that is emitted from the skin surface is in the infrared frequency range, and the relation between the radiated energy and temperature is defined by Stefan-Boltzmann law. The Stefan-Boltzmann law states that "The thermal energy radiated by a blackbody radiator per second per unit area is proportional to the fourth power of the absolute temperature" and its given by [20]:

$$
\frac{P}{A}=\sigma T^{4} \quad\left(\frac{j}{m^{2} s}\right)
$$

Where $\mathrm{P}$ is the net radiated power, $\mathrm{A}$ is the radiating area, $\sigma=5.6703 \times 10^{-8}\left(\frac{\text { watt }}{m^{2} K^{4}}\right)$ is Stefan's constant, and $\mathrm{T}$ is the temperature of the radiator.

Empirical evidence suggests that underlying tumors could affect the surface temperature due to their high metabolism and blood flow rate. Therefore, inherent ability to detect subtle, vascular and physiological changes has promoted infrared imaging technique as the method of early cancer detection.

\subsection{Background}

In 1957, Lawson discovered that the skin temperature over cancer in the breast was higher than that of healthy tissue. He first used surface temperature for tumor detection 1959 [21]. In 1969, Draper and Jones used IR scans to examine the relationship between the body temperature and different diseases [22]. In 1971, Feasy et al. used point heat sources to investigate the effects of natural and forced cooling on tumors thermographic patterns. The findings of this study suggest that tumor depth alone affects temperature distribution. Hence, surface cooling would not affect temperature distribution [23].

As well, in 1972, Davison and colleagues suggested that there exists a "linear relation between the depth of tumor and the width at half height of the resultant skin temperature distribution" 
which is independent of the tumor radius. During past decades, however, more studies have been conducted on this subject among which, thermographing breast tumor in 5800 patients to measure tumor temperature [24]. Numerous medical centers and clinics have started using thermograms for diagnostic purposes since the 1970s. The "Department of Health Education and Welfare" and the "Food and Drug Administration" has approved the thermography as an adjunctive diagnostic screening procedure for the detection of breast cancer in 1972 and 1982.

The medical application of thermography was very limited in the past years due to high cost and poor sensitivity provided by the output data generated by infrared cameras that were available at that time. However, Nowadays, with the advances in thermography and infrared cameras, infrared technology have again promoted its medical application as a promising non-invasive tool for imaging the functionality of superficial layers of tissues. Lawson [21] proposed the use of thermography as a mean of detection of breast cancer. He observed that the local of the skin over a tumor were significantly higher (approximately $2^{\circ} \mathrm{C}-3^{\circ} \mathrm{C}$ ) than the normal skin temperatures. Lawson and Chughtai [21,54] have concluded that the region temperature difference over a tumor is as a result of convection effects associated with increased blood perfusion, and the increased metabolism around the tumor. Further aspects of IR imaging techniques and detection methods of breast cancer from infrared images are described in detail by Diakides and Bronzino [55].

Also, Santa Cruz et al. [56] after making a comparative investigation between thermography and boron neutron capture therapy (BNCT), concluded that the thermography, a potential imager of tissue functionalities, can help to locate abnormally high-temperature regions as well as melanoma nodules that are virtually invisible in CT images. 
Table 2-1 summarizes some of the studied that have been conducted over the years along with their results.

Table 2-1 Summery of various studies along with results obtained from evaluation of thermograms.

\begin{tabular}{|c|c|c|c|c|}
\hline Size & Method & Results & Reference & Specifics \\
\hline $\begin{array}{l}4,000 \\
\text { women }\end{array}$ & Thermography & $\begin{array}{l}\text { - Results obtained showed } \\
94 \% \text { sensitivity along } \\
\text { with } 6 \% \text { of false positive } \\
\text { rate. }\end{array}$ & [25] & - \\
\hline $\begin{array}{l}\text { 61,000 } \\
\text { women }\end{array}$ & $\begin{array}{l}\text { Thermography } \\
\text { on abnormal } \\
\text { breast }\end{array}$ & $\begin{array}{l}\text { Detected } 91 \% \text { non } \\
\text { palpable cancer. } \\
\text { Predicted the risk factor } \\
\text { for future development of } \\
\text { caner more accurately } \\
\text { than radiographic } \\
\text { suspicion of malignancy. }\end{array}$ & [26] & $\begin{array}{l}\text { Study was } \\
\text { conducted for } 10 \\
\text { years. }\end{array}$ \\
\hline $\begin{array}{l}37,506 \\
\text { women }\end{array}$ & Thermography & $\begin{array}{l}\text { - } 12 \% \text { false-negative } \\
\text { - } 14 \% \text { false-positive } \\
\text { - } \quad \text { early indication that } 10 \% \\
\text { would have breast cancer. }\end{array}$ & [27] & - \\
\hline $\begin{array}{l}\text { 4,393 } \\
\text { women }\end{array}$ & $\begin{array}{l}\text { Thermography } \\
\text { and } \\
\text { mammograms }\end{array}$ & $\begin{array}{l}\text { - mammogram: } 7 \text { cancers } \\
\text { per } 1000 \\
\text { Thermograms: } 1,028 \text { with } \\
\text { abnormal images. } \\
\text { - Combined methods: } 24.1 \\
\text { cancers per } 1000 .\end{array}$ & [28] & $\begin{array}{l}\text { Combined } \\
\text { method increased } \\
\text { the sensitivity by } \\
10 \% \text {. }\end{array}$ \\
\hline $\begin{array}{l}39,802 \\
\text { women }\end{array}$ & $\begin{array}{l}\text { Thermograms, } \\
\text { mammogram, } \\
\text { and physical } \\
\text { testing. }\end{array}$ & $\begin{array}{l}\text { - } 85 \% \text { sensitivity } \\
\text { - } 70 \% \text { specificity for } \\
\text { thermography. }\end{array}$ & [29] & $\begin{array}{l}\text { The study was } \\
\text { conducted over } 3 \\
\text { years. } \\
\text { Results indicated } \\
\text { thermograms } \\
\text { to detect earlier } \\
\text { stage tumors. }\end{array}$ \\
\hline
\end{tabular}




\begin{tabular}{|c|c|c|c|c|}
\hline $\begin{array}{l}4,716 \\
\text { women } \\
\text { (cancer) } \\
3,305 \\
\text { (benign) } \\
8,757 \\
\text { (healthy) }\end{array}$ & $\begin{array}{l}\text { Thermograms, } \\
\text { mammogram, } \\
\text { and clinical } \\
\text { testing. }\end{array}$ & $\begin{array}{l}\text { - Thermography: } \\
\text { Sensitivity of } 85 \% \text { in } \\
\text { tumors less than } 1 \mathrm{~cm} \text { in } \\
\text { size specificity } 85 \% \text {. } \\
\text { Mammography: } \\
\text { Sensitivity } 80 \% \text { and } \\
\text { specificity } 73 \% \text {. } \\
\text { Clinical examination: } \\
\text { Sensitivity of } 50 \% \text { in } \\
\text { cancers less than } 2 \mathrm{~cm} \text { in } \\
\text { size. }\end{array}$ & {$[30]$} & $\begin{array}{l}\text { The study found } \\
\text { that the } \\
\text { combination of } \\
\text { multiple } \\
\text { approaches gives } \\
\text { better results in } \\
\text { detecting cancer. }\end{array}$ \\
\hline $\begin{array}{l}4,000 \\
\text { women }\end{array}$ & $\begin{array}{l}\text { Thermograms } \\
\text { and } \\
\text { mammogram }\end{array}$ & $\begin{array}{l}\text { mammography: } 10 \% \\
\text { cancer detection only, } \\
\text { - } 50 \% \text { by thermography } \\
\text { alone, } \\
\text { - } 40 \% \text { by combined } \\
\text { techniques. }\end{array}$ & [31] & $\begin{array}{l}130 \\
\text { sub-clinical } \\
\text { carcinomas } \\
\text { ranging in } \\
\text { diameter of } 3-5 \\
\text { mm was found. }\end{array}$ \\
\hline $\begin{array}{l}58,000 \\
\text { women }\end{array}$ & Thermography & $\begin{array}{l}\text { - } 40 \% \text { of healthy subjects } \\
\text { had abnormal } \\
\text { thermograms. } \\
\text { - They developed breast } \\
\text { cancer in the span of } 5 \\
\text { years. }\end{array}$ & {$[32]$} & $\begin{array}{l}\text { Abnormal } \\
\text { thermogram is the } \\
\text { single most } \\
\text { important marker } \\
\text { of high risk for } \\
\text { the future } \\
\text { development of } \\
\text { breast cancer. }\end{array}$ \\
\hline
\end{tabular}

As it can be seen in Table 2-1, many studies have suggested thermograms as a promising screening tool to determine early stage tumor accurately much sooner before mammograms.

Additionally, studies from the late 1900s indicate thermograms as a promising detection tool as body surface temperature is affected by metabolic rate and blood flow through the mass growing at a certain location [49].

In a study by Gautherie et al. [50], approximately 58,000 patients, a group of 1,245 women between the ages of 32 and 53 years was carefully followed during a twelve-year period due to questionable thermograms. The relationship between metabolic heat generation and the tumor doubling time was found to be proportional. It was concluded that the heat generated by the cancerous tissue with a very short doubling time of fewer than 50 days is, about $70 \mathrm{~mW} / \mathrm{cm} 3$, which was more than what was recorded for the most thermogenic healthy tissue and remarkably 
higher than what was found in normal glandular breast tissues $(12 \mathrm{~mW} / \mathrm{cm} 3)$.

In another paper by Molls et al. [51], it is mentioned that tumors have a more acidic and hypoxic microenvironment than normal tissue, therefore, to overcome hypoxia tumor induces a new vascular supply. Which in turn causes increased blood perfusion. It was observed that an increase in blood flow of $150 \mathrm{ml} / 100 \mathrm{~g} / \mathrm{min}$ causes an increase in thermal conductivity of $0.05[\mathrm{~W} /(\mathrm{m} . \mathrm{K})]$.

the internal temperature distribution was obtained by solving for Penne's bioheat equation assuming various boundary conditions and the influence of thermal conductivity, metabolism, blood perfusion and heat exchange rate was studied for homogeneous and isotropic tissues [52, $53]$.

Research, mostly carried out in the last decade, observed the theoretical studies of the thermal behavior of the human organ by Direct Solving the Pennes bio-heat transfer equation analytically.

In a study by Barrea et al. [57], the bio-heat problem was solved in the 3D rectangular tissue model by employing Finite difference method (FDM) scheme coupled with the Pattern Search Algorithm. They have used this methodology to locate the tumor, like melanoma nodules and estimate tumor parameters which are useful and important to study the tumor evolution after a treatment procedure. Additionally, in another study by M. Mital [42], he has the development of an in-vitro model experimental and evolutionary method, to determined parameters of an embedded heat source representing a tumor using IR. Again, he was able to estimate the parameters of integrated heat source representing a tumor using IR.

A literature survey indicates that only a few works $[42,57]$ have been conducted to estimate tumor parameters from a thermogram image. Other presented studies impose various limitations such as an anatomically accurate physical model of an organ considering its geometry and the tissue heterogeneity.

Sudharsan et al. [58] have proposed an anatomically correct model of the breast. However, the assumptions that were made to design tissue layers for all the models were inappropriate and inaccurate. In conclusion, results obtained from those studies were not validated and were not 
suitable for clinical application.

The objective of this study is the development of a novel methodology for correlating surface temperatures with hyperactive cell's thermal and physical behavior. During this study, accurate anatomical models of superficial human organs are developed in consideration of the geometrical and behavioral variation of biological tissues for tumor, and the problem has been addressed in numerical methods.

Most of the previous studies conducted, focus on diagnosis and detection for breast cancer patients only. However, the idea of this work is to use thermography- temperature profiles to predict the location, size and metabolism of tumors embedded in breast and chest tissue. In general, the superficial organs of the human body have flat and curved outlook. Therefore, the organs are modeled either as a solid rectangle, or hemisphere respecting to their physical structure, and the tumor is modeled as a spherical heat source.

This study also has applied Artificial Neural Network (ANN) optimization approaches to forecasting the thermal and physiological parameters of tumors developed in the breast and chest.

\subsection{SUMMARY}

Various studies have been conducted on large patient population with long survey periods. As a result of this studies carried out by studying over 300,000 women participants, and researching for over 30 years, thermograms ability to detect breast cancer has been demonstrated. However,

unfortunately, thermograms are not used widely in clinical practices in spite of the considerable research database and continued improvements in both thermographic technology and image analysis. 


\section{Chapter 3 \\ Analytical solution for breast tumor (spherical model)}

\section{Introduction}

Bioheat equation was developed by Penne during the year of 1948. The main principle of this equation is that the rate of heat transfer between blood and tissue is proportional to the product of the volumetric perfusion rate and the difference between the arterial blood temperature and the local tissue temperature [33].

$$
h_{b}=V \rho_{b} C_{b}(1-k)\left(T_{a}-T\right)
$$

where $h_{b}$ is the rate of heat transfer per unit volume of tissue, $V$ is the perfusion rate per unit volume of tissue, $\rho_{b}$ is the density of blood, $C_{b}$ is the specific heat of blood, $\mathrm{k}$ is a factor that accounts for incomplete thermal equilibrium between blood and tissue, $\mathrm{T}_{\mathrm{a}}$ is the temperature of arterial blood, and $\mathrm{T}$ is the local tissue temperature.

\subsection{Breast tumor modeling}

Infrared thermography could be used for measurement of skin surface temperature. To calculate tumor parameters from the obtained thermogram, it is essential to solve for inverse bioheat equation. The bioheat model was used in this study. This model was developed by solving the inverse heat conduction problem (IHCP) based on Penne's bioheat transfer equation [33].

$$
\rho c\left(\partial \mathrm{T}\left(\mathrm{r}^{\overrightarrow{1}}, \mathrm{t}\right) / \partial \mathrm{t}\right)=\nabla \mathrm{k}(\mathrm{r}) \nabla \mathrm{T}(\mathrm{r}, \mathrm{t})+\omega_{\mathrm{b}} \rho_{\mathrm{b}} \mathrm{c}_{\mathrm{b}}\left[\mathrm{T}_{\mathrm{a}}(\overrightarrow{\mathrm{r}}, \mathrm{t})-\mathrm{T}(\mathrm{r}, \mathrm{t})\right]+\mathrm{Q}(\overrightarrow{\mathrm{r}}, \mathrm{t}) \quad \mathrm{r} \in \mathrm{Q}
$$

where $\operatorname{\rho c}(\partial \mathrm{T}(\mathrm{r}, \mathrm{t}) / \partial \mathrm{t})$ is a transient term indicating the change in the temperature as a function of time. $\nabla \mathrm{k}(\overrightarrow{\mathrm{r}}) \nabla \mathrm{T}(\overrightarrow{\mathrm{r}}, \mathrm{t})$ is the heat conduction equivalent. Additionally, $\rho$, and $\mathrm{c}$ are defined as density and specific heat of the tissue. $\mathrm{k}(\mathrm{r})$ is thermal conductivity of the medium. $\omega_{\mathrm{b}} \rho_{\mathrm{b}} \mathrm{c}_{\mathrm{b}}\left[\mathrm{T}_{\mathrm{a}}(\mathrm{r}\right.$, $\mathrm{t})-\mathrm{T}(\overrightarrow{\mathrm{r}}, \mathrm{t})]$ defines blood perfusion and $\mathrm{Q}(\mathrm{r}, \mathrm{t})$ is the metabolic heat rate.

In order to solve for inverse bioheat equation, several assumptions have been made: 
1. breast tissue is mainly composed of adipose tissue.

2. bioheat model is assumed to be static, and hence, time has no effect on the model.

3. Model is homogeneous and isotropic with constant $\rho, \mathrm{c}$, and $\mathrm{k}$.

4. $\omega_{\mathrm{b}} \rho_{\mathrm{b}} \mathrm{c}_{\mathrm{b}}\left[\mathrm{T}_{\mathrm{a}}(\mathrm{r}, \mathrm{t})-\mathrm{T}(\mathrm{r}, \mathrm{t})\right]$ and $\mathrm{Q}(\overrightarrow{\mathrm{r}}, \mathrm{t})$ are considered to be constant heat source embedded in breast tissue. The heat generated by tumor is assumed as an additional heat source. These two were addressed by solving for an "equivalent point source" problem.

Hence, equation (3-2) can be rewritten as:

$$
\rho c(\partial \mathrm{T}((\overrightarrow{\mathrm{r}}) / \partial \mathrm{t})=\nabla[\mathrm{k} \nabla \mathrm{T}(\overrightarrow{\mathrm{r}})]+\mathrm{Q} \delta(\overrightarrow{\mathrm{r}})
$$

With $\partial \mathrm{T} / \partial \mathrm{t}=0$ since the model is static.

$$
\nabla^{2} \mathrm{~T}(\overrightarrow{\mathrm{r}})=(-1 / \mathrm{k}) \mathrm{Q} \delta(\overrightarrow{\mathrm{r}})
$$

where $\nabla^{2}=\left(\partial^{2} / \partial \mathrm{x}^{2}\right)+\left(\partial^{2} / \partial \mathrm{y}^{2}\right)+\left(\partial^{2} / \partial \mathrm{z}^{2}\right)$ is the Laplace term.

At the tissue surface, heat transfer is mainly convection mechanism.

In order to solve for a three dimensional model, an spherical coordinate was developed with the point heat source at the origin with body temperature as a function of $r, \varphi$, and $\theta$. Also, there exists a spherical symmetry with $\frac{\partial T}{\partial \theta}=0$ and $\frac{\partial T}{\partial \varphi}=0$.

$$
\begin{gathered}
\frac{1}{r^{2}} \frac{\partial}{\partial r}\left(r^{2} \frac{\partial T}{\partial r}\right)+\frac{1}{r^{2} \sin \theta} \frac{\partial}{\partial \theta}\left(\sin \theta \frac{\partial T}{\partial \theta}\right)+\frac{1}{r^{2} \sin \theta} \frac{\partial^{2} T}{\partial \varphi^{2}}=\frac{-Q}{k} \delta(r) \\
\frac{1}{r^{2}} \frac{\partial}{\partial r}\left(r^{2} \frac{\partial T}{\partial r}\right)=\frac{-Q}{k} \delta(r)
\end{gathered}
$$

we have solved the problem in two different sections:

1. $r \neq 0$

2. $r=0$

For the first assumption, equation (3-6) transforms into : 


$$
\frac{\partial T^{2}}{\partial r^{2}}+\frac{2}{r} \cdot \frac{\partial T}{\partial r}=0
$$

With a general equation form of $\mathrm{T}=(-\mathrm{c} / \mathrm{r})+\mathrm{D}$ with a constant $\mathrm{c}$ and $\mathrm{D}$.

In addition, for the latter assumption, $\mathrm{r}=0$, the volume integral is used to solve for the problem with $\mathrm{r}$ being the radius of the sphere (a positive number $\varepsilon$ ) and $\mathrm{v}$ being the sphere itself. According to Gaussian theorem [34]

$$
\begin{gathered}
\iiint \nabla^{2} \mathrm{~T} \mathrm{dv}_{\varepsilon}=\oiint \nabla \mathrm{T} . \mathrm{ds} \\
\oiint \frac{C}{r^{2}} \cdot \mathrm{ds}=-\mathrm{Q} / \mathrm{k}
\end{gathered}
$$

To find C we can take the limit of equation [34] :

$$
\begin{gathered}
\lim _{\varepsilon \rightarrow 0} \oiint \frac{C}{r^{2}} \cdot \mathrm{ds}=\frac{C}{\varepsilon^{2}} \cdot 4 \pi \varepsilon^{2} \\
C=\frac{-Q}{4 \pi k}
\end{gathered}
$$

Also assuming environmental temperature being $\mathrm{T}_{\mathrm{e}}[34]$ :

$$
\mathrm{D}=\lim _{\varepsilon \rightarrow \infty} T=\mathrm{T}_{\mathrm{e}}
$$

Finally, the temperature distribution of the tissue in three dimensional coordinates can be expressed as [34]:

$$
T(r, \varphi, \theta)=\frac{Q}{4 \pi k r}+\mathrm{T}_{\mathrm{e}}
$$

A cancerous tissue can be modeled with intensity $\mathrm{Q}$, radius $\mathrm{R}$, and depth $\mathrm{d}$ in spherical coordinates. Considering an ideal condition (radiated heat from the heat source is exchanged with environment entirely).

$$
\begin{gathered}
Q_{\text {in }}=Q_{\text {out }} \\
\mathrm{Q} / 4\left[(\mathrm{~d}+\mathrm{R})^{2}+\mathrm{a}^{2}\right]=\mathrm{h} 0\left(\mathrm{~T}_{(\mathrm{a})}-\mathrm{T}_{\mathrm{e}}\right)
\end{gathered}
$$


Hence :

$$
\mathrm{T}_{(\mathrm{a})}=\mathrm{T}_{\mathrm{e}}+\mathrm{Q} /\left(4 \mathrm{~h}_{0}\left[(\mathrm{~d}+\mathrm{R})^{2}+\mathrm{a}^{2}\right)\right.
$$

Where $h_{0}$ is the heat exchange coefficient, $\mathrm{T}_{(\mathrm{a})}$ is the temperature at the surface, and $\mathrm{T}_{\mathrm{e}}$ is the environment temperature.

The heat source parameters such as depth, radius, and heat intensity of the proposed model are calculated through the following equations:

$$
\begin{gathered}
\frac{Q}{4[(\mathrm{~d}+\mathrm{R}) 2+\mathrm{a} 2]}=\mathrm{h}(\mathrm{T}(\mathrm{a})-\mathrm{Te}) \\
d=\frac{a \sqrt{\mathrm{T}(\mathrm{a})-T e}}{\sqrt{T m a x-T(a)}} \\
R^{3}=\frac{\left(T_{a}-T_{e}\right)\left(a^{2}+d^{2}\right) 4 \pi h}{q_{m} \times 10^{-6}} \\
\mathrm{R}=\sqrt[3]{\frac{Q}{Q_{m} A_{t}}} \\
T(a)=\frac{T(e)+T(\max ) \frac{d^{2}}{a^{2}}}{1+\frac{d^{2}}{a^{2}}}
\end{gathered}
$$

where $Q_{m}$ is the metabolic heat generation $\left(\mathrm{W} / \mathrm{m}^{3}\right)$, and $A_{t}$ is the volume of a single cell as $1 \mu \mathrm{m}$, $h$ is the heat exchange coefficient, $\mathrm{T}_{(\mathrm{a})}$ is the temperature at the surface, $\mathrm{T}(\max )$ is the maximum temperature, $q_{m}$ is Metabolic heat generation (breast), and $\mathrm{T}_{\mathrm{e}}$ is the environment temperature. Figure 3-1 shows generated model for parameter estimation. 


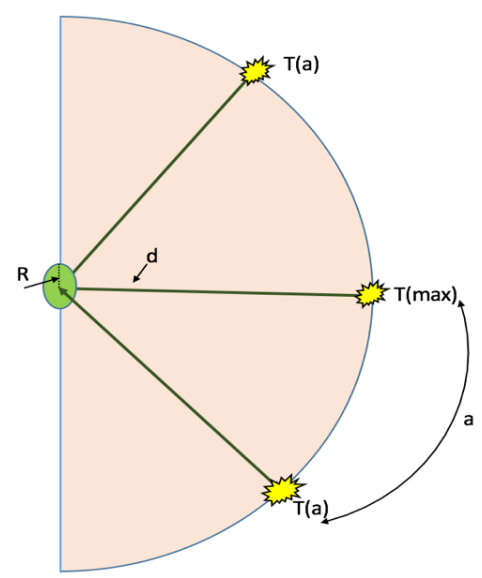

Figure 3-1 Generated model including all the assumptions and parameters namely: depth, intensity, and radius measurement model.

Additionally, the thermal and biological parameters of sound tissue at room temperature of 27 ${ }^{\circ} \mathrm{C}$ are listed in Table 3-1.

Table 3-1 Thermal and Biological Parameters of tissue $[35,36]$.

\begin{tabular}{|c|c|c|c|}
\hline Parameter & Symbol & Value & Unit \\
\hline $\begin{array}{l}\text { Thermal conductivity } \\
\quad>\text { Muscle } \\
>\text { Fat }\end{array}$ & $\mathrm{K}$ & $\begin{array}{l}0.52 \\
0.21\end{array}$ & $\mathrm{~W} /(\mathrm{m} . \mathrm{K})$ \\
\hline Heat exchange coefficient & $\mathrm{h}_{\mathrm{a}}$ & 8.77 & $\mathrm{~W} /\left(\mathrm{m}^{2} \cdot \mathrm{K}\right)$ \\
\hline $\begin{array}{l}\text { Specific heat } \\
\quad>\text { Every where }\end{array}$ & $\mathrm{c}_{\mathrm{b}}$ & 4186 & $\mathrm{~J} /(\mathrm{kg} . \mathrm{K})$ \\
\hline $\begin{array}{l}\text { Density } \\
\qquad>\text { Every where }\end{array}$ & $\rho_{b}$ & 1000 & $\mathrm{Kg} / \mathrm{m}^{3}$ \\
\hline $\begin{array}{l}\text { Metabolic heat generation } \\
\text { (breast) }\end{array}$ & $\mathrm{q}_{\mathrm{m}}$ & 700 & $\mathrm{~W} / \mathrm{m}^{3}$ \\
\hline $\begin{array}{l}\text { Metabolic heat generation of } \\
\text { tumor }\end{array}$ & $\mathrm{Q}_{\mathrm{t}}$ & $25000-90000$ & $\mathrm{~W} / \mathrm{m}^{3}$ \\
\hline $\begin{array}{l}\text { Perfusion rate } \\
\quad>\text { Muscle } \\
\quad>\text { Fat }\end{array}$ & $\omega_{\mathrm{b}}$ & $\begin{array}{l}0.00052 \\
0.00022\end{array}$ & $1 / \mathrm{s}$ \\
\hline Arterial blood temperature & $\mathrm{T}_{\text {artery }}$ & 37 & ${ }^{\circ} \mathrm{C}$ \\
\hline Environmental temperature & $\mathrm{T}_{\mathrm{e}}$ & 27 & ${ }^{\circ} \mathrm{C}$ \\
\hline
\end{tabular}




\subsection{Breast tumor simulation}

In order to evaluate the effect of parameters such as depth (d), intensity (Q), and radius (R) on the model equations (3-17) and (3-21) was utilized. A parametrtic study was performed in MATLAB ${ }^{\circledR}$ varying one parameter at a time while keeping the other two constant.

The values for thermal and physical properties of breast tissue are listed in Table (3-2) The thermal and biological parameters of sound tissue are listed in Table (3-1).

Table 3-2: Thermal and Biological Parameters [35-36].

\begin{tabular}{|l|l|l|l|}
\hline $\begin{array}{l}\text { Parameter Symbol } \\
\text { Thermal conductivity }\end{array}$ & $\mathrm{k}$ & 0.52 & $\mathrm{~W} /(\mathrm{m} . \mathrm{K})$ \\
\hline $\begin{array}{l}\text { Heat exchange } \\
\text { coefficient }\end{array}$ & $\mathrm{h}_{\mathrm{a}}$ & 8.77 & $\mathrm{~W} /\left(\mathrm{m}^{2} . \mathrm{K}\right)$ \\
\hline $\begin{array}{l}\text { Specific heat (blood) } \\
\text { Density (blood) heat }\end{array}$ & $\mathrm{c}_{\mathrm{b}}$ & 4186 & $\mathrm{~J} /(\mathrm{kg} \cdot \mathrm{K})$ \\
\hline $\begin{array}{l}\text { Metabolic } \\
\text { generation (breast) }\end{array}$ & $\mathrm{q}_{\mathrm{b}}$ & 1000 & $\mathrm{Kg} / \mathrm{m}^{3}$ \\
\hline $\begin{array}{l}\text { Metabolic } \\
\text { generation of tumor }\end{array}$ & $\mathrm{Q}_{\mathrm{t}}$ & 25000 to 90000 & $\mathrm{~W} / \mathrm{m}^{3}$ \\
\hline Perfusion rate blood & $\mathrm{T}_{\mathrm{a}}$ & 0.00052 & $1 / \mathrm{s}$ \\
\hline $\begin{array}{l}\text { Arterial } \\
\text { temperature }\end{array}$ & 310.15 & $\mathrm{~K}$ \\
\hline $\begin{array}{l}\text { Environmental } \\
\text { temperature }\end{array}$ & $\mathrm{T}_{\mathrm{e}}$ & 300.15 & $\mathrm{~K}$ \\
\hline
\end{tabular}

The experiment was conducted twice. First we have assumed that the heat source is a point source hence its radius is negligible. For the second set of experiments, it was assumed that the heat source radius is very small but not negligible. 
First, the model was simulated by applying a constant heat source intensity of $0.1 \mathrm{~W}$ and changing the depth of the heater embedded in the model. The heat source was assumed as a point source, hence $\mathrm{R}=0$.

The depth of heat source affects the maximum temperature $\left(T_{\max }\right)$ as shown in Figure 3-2. However, the area of temperature elevation is not affected by varying the depth. It can be also observed that temperature rises significantly when the heat source is located at depth of around $\pm 0.037 \mathrm{~m}$.

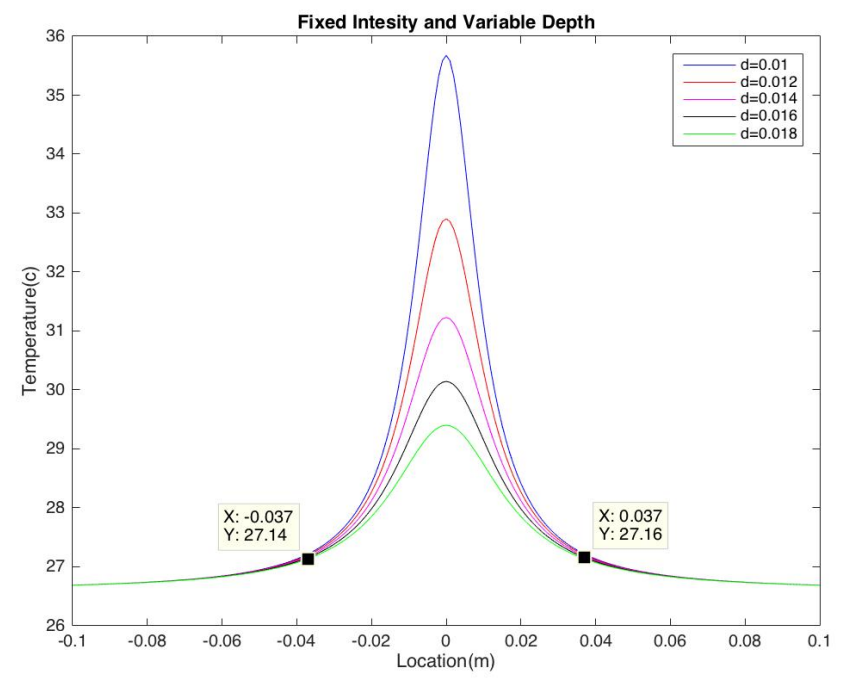

Figure 3-2. Fixed intensity and varying depth: Surface Temperature directly depends on the depth wherein the heat source is located.

Next, the model was used by positioning the heat source at the depth of $d=0.014 \mathrm{~m}$ and varying the intensity. The radius was zero.

Variation in the intensity affects both the maximum temperature and the area over which the temperature rises, as illustrated in Figure 3-3. 


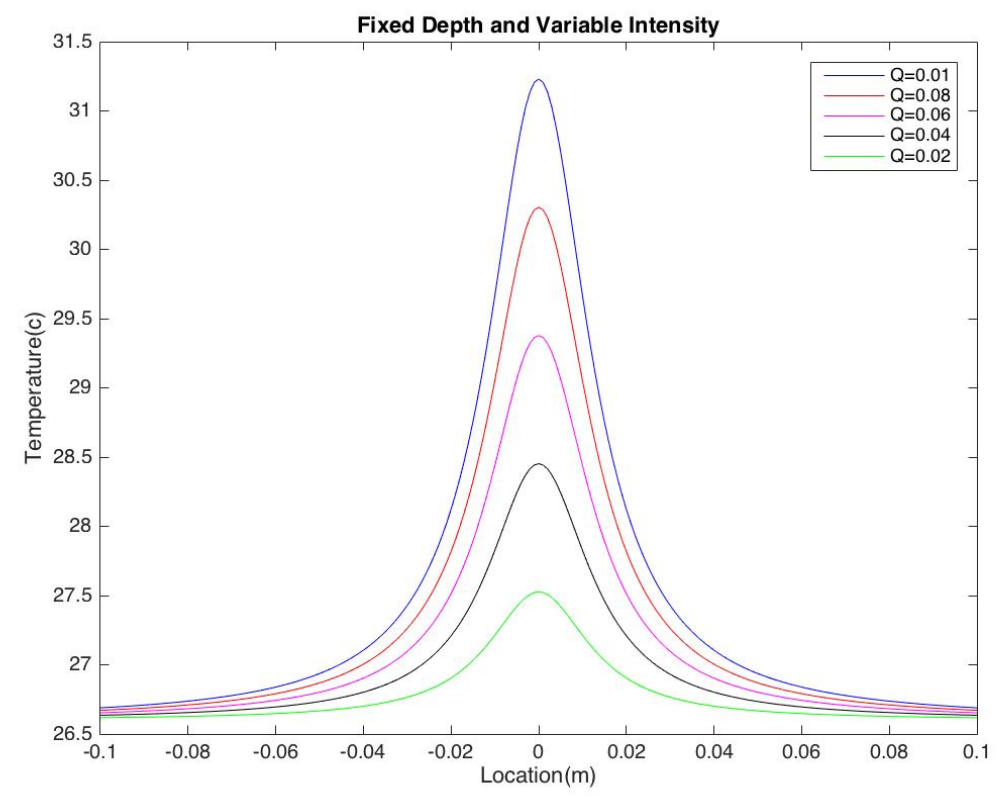

Figure 3-3. Fixed heat source depth and varying intensity: Variation in intensity affects the area over which temperature rises.

For the second set of experiments, it was assumed that the the heat source is not a point, i.e., $\mathrm{R}$ $\neq 0$. In Figure 3-4, the heat source radius and intensity were assumed to be $0.005 \mathrm{~m}$ and $0.3 \mathrm{~W}$, respectively. In Figure 3-5 however, the heat source depth was fixed at $d=0.02 \mathrm{~m}$, while $\mathrm{R}=$ 0.005 .

It can be seen that a model with a spherical heat source of radius $\mathrm{R}$ has similar affects on the surface temperature as the point heat source with $R=0(R$ is a very small number in this case hence, it is possible to ignore its value). As illustrated in figure 3-4, variation in the depth affects $\mathrm{T}_{\max }$. Also, the area over which the temperature changes, is affected by varying intensity as it can be seen in figure 3-5. 


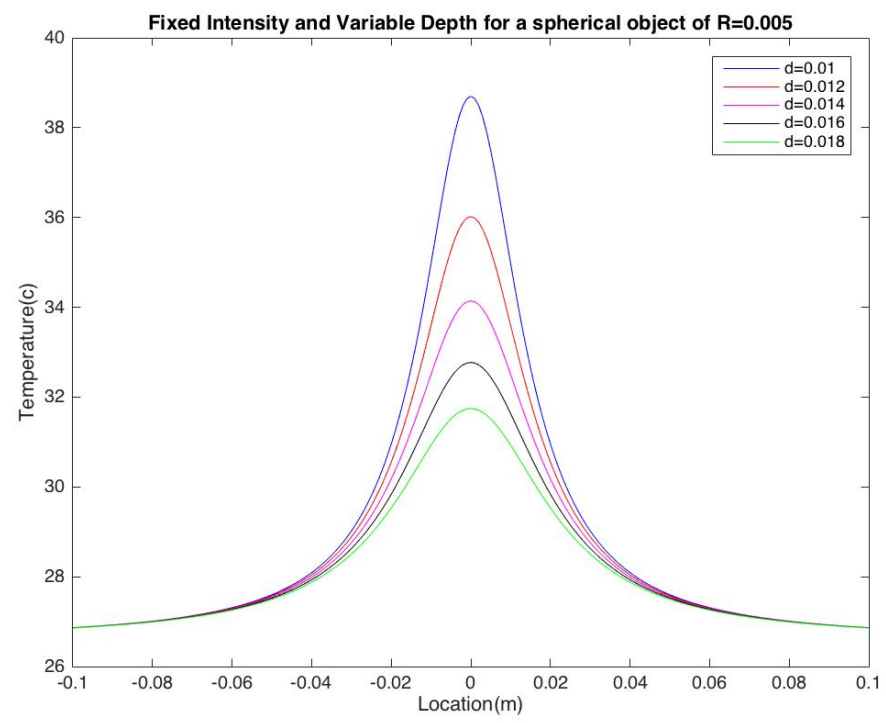

Figure 3-4. Fixed intensity and varying depth for a spherical object with $\mathrm{R}=0.005$ : Temperature on the model surface directly depends on the depth wherein the heat source is located.

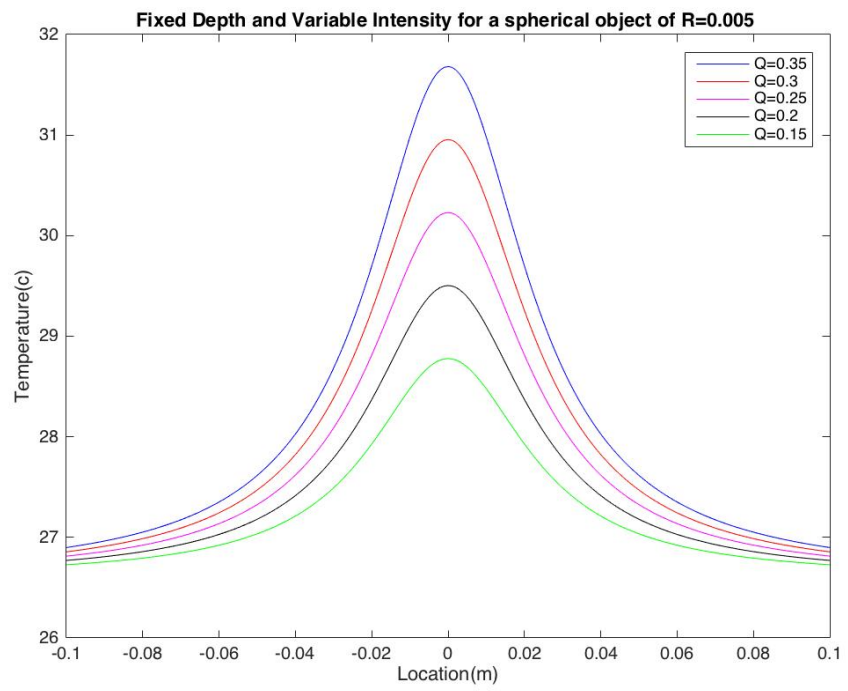

Figure 3-5. Fixed heat source depth and varying intensity for a spherical object with $\mathrm{R}=0.005$ : Variation in intensity affects the area over which temperature rises.

Finally, we have investigated the effects of radius of the heat source on the surface temperature. Figure 3-6 shows the effect of radius variation $(\mathrm{R})$ on the surface temperature, for the depth of heat source and intensity of $\mathrm{d}=0.02 \mathrm{~m}$ and $\mathrm{Q}=0.3 \mathrm{~W}$, respectively. It can be observed that as the radius increases, the maximum temperature increases as well. Furthermore, the area 
over which the temperature rises stays unchanged. However, by comparing figure 3-6 with figures 3-5 and 3-4, it is concluded that the effect of radius is not as significant on the surface temperature as the effects of depth and intensity.

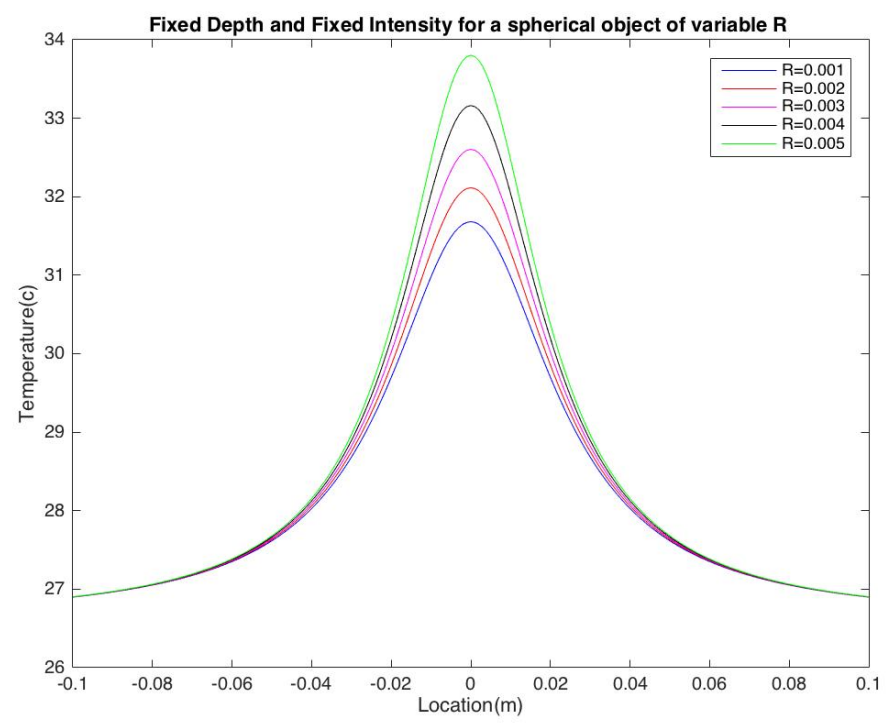

Figure 3-6. Fixed heat source depth and fix intensity for spherical objects with varying Rs.

\subsection{ANN model}

The depth, radius, and intensity of the model which were found through the proposed model, were optimized by training artificial neural network (ANN) tool of MATLAB. A 3-layer feed forward ANN with back propagation learning was developed to represent surface temperature. The model was simulated using various parameters and the results were used for training ANN. The algorithm was developed to have 3 inputs, and 10 hidden layer.

Two set of data was used to train the ANN. The first dataset was obtained assuming the ideal (noiseless) situation. Using equations (3-17) to (3-21), the parameters of the model were found to be $\mathrm{Q}=0.35 \mathrm{~W}, \mathrm{~d}=2 \mathrm{~cm}$, and $\mathrm{R}=5 \mathrm{~mm}$. Also, initial values were assumed to be $\mathrm{Q}=0.356 \mathrm{~W}$, $\mathrm{d}=2.02 \mathrm{~cm}$, and $\mathrm{R}=5 \mathrm{~mm}$. Using the initial values to train the ANN, these parameters were optimized to $\mathrm{Q}=0.3559 \mathrm{~W}, \mathrm{~d}=2.03 \mathrm{~cm}, \mathrm{R}=4.5 \mathrm{~mm}$. Comparing the maximum temperature of the model with the maximum temperature obtained from ANN it could be seen that there is $0.01^{\circ} \mathrm{C}$ difference (Figure 3-7). However, the difference is negligible due to the low intensity of the tumor. By increasing the intensity of the heat source, the difference between the two maximum 
temperatures increases respectively. Assuming $\mathrm{Q}=5 \mathrm{~W}, \mathrm{~d}=1 \mathrm{~cm}$, and $\mathrm{R}=5 \mathrm{~mm}$ and training the ANN with initial values of $\mathrm{Q}=5.5 \mathrm{~W}, \mathrm{~d}=3 \mathrm{~cm}$, and $\mathrm{R}=0 \mathrm{~mm}$, the new optimized values for these parameters would be $\mathrm{Q}=5.5276 \mathrm{~W}, \mathrm{~d}=1.62 \mathrm{~cm}$, and $\mathrm{R}=4.1 \mathrm{~mm}$ with the maximum temperature difference of $0.3611^{\circ} \mathrm{C}$. Based on our previous observations, these results were expected.

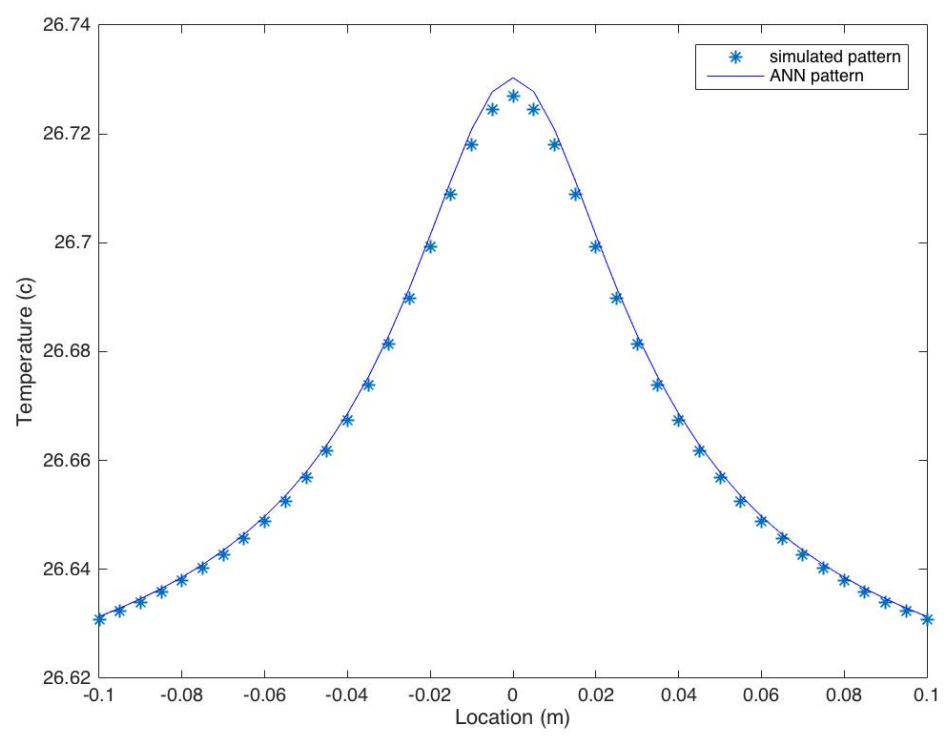

Figure 3-7. Heat source model and ANN simulated model

For the second dataset, a random noise of $10 \%$ was added to the model. Therefore, the parameter values were changed to $\mathrm{Q}=0.05 \mathrm{~W}$, with $\mathrm{d}=10 \mathrm{~cm}$, and $\mathrm{R}=0 \mathrm{~mm}$. By simulating and training $\mathrm{ANN}$ the optimized values of $\mathrm{Q}=0.0478 \mathrm{~W}, \mathrm{~d}=0.0296 \mathrm{~m}$, and $\mathrm{R}=0.1 \mathrm{~mm}$ were obtained. In this case, the maximum temperature difference was $0.03^{\circ} \mathrm{C}$ 


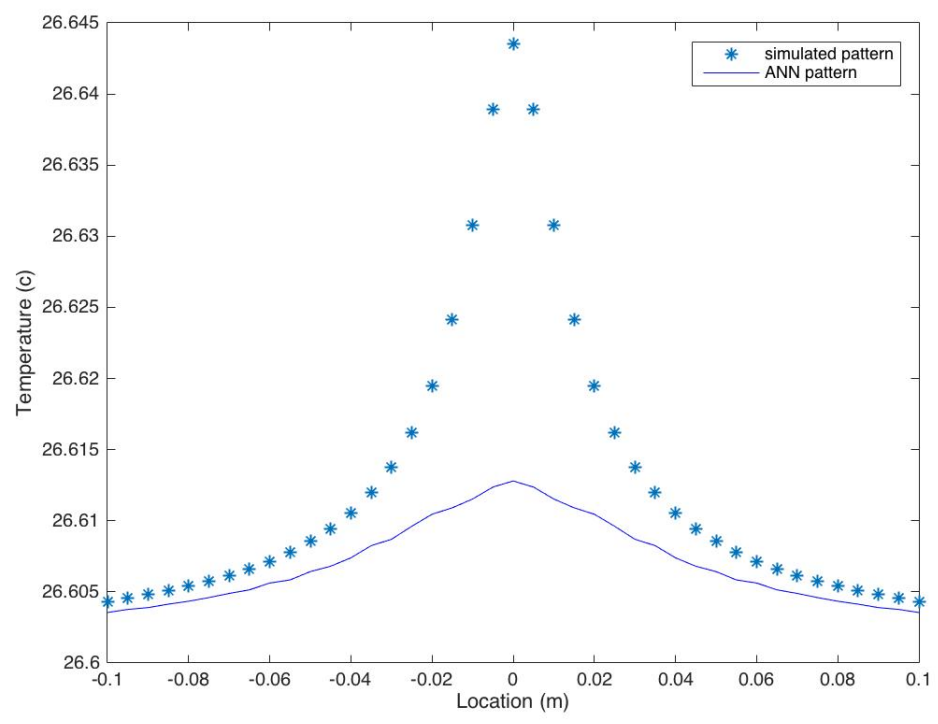

Figure 3-8. noisy model of analytical solution with and without ANN simulation. Maximum temperature increases after optimization process to a more accurate temperature.

Figure 3-9 compares the optimized parameters with the non-optimized ones. It illustrates two spheres inside each other. As it is shown below, the larger sphere is the optimized location of the heat source as the small one is the original location.

Table 3-3 illustrates the error analysis for the noisy and no noise conditions. As it could be concluded, the higher the intensity, the higher the error in parameter estimation. This error would be reflected as temperature difference on the skin surface for various ranges and would affect the correct estimation of tumor location. Therefore, its critical to use the optimized model for research and clinical purposes. 
Table 3-3: Error analysis for optimization of the two cases.

Data set (I): A condition with no noise and low intensity of tumor.

\begin{tabular}{|c|c|c|c|}
\hline Parameter & Original value & $\begin{array}{l}\text { Optimized } \\
\text { value }\end{array}$ & Error $(\%)$ \\
\hline Depth (d) & $2 \mathrm{Cm}$ & $2.03 \mathrm{Cm}$ & $1.5 \%$ \\
\hline Raduse (R) & $5 \mathrm{~mm}$ & $4.5 \mathrm{~mm}$ & $10 \%$ \\
\hline Intensity (Q) & $0.37 \mathrm{~W}$ & $0.3559 \mathrm{~W}$ & $3.81 \%$ \\
\hline
\end{tabular}

Data set (I): A condition with no noise and higher intensity of tumor.

\begin{tabular}{|l|l|l|l|}
\hline Parameter & Original value & $\begin{array}{l}\text { Optimized } \\
\text { value }\end{array}$ & \begin{tabular}{l} 
Error (\%) \\
\hline Depth (d)
\end{tabular} \\
\hline Raduse (R) & $1 \mathrm{Cm}$ & $1.62 \mathrm{Cm}$ & $62 \%$ \\
\hline Intensity (Q) & $5 \mathrm{~mm}$ & $4.1 \mathrm{~mm}$ & $18 \%$ \\
\hline
\end{tabular}

Data set (II): A condition with $10 \%$ noise.

\begin{tabular}{|l|l|l|l|}
\hline Parameter & Original value & $\begin{array}{l}\text { Optimized } \\
\text { value }\end{array}$ & \begin{tabular}{l} 
Error (\%) \\
\hline Depth (d)
\end{tabular} \\
\hline Raduse (R) & $1 \mathrm{Cm}$ & $2.96 \mathrm{Cm}$ & $66.2 \%$ \\
\hline Intensity (Q) & $0.09 \mathrm{~mm}$ & $0.1 \mathrm{~mm}$ & $11.11 \%$ \\
\hline & $0.05 \mathrm{~W}$ & $0.0478 \mathrm{~W}$ & $4.4 \%$ \\
\hline
\end{tabular}




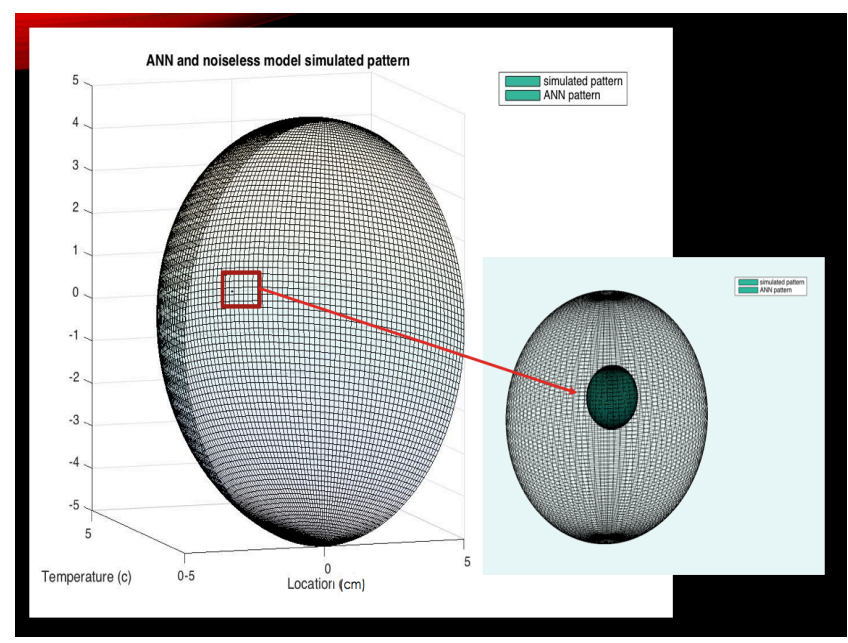

Figure 3-9. A comparison between the optimized and non-optimized parameters (depth and radius) assuming a spherical breast of diameter $10 \mathrm{~cm}$. The larger sphere illustrates the optimized location of the tumor with in the breast tissue.

\subsection{Sensitivity of data analysis}

In the following sections, the sensitivity of each parameter along with temperature sensitivity was studied.

\subsubsection{Parameter sensitivity}

To analyze the sensitivity of each parameter, a model was developed with the following parameters: $\mathrm{Q}=0.045 \mathrm{~W}, \mathrm{~d}=1.05 \mathrm{~cm}$, and $\mathrm{R}=5 \mathrm{~mm}$. Subsequently, these parameters were changed by $\pm 20 \%$.

In the first step, all parameters were kept constant, only the intensity was adjusted to $\mathrm{Q}=0.036 \mathrm{~W}$. As shown in figure (3-10A), there was only a small difference of $0.3^{\circ} \mathrm{C}$ between the initial Q and Q measured with $20 \%$ error. However, the difference increased to about $1.5003^{\circ} \mathrm{C}$ as the depth of heat source was increased by $20 \%$ (Figure 3-10B). Additionally, changing R by $20 \%$ was accompanied by a temperature difference of $0.24^{\circ} \mathrm{C}$ (Figure $3-10 \mathrm{C}$ ). it could be concluded that the most sensitive parameter is depth of the heat source as the small change in depth resulted in over $1{ }^{\circ} \mathrm{C}$ change in temperature difference. 


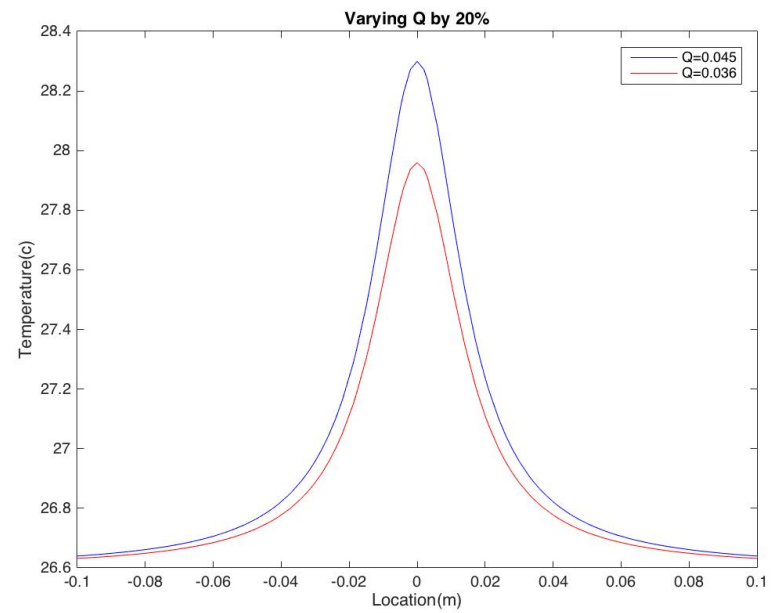

(A)

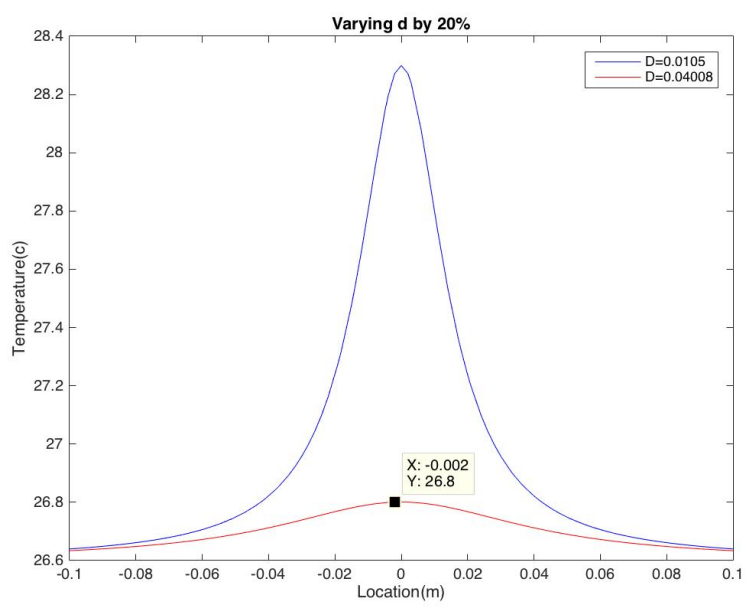

(B)

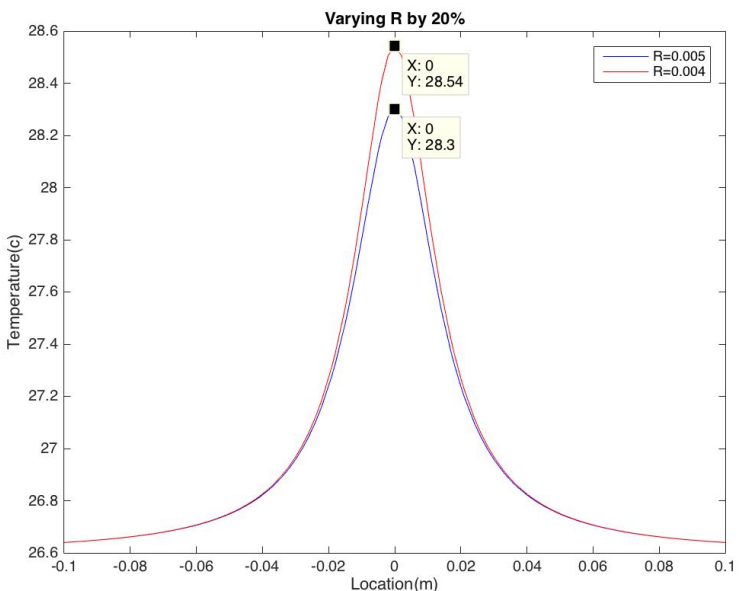

(C)

Figure 3-10. Sensitivity studies with $20 \%$ change in data.

Considering a case with a heat source of higher Q, R, and D and applying the same $\pm 20 \%$, generated graphs would follow the same trend, illustrated in Figure 3-10 as well. 


\subsubsection{Temperature sensitivity}

Temperature sensitivity study was performed by assuming that there only exists information about maximum temperature and two local temperatures, as shown in Figure 3-1. Using geometric rules, the depth of the heat source was found. Subsequently, it was possible to find the heat source radius and precise location. Equation (3-19) is showing the relationship between the depth of heat source and its radius and could be utilized to find the radius of the heat source without utilization of the intensity.

It would be more efficient to use equation (3-19) during biological and clinical testing, where the local and maximum temperatures are measured using an IR camera, rather than using the analytical solution, where the parameters of the tumor are found by solving analytical governing equations.

The temperature sensitivity was studied assuming two conditions. The first condition was implemented by adding a random error of $\pm 5 \%$ to the temperature at various locations. There is approximately $1.41^{\circ} \mathrm{C}$ difference between maximum temperatures as shown in Figure 3-11.

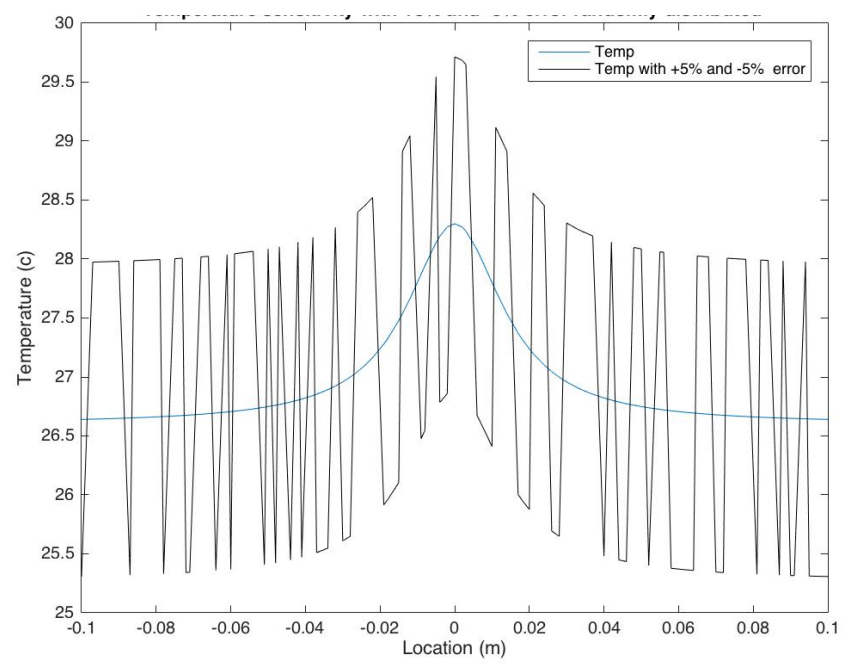

Figure 3-11. Sensitivity models with $\pm 5 \%$ change in surface temperature. There is about $1.41^{\circ} \mathrm{C}$ difference between maximum temperatures. 
In the second condition, the difference between the two temperatures decreases. Under this condition, the maximum and minimum temperatures were found to be $28.2996^{\circ} \mathrm{C}$ and $26.6399^{\circ} \mathrm{C}$, respectively. Subtracting the two, there is $1.6597^{\circ} \mathrm{C}$ temperature difference between the two extreme points. This difference was used to find the new value of temperature at each location with a random $\pm 5 \%$ error. Figure 3-12 illustrates the difference between the two maximum temperatures. This difference was around $0.0504^{\circ} \mathrm{C}$.

Comparing the figures 3-11 and 3-12, it could be concluded that surface temperature is extremely sensitive as a small error in measuring the surface temperature could affect the localization of the heat source drastically. Therefore, it is vital to use a well calibrated camera in biological and clinical tastings. It is recommended that in analytical research where an IR camera is not used, the heat intensity generated by the tumor should be measured first, and all other parameters should be calculated based on the intensity.

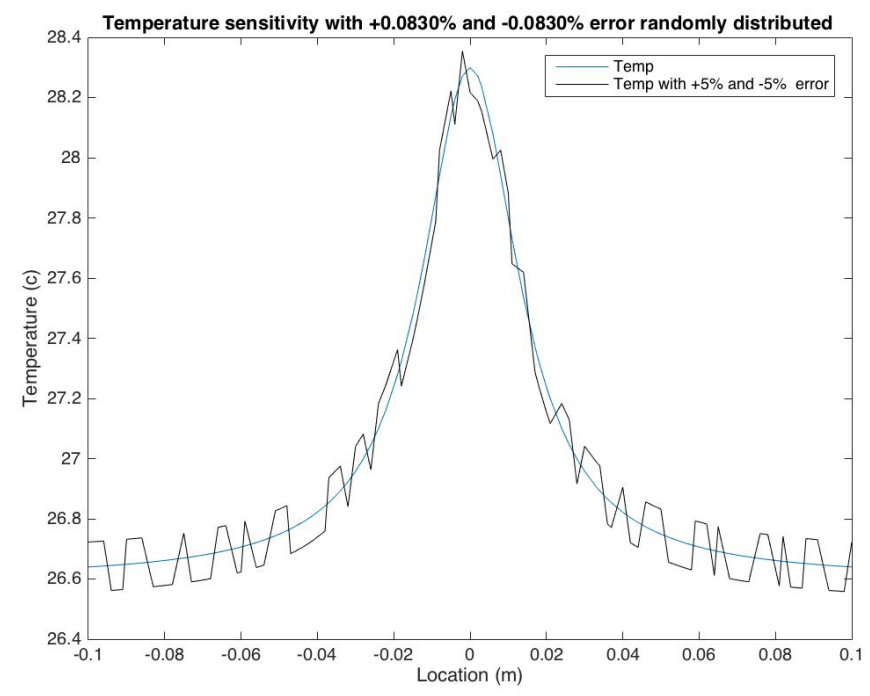

Figure 3-12. Sensitivity models with $\pm 5 \%$ (of maximum and minimum points ) change in surface temperature .

\subsection{Application}

To apply this method, there is a need for three parameters namely room temperature, patient body surface temperature, as well as maximum temperature of any point on the breast. Room temperature could be measured by any digital thermometer. Maximum and body temperature could be measured via IR camera. 
We have taken the figure 3-13 from clinicalthermography.com in order to carry out analysis using proposed algorithm. Thermo graphic examinations were performed in a controlled $20^{\circ} \mathrm{C}$ ambient temperature with normal skin temperature of $30^{\circ} \mathrm{C}$ according to [48].

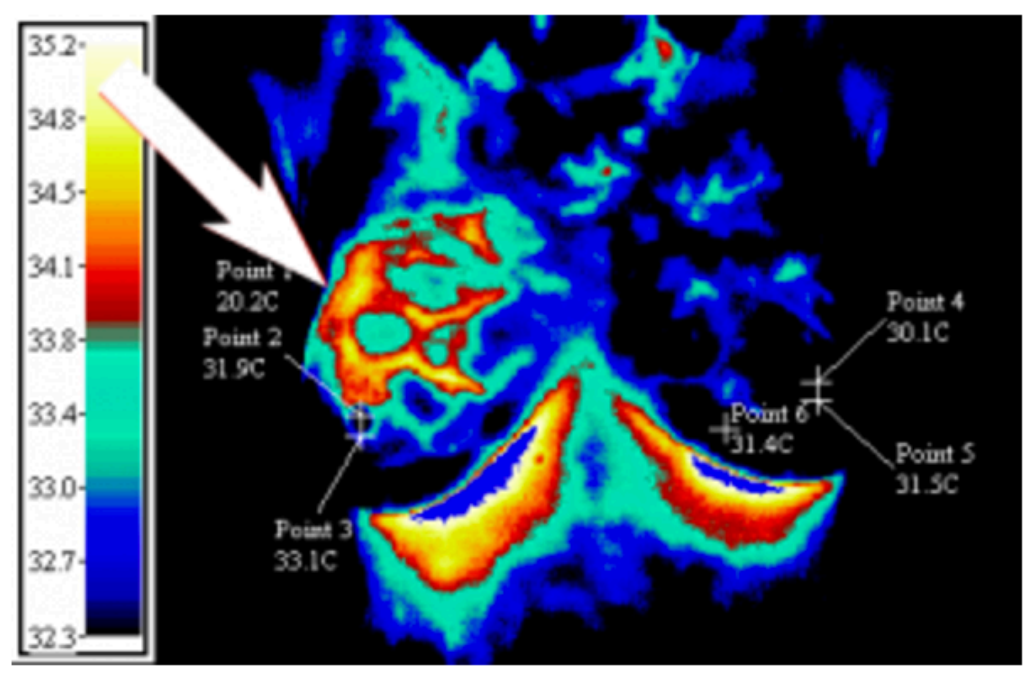

Figure 3-13. Thermal image of breast with an abnormal mass in the right breast.

Additionally, according to [48], "Clinical experiments by Draper, indicate that only heat brought to within $6 \mathrm{~mm}(\sim 1 / 4 ")$ of the surface of the dermis is emitted." Therefore, ran the algorithm for tumors of depth $6 \mathrm{~mm}$ to $1 \mathrm{~cm}$ depth. We have used equation 15 , and equation 16 assuming the tumor to have an almost negligible radius $(0.001 \mathrm{~m})$ :

Equation (3-15) was used to find $\mathrm{Q}$ using the parameters that were given in the website $\left(\mathrm{Ta}=33.4-35.1^{\circ} \mathrm{C}\right.$ and $\mathrm{Tmax}=35.2 \mathrm{C}$ according to the image). This equation would provide us with a range for intensity depending on the location the tumor is located under the skin. We have run the algorithm multiple times in and took the average of the results. This would lead in to intensity of $0.083204 \mathrm{~W}$. Afterwards, we have utilized equation (3-16) to find the surface temperature range.

Where $\mathrm{Te}=20^{\circ} \mathrm{C}, \mathrm{R}=0.001$ (the size of the tumor is not mentioned in the manuscript. However, smaller tumor is typically harder to detect), $\mathrm{a}=-0.1: 0.0005: 0.1 \mathrm{~m}$ (from each side of the maximum temperature location), and $\operatorname{Tmax}=35.2^{\circ} \mathrm{C}$ (according to the image).

By using these parameters in the proposed algorithm, the following results were obtained for $\mathrm{T}$ (local temperature on the skin around the tumor).

As it can be seen from Fig. 3-14 the maximum temperature obtained by the algorithm is in good agreement with the one provided by the image (see Fig. 3-13). 


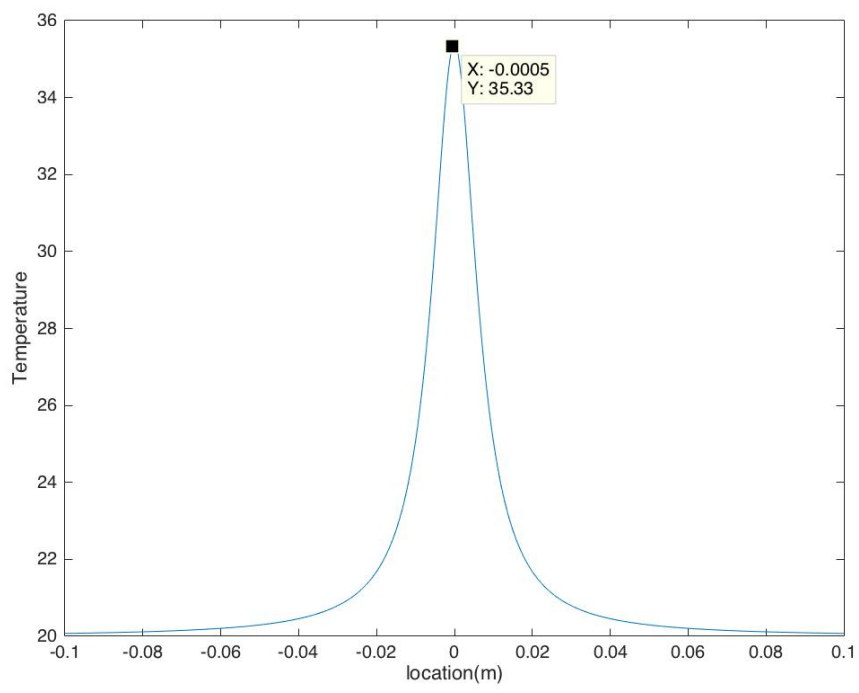

Figure 3-14 Maximum temperature provided by the algorithm

\subsection{Summary}

A model has been developed in order to estimate of thermo-Physio-biological parameters of tumor using the temperature profile over the skin surface. This model has been developed by solving bio-thermal problems. The proposed methodology was based on solving bio-thermal problems in presence of tumor. Artificial neural network (ANN) was used to optimize tumor parameters that may be obtained by infrared (IR) camera. As a noninvasive method, IR camera is a superior asset for the presented tumor detection method. Using a simple heat source model in training ANN allows the system to measure $0.01^{\circ} \mathrm{C}$ temperature difference in an ideal condition and $0.03^{\circ} \mathrm{C}$ temperature difference under $10 \%$ noise condition.

Additionally, Sensitivity of the parameter was studied along with the surface temperature sensitivity. According to the obtained results, the skin surface temperature is the most sensitive among all the parameters studied (i.e. depth, and intensity). Also, since the method measures very low temperature difference, it requires a highly sensitive and accurately calibrated IR camera system. According to the results, the methodology can help locate a tumor region on external body part, which could be useful and important in studying tumor evolution after a treatment procedure. 


\section{Chapter 4 \\ Analytical solution for chest tumor (cubical model)}

\section{Introduction}

According to Canadian National Breast Cancer Foundation, one in thousands men are diagnosed with breast cancer which often in men between 60 and 70 years of age [1]. While chances of being diagnosed with breast cancer in male is much lower than in female subjects, the rate of survival is similar in both genders [37].

Formation of malignant cells in chest tissue could be due to various factors such as exposure to radiation, increased levels of estrogen, inherited gene mutations, family history, etc [38, 39]. Four types of breast cancer could happen in men:

1. Infiltrating ductal carcinoma: this type is the most common type of breast cancer in male and is due to malignant cells spreading beyond the cells lining ducts in the breast.

2. Ductal carcinoma in situ: also called intraductal carcinoma. In this case, malignant cells are found in the lining of a duct.

3. Inflammatory breast cancer: in this case, breast looks red and swollen and feels warm.

4. Paget disease of the nipple: in this case tumors grow from the ducts beneath the nippleon to the surface of the nipple.

We have investigated heat source problem for a cubical tissue (i.e chest tissue) by using the point heat source model from two different approaches to find the maximum temperature. Again, using Penne's Bioheat equation, the chest model was developed and the effect of the different tumor parameters, such as, depth and radius on the surface temperature utilizing the body core temperature (arterial temperature) was investigated. In addition, an equation for measurement of the intensity of the tumor and hence validating our results was developed.

As per the second part, the results obtained from the first part was optimized using artificial neural network (ANN) which is, an information processing algorithm behaving like human 
nerves system. Also, sensitivity of each parameter was studied and a conclusion has been drawn based on the obtained results.

\subsection{Analytical model}

Penne's bio-heat equation was used to obtain the analytical model. Penne's bio-heat equation accounts for variables such as: metabolic heat generation, heat transfer by conduction, and perfusion heat loss rate due to alteration between the body core blood temperature and the local tissue temperature $[40,41]$.

To develop the cubical model, we have utilized penne's bioheat equation again:

$$
\rho c \frac{\partial T}{\partial t}=\nabla \cdot(\mathrm{k} \nabla \mathrm{T})+Q_{b}+Q_{m}
$$

where $\mathrm{T}$ is the local temperature, $\rho$ is the tissue density, $\mathrm{c}$ is the tissue (muscle) density, and $\mathrm{k}$ is thermal conductivity. Additionally, $\mathrm{Qb}$ and $\mathrm{Qm}$ are the Penne's perfusion terms, and metabolic heat production.

Assuming a steady state case (in vitro), the physical variables do not change with time, therefore, the above equation can be rewritten as [40]:

$$
0=\left(k \nabla^{2} T\right)+k_{b}\left(T_{a}-T\right)+Q_{m}
$$

Chest tissue is mainly made of muscle as shown in figure 4-1 [40]. Therefore, it is possible to assume tissue homogeneity to solve for inverse bio-heat equation. 


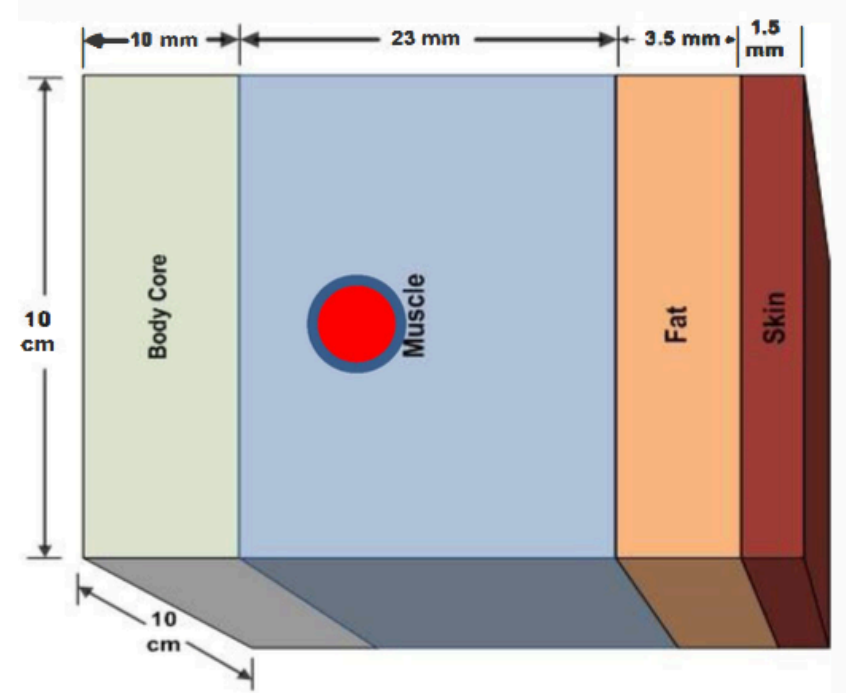

Figure 4-1 Chest structure and its tissue integrity as well as the assumed dimensions as proposed by Hossain et al [40].

In order to solve for inverse heat conduction solution (IHCP), the following assumption were taken into consideration.

1. The bio-heat equation was solved for chest tissue.

2. The chest tissue is mainly composed of muscle.

3. The generated bio-heat model is assumed to be in steady state so time has no effect on the model.

4. Model is homogeneous and isotropic with constant $\rho$, c, and $\mathrm{k}$.

5. The heat generated by tumor is assumed as an additional heat source.

Figure 4-2 was generated by considering the above assumptions, with $\mathrm{T}_{\mathrm{a}}$ being the temperature at any distance on skin surface from the maximum temperature location, $\mathrm{T}_{\max }$ being the maximum temperature on the surface, right above the tumor, and q being the heat intensity at any distance $\mathrm{d}$ from the tumor. 


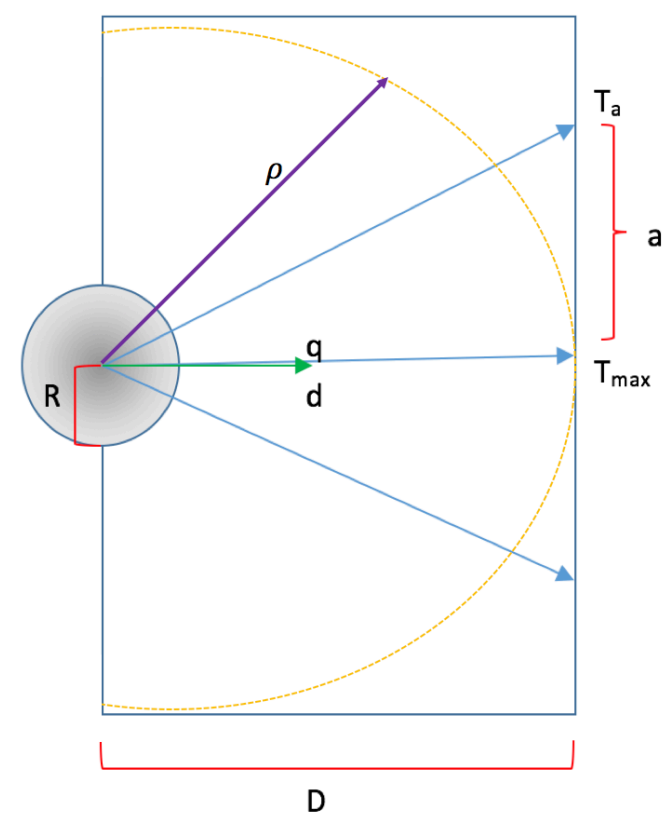

Figure 4-2 Conditions and approximations for solving the inverse heat conduction (IHCP) deducted according to conditions 1 to 5 stated in section 4.1.

There are two main factors to consider while solving for IHCP. Firstly, the heat generated from the heat source $(\mathrm{Q})$ is totally exchanged with the environment. Secondly, heat is emitted as a form of spherical wave. Therefore, the heat density at a distance $d$ from the heat source could be calculated as:

$$
\begin{aligned}
& \mathrm{q}_{\text {in }}=\mathrm{q}_{\text {out }} \\
& q=\frac{Q}{4 \pi d^{2}}
\end{aligned}
$$

and the heat generated at the core (i.e. tumor) could be calculated as [41]:

$$
q_{\text {in }}=\frac{Q}{4 \pi d^{2}}=\frac{k R\left(T_{\text {core }}-T_{a}\right)}{d(d-R)}
$$

Also the heat emitted from the surface could be calculated as [41]:

$$
q_{\text {out }}=h_{0}\left(T_{a}-T_{e}\right)
$$

where $\mathrm{h}_{0}$ is the heat exchange coefficient, $T_{a}$ is the local temperature at the distance a from the maximum temperature and $T_{e}$ is the temperatute of the surrounding environment . 
As it can be seen in figure 4-2, there exist two cases:

1. $\rho<\mathrm{d}$ (T would be the interior temperature.)

2. $\rho \geq d$ (T would measure the surface temperature where, $T(\rho=D)=T_{\max }$.)

Hence $\mathrm{T}_{\max }$ could be found as [41]:

$$
T_{\text {max }}=T_{e}+\frac{k R\left(T_{\text {core }}-T_{e}\right)}{h_{0}\left(\sqrt{d^{2}+a^{2}}\right)\left(\sqrt{d^{2}+a^{2}}-R\right)+1}
$$

Also $\mathrm{T}_{\mathrm{a}}$ could be calculated as below according to $[9,41]$, where, $\gamma$ is the non-linear parameter and could be calculated as :

$$
\gamma=\left(2000\left((d-2.2)^{2}+2.6\right) R n^{-0.96}\right.
$$

In addition, $\mathrm{n}$ is the ratio to the metabolism of tumor and the healthy tissue of a particular organ.

$$
\mathrm{n}=\frac{Q_{m-T u m o r}}{Q_{m-\text { Healthy tissue }}}
$$

It is important to note that $Q_{m-\text { Tumor }}>0$ and $Q_{m-\text { Tumor }}>Q_{m \text {-healthy tissue }}$ due to higher vascularity and blood perfusion rate.

$$
T_{a}=T_{e}+\frac{\left(T_{\text {core }}-T_{e}\right)}{\frac{\gamma h_{0}}{k R}\left(\sqrt{d^{2}+a^{2}}\right)\left(\sqrt{d^{2}+a^{2}}-R\right)+1}
$$

\subsection{Chest tumor simulation}

Model parameters such as depth, and radius were measures and assessed by utilizing equations (4-7) and (4-10). The data regarding chest (muscle) parameters during this experiment are listed in Table 4-1. In this section, we have assume two cases of $R=0$ and $R \neq 0$. 
Table4-1 Thermal and physical properties of chest (muscle) tissue $[9,36,40]$.

\begin{tabular}{|l|l|l|l|}
\hline Parameter & \multicolumn{1}{|c|}{ Symbol } & \multicolumn{1}{l|}{ Value } & Unit \\
\hline Thermal conductivity & $\mathrm{k}$ & 8.77 & $\mathrm{~W} /(\mathrm{m} \cdot \mathrm{K})$ \\
\hline $\begin{array}{l}\text { Heat blood } \\
\text { coefficient }\end{array}$ & $\mathrm{T}_{\mathrm{a}}$ & $36.15-37$ & ${ }^{\circ} \mathrm{C}$ \\
\hline $\begin{array}{l}\text { Arterial } \\
\text { temperature }\end{array}$ & $\mathrm{h}_{0}$ & & \\
\hline $\begin{array}{l}\text { Environmental heat } \\
\text { temperature } \\
\text { Metabolic } \\
\text { generation of healthy } \\
\text { tissue }\end{array}$ & $\mathrm{Q}_{\mathrm{m}}$ & $26.6-28$ & ${ }^{\circ} \mathrm{C}$ \\
\hline $\begin{array}{l}\text { Metabolic heat } \\
\text { generation of tumor }\end{array}$ & $\mathrm{Q}_{\mathrm{m}}$ & $25000 \quad$ to & $\mathrm{W} / \mathrm{m}^{3}$ \\
\hline
\end{tabular}

\subsubsection{Effect of the heat source parameters on the surface temperature}

To assess the effect of the heat source parameters on the surface temperature, the developed model was simulated by varying one parameter at a time and keeping the other two constant using MATLAB. Therefore, the simulation was performed by assuming $\mathrm{R}$ to be negligible (0.002 $\mathrm{m}$ ), and varying the depth. The core temperature was assumed to be $37^{\circ} \mathrm{C}$, and the environment temperature was kept at $26.6^{\circ} \mathrm{C}$.

The maximum temperature $\left(\mathrm{T}_{\max }\right)$ is mainly affected by the depth of the heat source, as shown in figure 4-3. However, the area of temperature elevation is not affected by varying the depth. It was observed that the temperature rises significantly over $\pm 0.045 \mathrm{~m}$. 


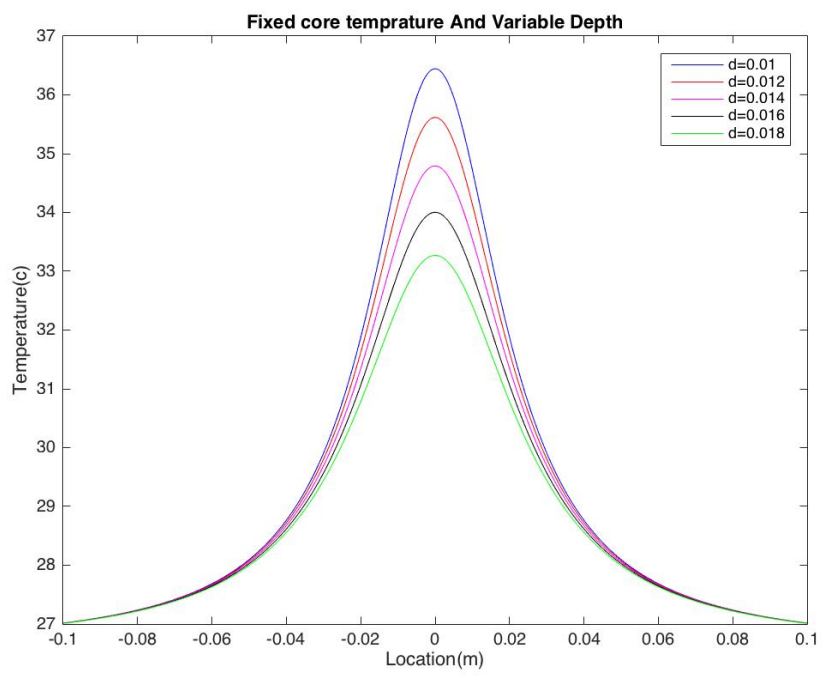

Figure 4-3 Fixed core temperature at $37{ }^{\circ} \mathrm{C}$ and varying depth. Surface temperature of the model is directly dependent on the depth of the heat source.

For the purpose of results validation, Tmax was measured using the heat source intensity. To do so, the following equation was derived using equations (4-5) and (4-6). $R \ll d$ hence $(d+R) \approx d$.

$$
T_{a}=\frac{Q}{4 \pi\left((d)^{2}+(a)^{2}\right) h_{0}}+T_{e}
$$

Assuming a point heat source with the intensity of $0.122 \mathrm{~W}$.

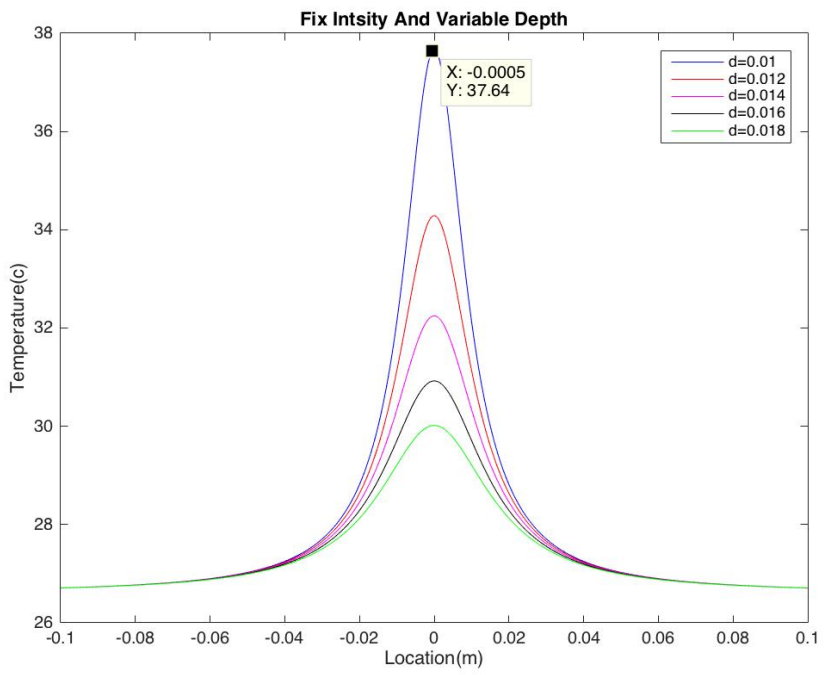

Figure 4-4 Fixed intensity and varying depth. Maximum temperature decreases as depth increase. In other words, depth and $\mathrm{T}_{\max }$ are inversely proportional. 
Figure 4-4 illustrates the maximum temperature for various depth for a heat source of intensity $0.122 \mathrm{~W}$. Comparing figures 3-4 and 4-4, it could be seen that there is only a small difference of $0.18^{\circ} \mathrm{C}$ between the maximum temperatures.

Additionally, the same steps were taken for measurement of the surface temperature for a case with larger radius $0.008 \mathrm{~m}$. Results were validated using the intensity of $0.15 \mathrm{~W}$. This consideration has resulted to the following graphs (Figure 4-5).

$$
T_{a}=\frac{Q}{4 \pi\left((d+R)^{2}+(a)^{2}\right) h_{0}}+T_{e}
$$

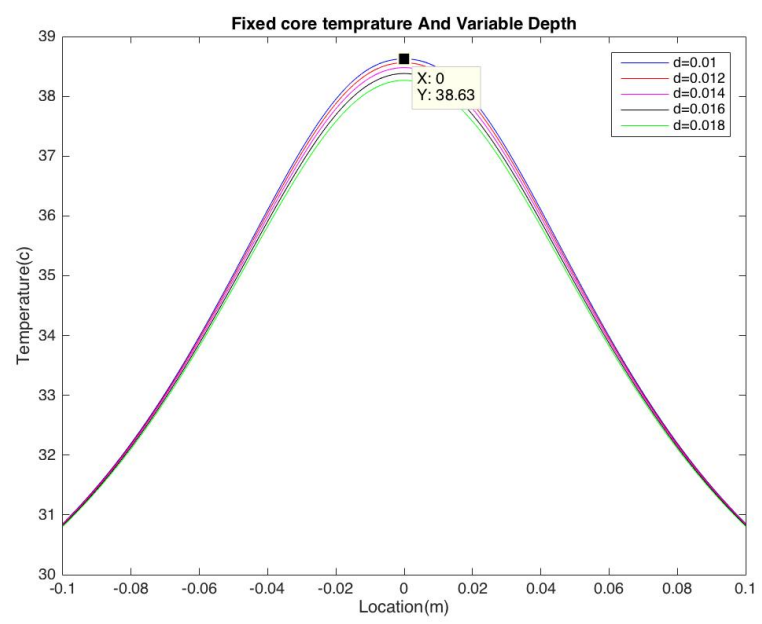

Figure 4-5 Fixed core temperature of $37^{\circ} \mathrm{C}$ and varying depth with $\mathrm{R}=0.008$. Surface temperature of the model is directly dependent to the depth of the heat source.

Also, using intensity (i.e equation 4-8), results are validated for the above case with intensity of $0.122 \mathrm{~W}$ as shown in figure 4-6.

It could be seen that there is a $1.09{ }^{\circ} \mathrm{C}$ difference between the two maximum temperatures in figures 4-5 and 4-6. 


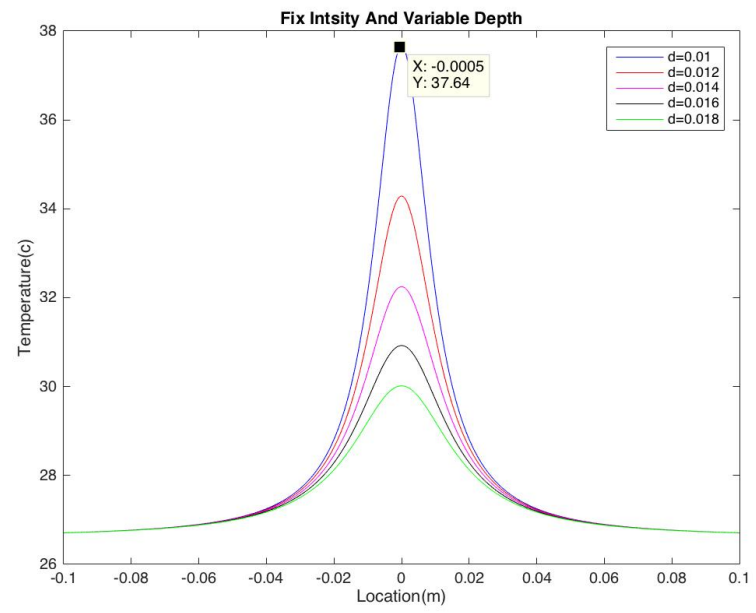

Figure 4-6 Fixed intensity and varying depth. As the heat source radius increases, it would be more applicable to use intensity as the basis of the calculation.

Furthermore, the effect of heat source radius was studied as shown in figure 4-7. It could be seen that the area over which the temperature rises, is increased as the radius is increased by keeping depth constant at $\mathrm{d}=0.02 \mathrm{~m}$.

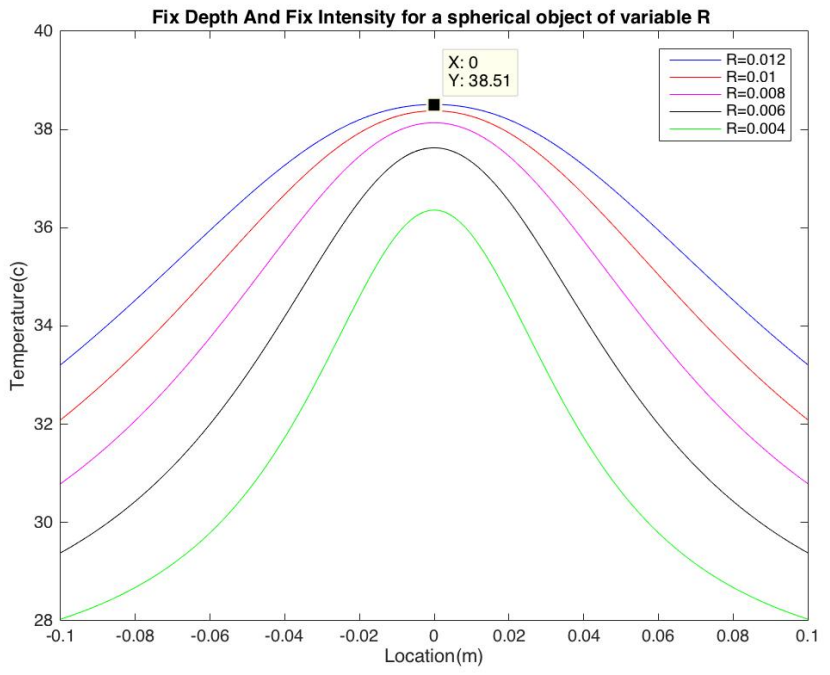

Figure 4-7 Fixed depth and varying radius. It could be seen that as the heat source radius increases, the area of the temperature elevation increases as well. 


\subsubsection{ANN model}

In order to optimize the model parameters such as depth, radius, and the core temperature an artificial neural network (ANN) was trained using MATLAB. In order to represent the surface temperature, a 3-layers feed forward ANN with back propagation learning, was developed and simulated using different parameters.

ANN was trained for two sets of data. The first set of data were trained in an ideal condition (no noise). Employing equation (4-10), the values were found to be $\mathrm{T}_{\text {core }}=37{ }^{\circ} \mathrm{C}, \mathrm{d}=0.01 \mathrm{~m}$, and $\mathrm{R}=0.009 \mathrm{~m}$. Additionally, the initial values were assumed to be $\mathrm{T}_{\text {core }}=38{ }^{\circ} \mathrm{C}, \mathrm{d}=0.015 \mathrm{~m}$, and $\mathrm{R}=0.01 \mathrm{~m}$. ANN was trained using the initial values, and following optimizes variables were obtained: $\mathrm{T}_{\text {core }}=40.8941{ }^{\circ} \mathrm{C}, \mathrm{d}=0.0199 \mathrm{~m}$, and $\mathrm{R}=0.0093 \mathrm{~m}$. As shown in figure $4-8$, the temperature difference between the two plots is $0.35^{\circ} \mathrm{C}$. This difference is small due to the low intensity of the tumor. This difference increases by any increase in the intensity or size of the heat source.

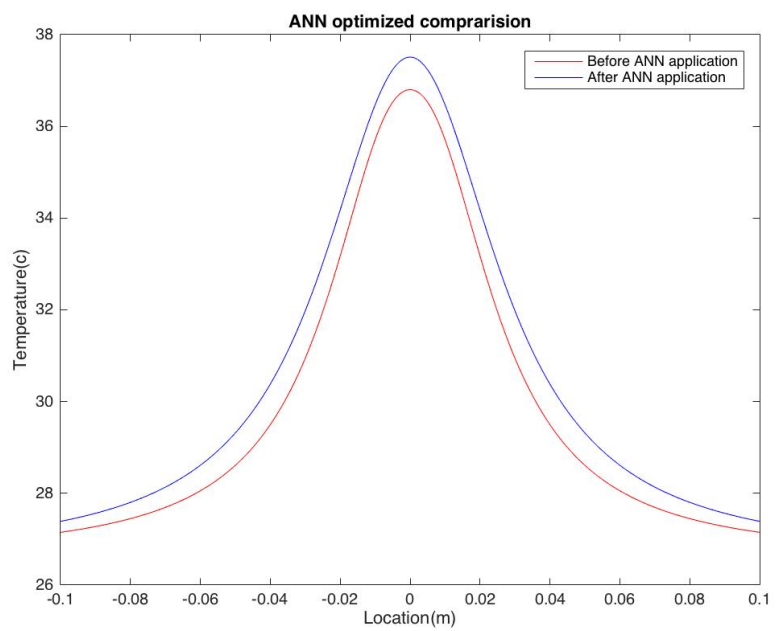

Figure 4-8 Analytical Model and ANN simulated model. Using ANN optimization technique, the heat source parameters were optimized to a more accurate value.

For the second data set, the model was stimulated by adding a random noise of $5 \%$. In this case, again, $\mathrm{T}_{\text {core }}=37^{\circ} \mathrm{C}, \mathrm{d}=0.01 \mathrm{~m}$, and $\mathrm{R}=0.009 \mathrm{~m}$. Training the $\mathrm{ANN}$ the following optimized variables were found to be $\mathrm{T}_{\text {core }}=40.9333{ }^{\circ} \mathrm{C}, \mathrm{d}=0.0218 \mathrm{~m}$, and $\mathrm{R}=0.0091 \mathrm{~m}$. As well, the 
maximum temperature difference was obtained to be $1.85{ }^{0} \mathrm{C}$. Figure $4-9$ shows analytical model and ANN simulated model with 5\% noise.

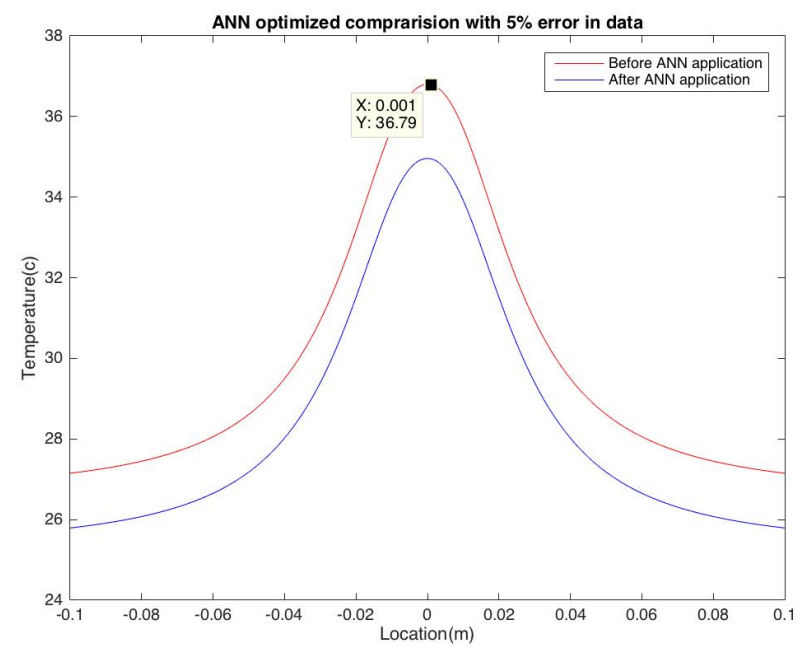

Figure 4-9 Analytical model and ANN simulated model with 5\% noise. The temperature difference between the two maximum peaks increase due to the random noise added to the data.

Additionally, figure 4-10 illustrates the comparison between $\mathrm{t}$ optimized and non optimized parameters in chest tissue for analytical model with the colored sphere as the location of the tumor befor optimization and the black and white sphere the optimized location of the embedded tumor.

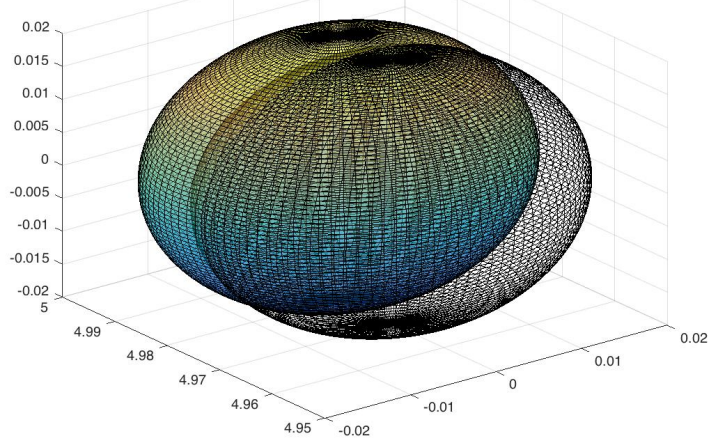

Figure 4-10 Comparison between the optimized and non optimized parameters in chest tissue for analytical model. 


\subsection{Data sensitivity analysais}

\subsubsection{Parameter sensitivity}

To analyze the sensitivity for each parameter, a simple model of $\mathrm{R}=0.002 \mathrm{~m}$ and $\mathrm{d}=0.01 \mathrm{~m}$ was developed. Each parameter was changed, by adding $20 \%$ random noise. First, the radius was kept the same and the depth was changed by adding $20 \%$ calculation error to it. This is illustrated in figure 4-11(a). The temperature difference between the two curves in this case is $0.79{ }^{\circ} \mathrm{C}$.

The same steps were taken to asses the sensitivity of the radius ( $R=0.015$ for $d=0.02)$, with the exception that $\mathrm{R}$ was affected by $20 \%$ for once and random noise by $50 \%$ as well. This could be seen in figure 4-11(b). As could be seen in the figure 4-11, the temperature difference between the actual and noisy curve $(20 \%$ random noise $)$ is $0.1{ }^{\circ} \mathrm{C}$, and for $50 \%$ noise is $0.57{ }^{\circ} \mathrm{C}$.

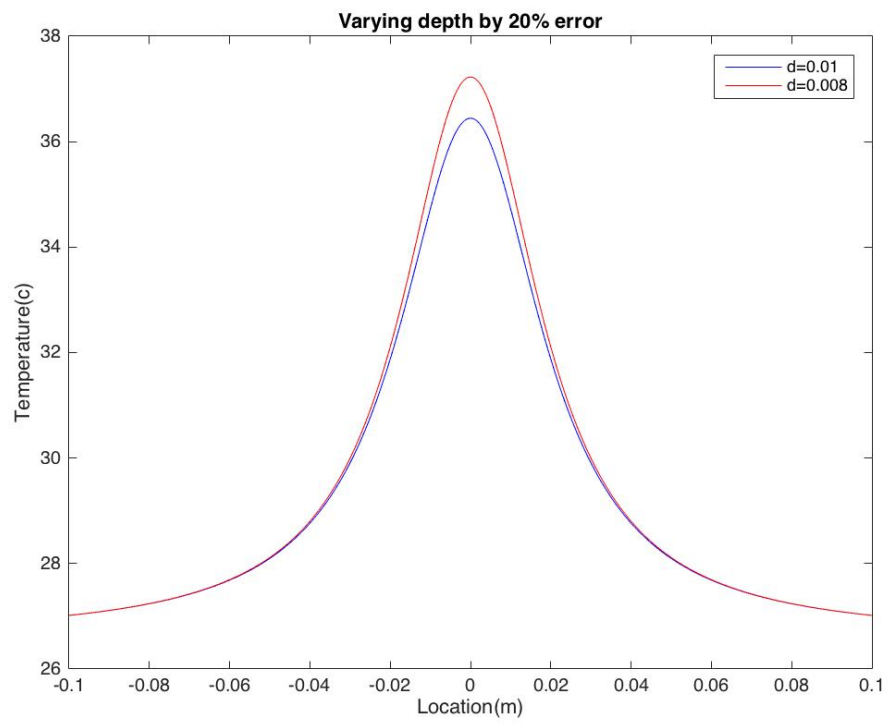

(A)

Figure 4-11(a) Sensitivity analysis with $20 \%$ change in depth value. 


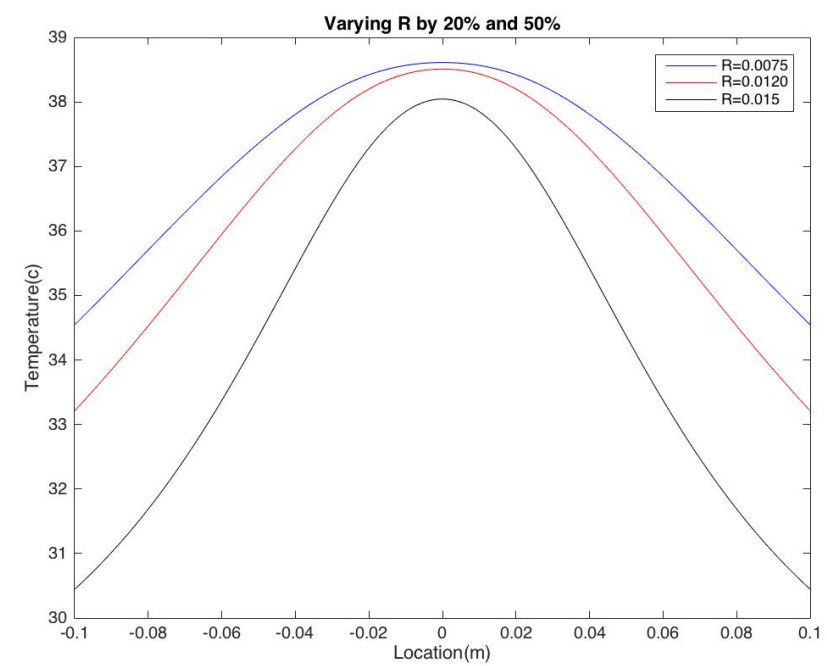

(B)

Figure 4-11(b) Sensitivity analysis with 20\% and 50\% change in radius value.

The temperature difference would grow, considering a case with a heat source of higher $\mathrm{R}$, and $\mathrm{d}$ and applying the same $\pm 20 \%$.

\subsubsection{Temperature sensitivity}

To assess temperature sensitivity, it was assumed that method is associated with $5 \%$ error (this error could be caused by a non calibrated camera, or fluctuation in room temperature), while measuring the surface temperature. As it could be observed in the figure 4-12, in case of the surface temperature, 5\% measuring error has a greater effect on the model than a higher error ( $20 \%$ error) on each parameter does. This difference is as large as $1.82{ }^{\circ} \mathrm{C}$. Therefore, local temperature is the most sensitive parameter, during tumor localization, using IR cameras. 


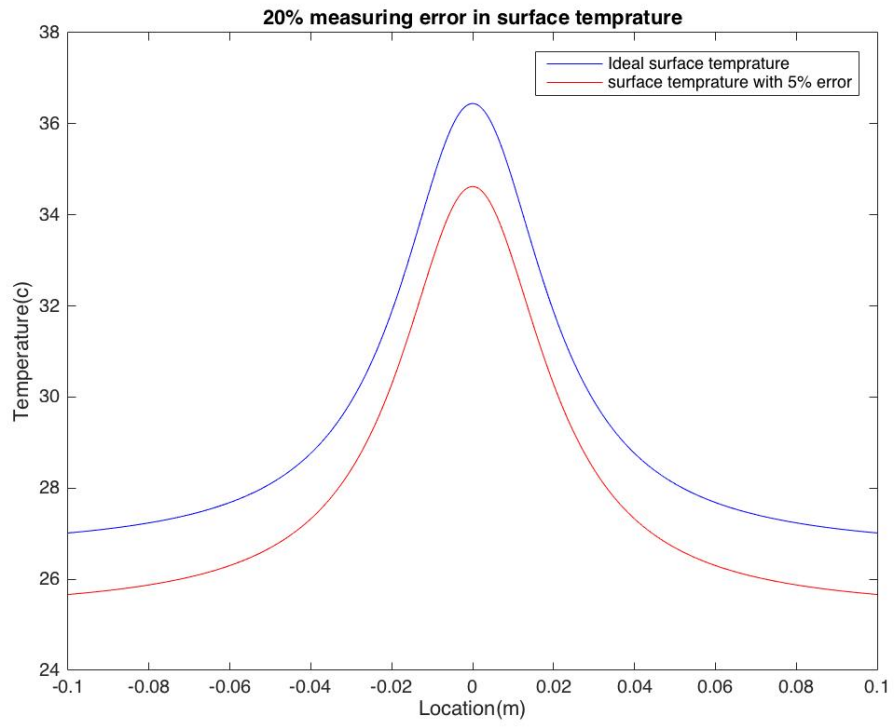

Figure 4-12 Sensitivity analysis with 5\% error in measured surface temperature.

\subsection{Summary}

A bio-heat model was developed utilizing Penne's Bioheat equation and analytical methods were employed to estimate tumor parameters in the chest tissue. Artificial neural network (ANN) was used to optimize the obtained results. The initial values for training the ANN could be found using an IR camera, or, through estimation using any analytical method. By training the ANN, $0.35^{\circ} \mathrm{C}$ temperature difference was found (between the two curves) for ideal model, and $1.82^{\circ} \mathrm{C}$ temperature deference for model with 5\% random noise.

Additionally, sensitivity of the parameters was studied along with the surface temperature sensitivity. As finding indicate, surface temperature is the most sensitive parameter since, surface temperature can affect the degree of the accuracy to which all other parameters are found. Therefore, during biological testing it is very important to use a well calibrated camera. 


\section{Chapter 5 \\ Experimental results of the breast model}

\section{Introduction}

In this chapter, we have used the developed model in chapter 3 along with an experimental setting to validate our results. To validate the proposed method and its outcomes, a laboratory set up was developed. This set up (Figure 5-2) was composed of a 0-50 DC analog power supply, an IR camera (FLIR SC 4000), a cylindrical cartridge heater dimension $12.7 \mathrm{~mm} \times 3.1 \mathrm{~mm}$, a digital thermometer, and a thermocouple (for calibration of camera).

In this test we have used Noble Agar to perform as tissue phantom. Hence, to mold the phantom, two hemispheres with radiuses of 7.5 (inner diameter) $\mathrm{cm}$ and $6.5 \mathrm{~cm}$ (outer diameter) were designed utilizing SolidWorks and 3D printed using PLA plastic. The thickness and diameters of the hemispheres were designed in such way that if one is put inside the other one there is a $1 \mathrm{~cm}$ gap between them as shown figure 5-1. This was done so that we are able to mold two different layers with different densities to account the skin and adipose tissue.

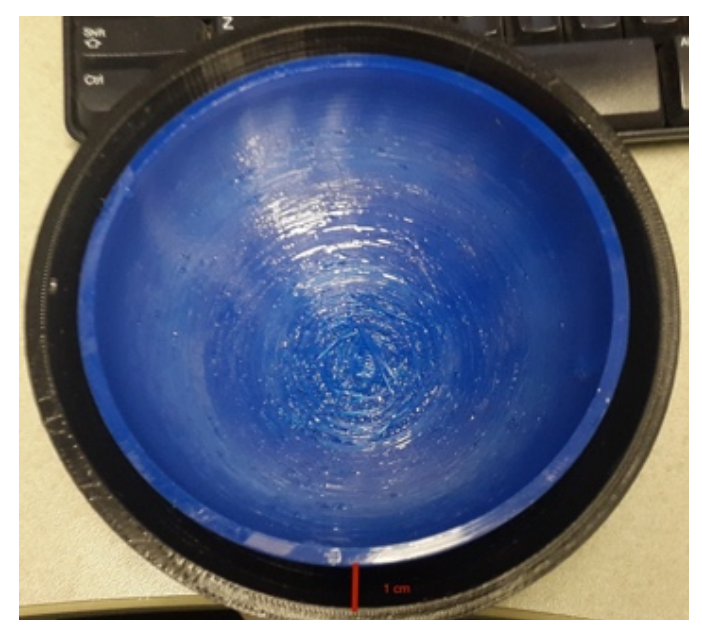

Figure 5-1 Two hemispheres inside each other to mold the layers of phantoms. The read line is the gap between the two bowls that is $1 \mathrm{~cm}$. 


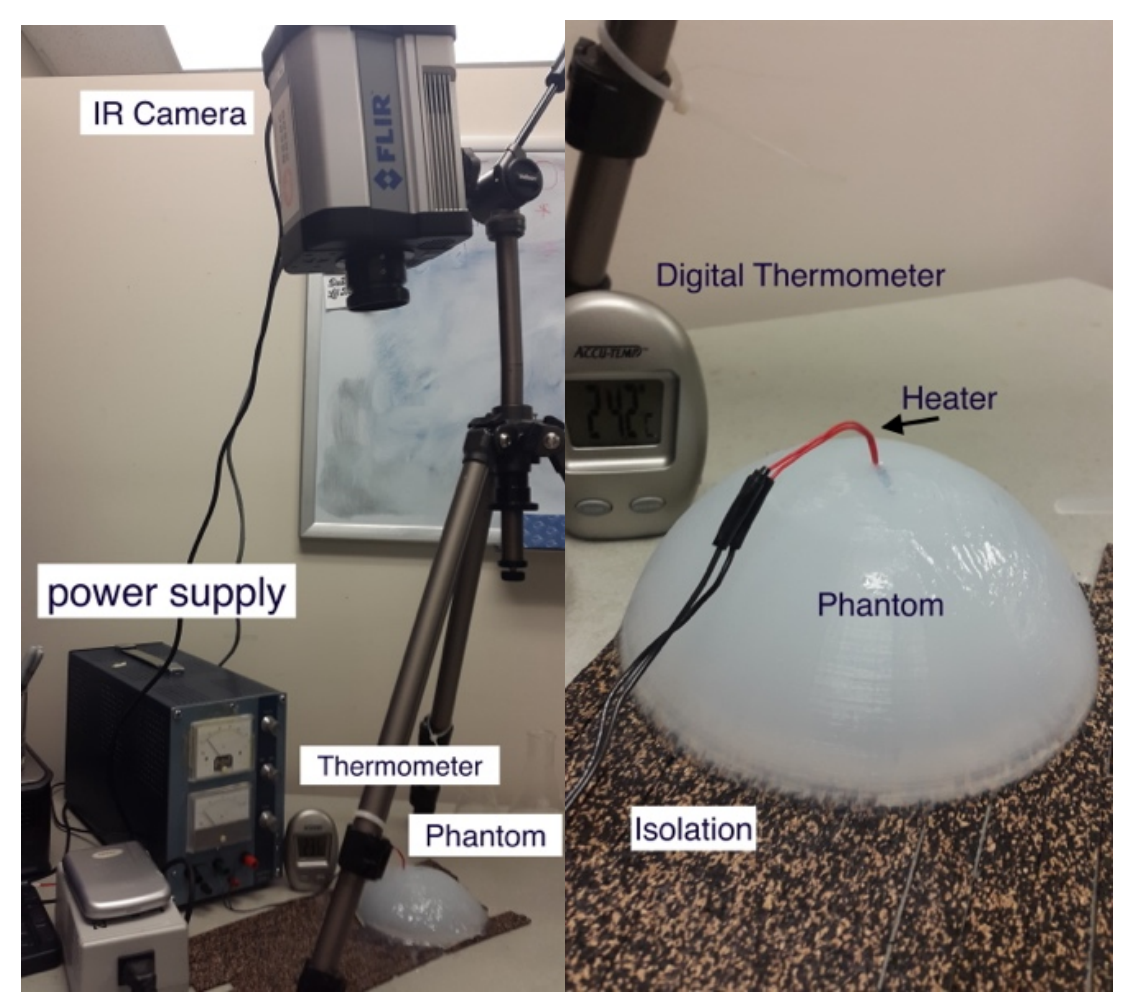

Figure 5-2 Laboratory test set-up.

The phantom was made of $1 \%$ Noble Agar solution to act as adipose tissue with a layer of $1.5 \%$ Noble Agar poured on the top to act as skin. Since Noble Agar is not granulated, it makes it a good candidate for imaging peruses. To make the phantom $500 \mathrm{ml}$ Agar was brought to boil and then carefully poured in to the blue (smaller) container to harden. After the 1\% Agar solution have harden, it was placed inside the black (larger) container and, 200ml of boiled, 1.2\% Agar was pored in to the gap between the two. The model is shown in figure 5-3.

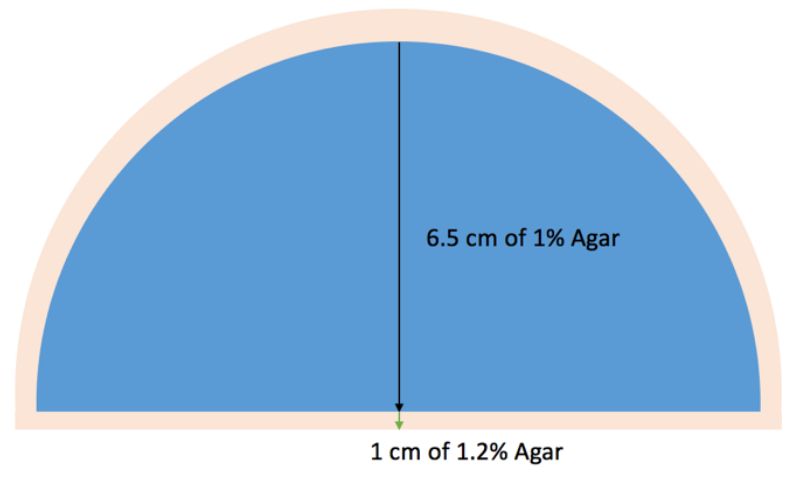

Figure 5-3 Phantom model. 
Afterwards, the molded phantom was removed from the container and placed on an isolated (using crock strips) surface (so there is no thermal exchange with the surface of the table). This way, the only heat exchange would be from the round surface of phantom representing the breast.

Thermal conductivity of the different gallous materials are illustrated in Table 5-1. It is obvious that at $21{ }^{\circ} \mathrm{C}$ the closest gel material to represent muscle is Agar 1.5\%. Since we need our phantom to represent adipose tissue, we have used Agar solution of $1 \%$ at $21{ }^{\circ} \mathrm{C}-24{ }^{\circ} \mathrm{C}$. according to M. Mital and E. P. Scott 1\% Agar solution is a good candidate to act as breast phantom [42].

Table 5-1 Thermal conductivity of various gelatinous materials [36, 44-46].

\begin{tabular}{|c|c|c|c|}
\hline Gel & $\mathrm{T}\left({ }^{\circ} \mathrm{C}\right)$ & $\begin{array}{c}\text { Thermal } \\
\text { conductivity } \\
\mathrm{W} /(\mathrm{m} . \mathrm{K})\end{array}$ & Reference \\
\hline Agar $1.5 \%$ & 21 & $0.597 \pm 0.007$ & {$[44]$} \\
\hline Gelatin 2\% & 20 & 0.619 & {$[36,43,45]$} \\
\hline Carrageenan 2\% & 10 & $0.592 \pm 0.031$ & {$[46]$} \\
\hline Carrageenan 2\% & 25 & $0.609 \pm 0.018$ & {$[36,46]$} \\
\hline Carrageenan & 37 & 0.496 & {$[36]$} \\
\hline $19 \%$ & & & \\
\hline
\end{tabular}

The body temperature (core temperature) was assumed constant at $37^{\circ} \mathrm{C}$. This parameter does not affect the study since, it is a constant and affects all points on the same layer in a similar fashion.

The phantom was allowed to harden for 24 hours so it has the same temperature as the room. The experiment was conducted in two different sets, the second set being the control tests. Additionally, each experiment was running for at least 4 hours allowing the system to reach steady state (the point that the surface temperature is not affected by time). 
Additionally, the main experiments were conducted by locating the heater at various depth in the center of the phantom. However, in control sets, the heater was located randomly at various places around the surface of the phantom. This was carried out to make sure that at high randomness, the analytical and experimental results are close to each other and therefore accurate.

\subsection{Experimental tests}

In this part we have fed the heater ( $3.1 \mathrm{~mm}$ diameter) with the constant voltage of approximately $6 \mathrm{~V}$ for all three experiments. However, the depth of the heater and room temperature were variable. Additionally, at this voltage, the heater has a power of $0.9 \mathrm{~W}$. It is important to point out that the tip of the heater was measured to be the hottest point. Therefore, the tip heater was located exactly at each depth.

\subsubsection{Experiment 1}

The heater was located the depth of $1.5 \mathrm{~cm}$ inside the phantom (shallowest) and it was covered using a $1.2 \%$ Agar. The room temperature was measured to be fluctuating between $23.9{ }^{\circ} \mathrm{C}-24$ ${ }^{\circ} \mathrm{C}$. Figure 5-4 illustrates the thermal image captured by the camera.

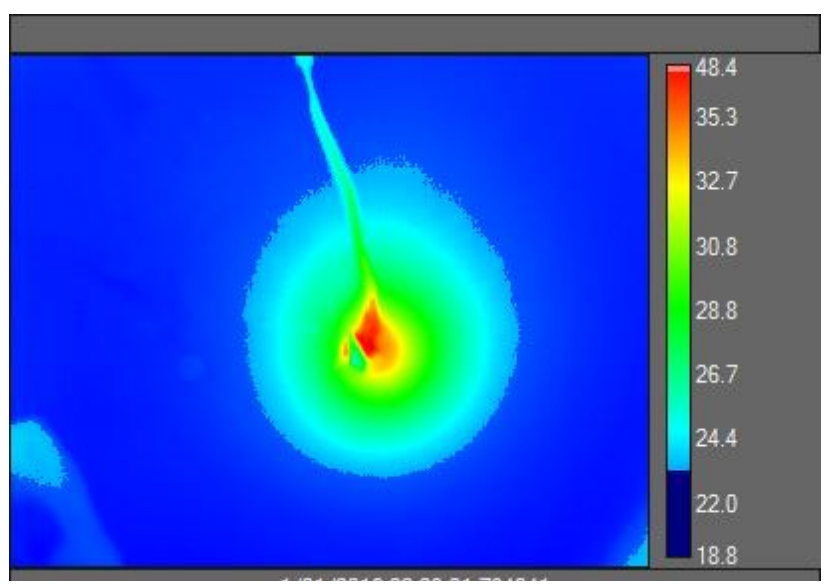

Figure 5-4 Thermal image of a heater located at $1.5 \mathrm{~cm}$ depth having diameter of $3.1 \mathrm{~mm}$. The location of the maximum temperature is shown as opaque red in the image. 
As shown by figure 5-4, the maximum temperature is $48.4^{\circ} \mathrm{C}$. This high temperature is due to using a heater of high power. However, to validate this result, we have used the analytical algorithm developed to measure the surface temperature using the same diameter and depth this time. We have used the algorithm that was developed based on equations 3-21.

From figure 5-5, it could be seen that the maximum temperatures calculated based on mathematical $\left(48.83{ }^{\circ} \mathrm{C}\right)$ model and obtained from experimental set are very close to each other with a small difference of $0.43{ }^{\circ} \mathrm{C}$. This difference could be due to fluctuation of ambient temperature.

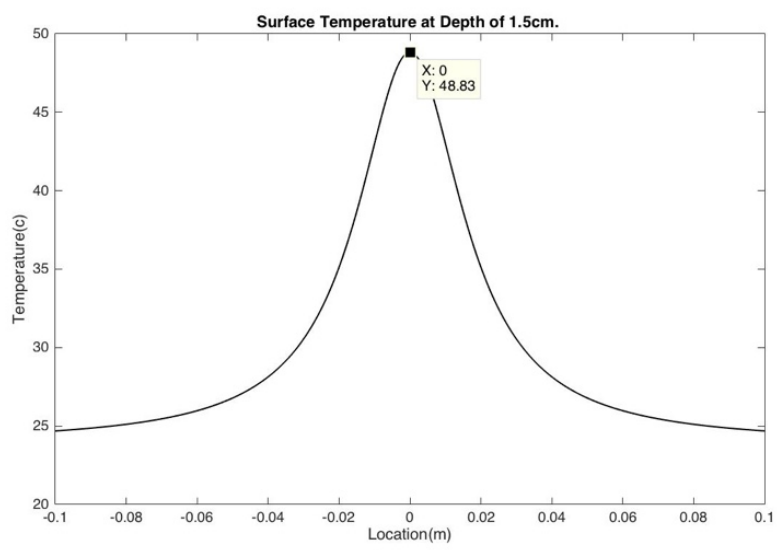

Figure 5-5 Analytical simulation for a heater located at $1.5 \mathrm{~cm}$ depth having diameter of $3.1 \mathrm{~mm}$.

\subsubsection{Experiment 2}

In this experiment we have taken the same steps as experiment 1 . However, this time the heater was located at the depth of $2 \mathrm{~cm}$ and the room temperature was fixed at $24.9^{\circ} \mathrm{C}$ during the whole time of experiment. For $6 \mathrm{~V}(0.9 \mathrm{~W})$ power level, maximum temperature contours are illustrated in figure 5-6 and 5-7. 


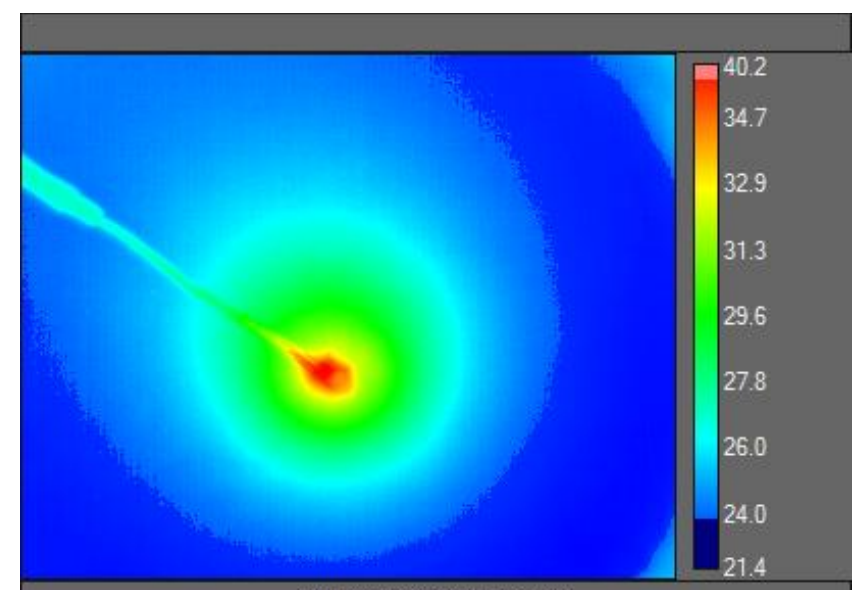

Figure 5-6 Thermal image of a heater located at $2 \mathrm{~cm}$ depth having diameter of $3.1 \mathrm{~mm}$. the location of the maximum temperature is shown as opaque red in the image.

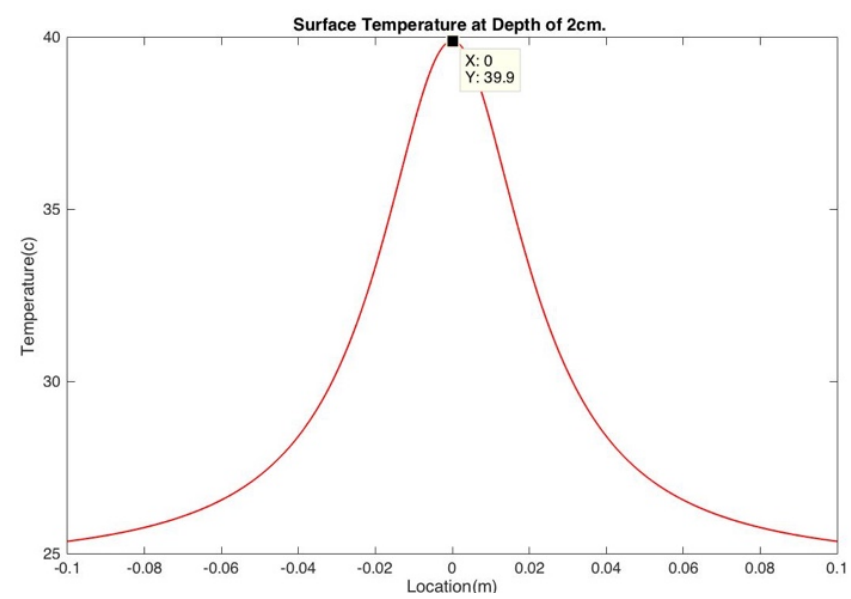

Figure 5-7 Analytical simulation for a heater located at $2 \mathrm{~cm}$ depth having diameter of $3.1 \mathrm{~mm}$.

Again, the maximum temperature found to be $40.2^{\circ} \mathrm{C}$ in figure $5-6$ which is very close to the maximum temperature of $39.9^{\circ} \mathrm{C}$ which was calculated mathematically and illustrated in figure 5-7. The difference in this case is $0.3^{\circ} \mathrm{C}$. 


\subsubsection{Experiment 3}

Lastly, the third experiment was conducted by locating the heater at the depth of $3 \mathrm{~cm}$, at the room temperature of $23{ }^{\circ} \mathrm{C}$, and at applied $6 \mathrm{~V}$ voltage $(0.9 \mathrm{~W})$. Figure 5-8 and 5-9 illustrate the obtained results.

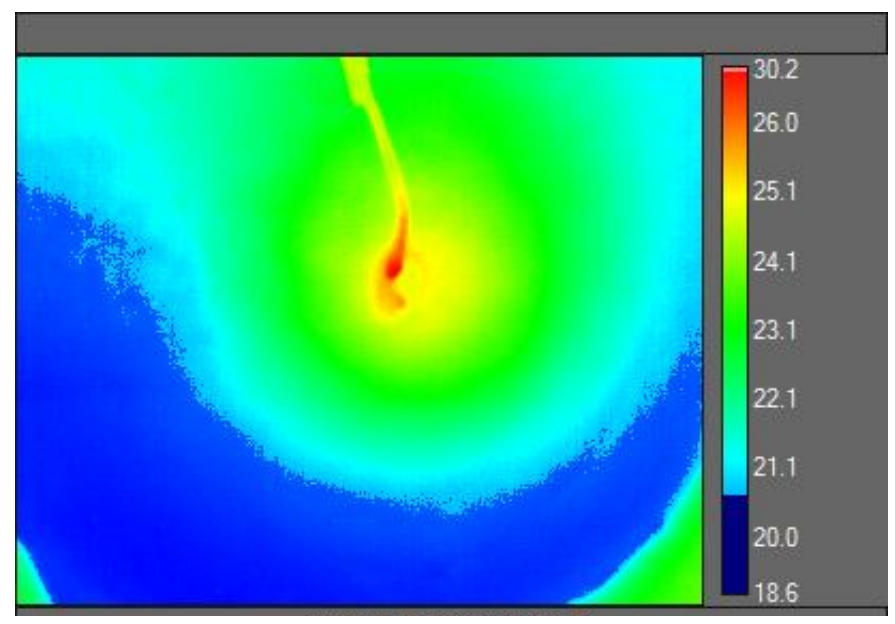

Figure 5-8 Thermal image of a heater located at $3 \mathrm{~cm}$ depth having diameter of $3.1 \mathrm{~mm}$. The location of the maximum temperature is shown as opaque red in the image.

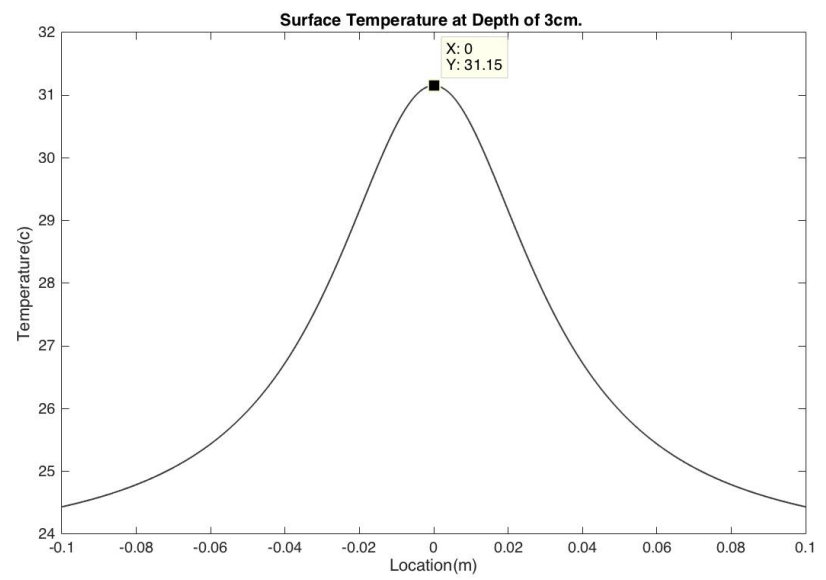

Figure 5-9 Analytical simulation for a heater located at $3 \mathrm{~cm}$ depth having diameter of $3.1 \mathrm{~mm}$.

In this case the difference between the analytical simulation and test results are $1.25^{\circ} \mathrm{C}$. Table 52 lists a summery of the results of the experiment carried out at approximately $6 \mathrm{~V}(0.9 \mathrm{~W})$. 
Table 5-2 results of the 3 tests.

\begin{tabular}{|ccccc|}
\hline $\begin{array}{c}\text { Depth } \\
(\mathrm{cm})\end{array}$ & $\begin{array}{c}\text { Maximum } \\
\text { temperature } \\
\text { (Analytical) }\end{array}$ & $\begin{array}{c}\text { Maximum } \\
\text { temperature } \\
(\text { Experimental) }\end{array}$ & $\begin{array}{c}\text { Error } \\
(\%)\end{array}$ & $\begin{array}{c}\text { Temperature } \\
\text { Difference } \\
\left({ }^{\circ} \mathrm{C}\right)\end{array}$ \\
\hline 1.5 & 48.83 & 48.4 & 0.88 & 0.43 \\
\hline 2 & 39.9 & 40.2 & 0.74 & 0.3 \\
\hline 3 & 31.15 & 30.2 & 3.04 & 0.95 \\
\hline
\end{tabular}

It can be seen in Table 5-2 that, the deeper the heat source, the higher the percentage of error. However, it is evident that the first two experiments are not following this statement. That could be due to fluctuation in room temperature, however, the percentage error for all three cases is less than $1 \%$ which makes this technique very accurate.

\subsection{Control experimental tests}

The control experiments were conducted to increase the accuracy of the study. To prepare the phantom for experiment, the top layer of the phantom was removed and a new layer was created on top of the 1\% Agar phantom. The top layer was consisting 1.5\% less dissolved Agar solution. This would allow for more inhomogeneity in the phantom. Finally, the phantom was allowed to cool down and reach the room temperature.

During control experiments, unless the actual experiment that heater was located at the center of the phantom, the heater was located at random corners of the phantom.

\subsubsection{Control experiment 1}

Heater was located at $1.5 \mathrm{~cm}$ depth inside the phantom at $23^{\circ} \mathrm{C}$ ambient temperature. The ambient temperature fluctuated during the course of experiment by $0.2^{\circ} \mathrm{C}$ which is negligible. The analytical maximum temperature was found to be $47.93^{\circ} \mathrm{C}$.

In this experiment, the difference between maximum analytical temperature compared to experimental temperature was recorded to be $0.33{ }^{\circ} \mathrm{C}$. This difference was recorded after the 
system reached steady state. It can be seen that the results obtained from control experiment 1 , are very similar to the actual experiment. Figures 5-10 and 5-11 illustrate the thermal image of a heater located at $1.5 \mathrm{~cm}$ depth and the temperature profile of the heater per pixel respectively.

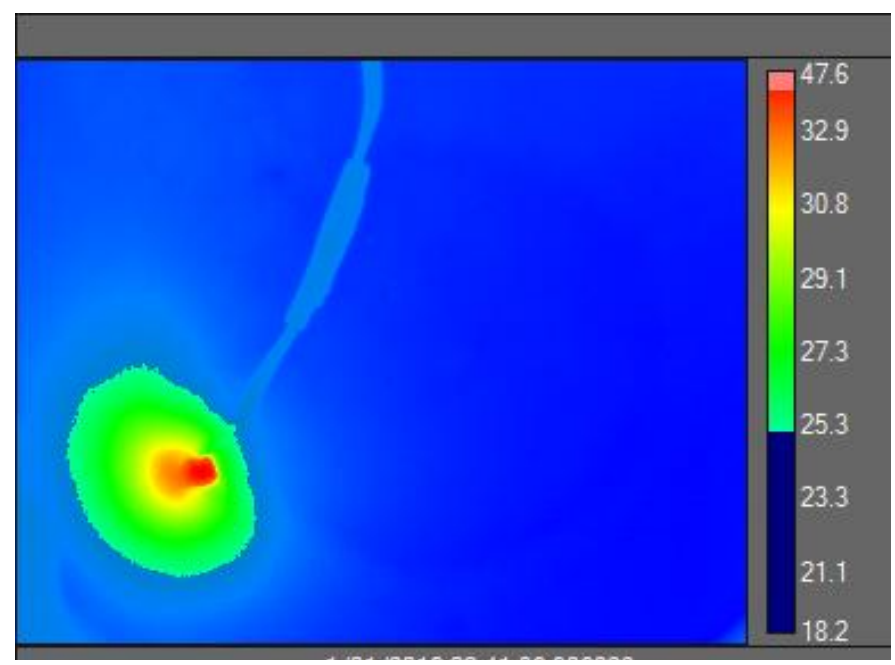

Figure 5-10 Thermal image of a heater located at $1.5 \mathrm{~cm}$ depth having diameter of $3.1 \mathrm{~mm}$. the heater was located at a random corner of the heater.

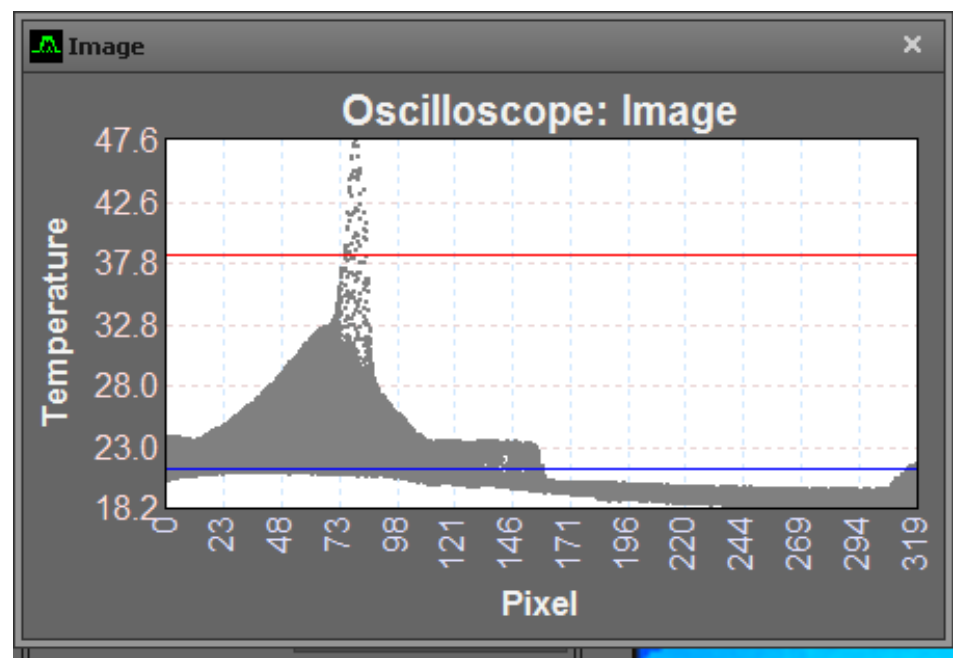

Figure 5-11: Temperature profile of the heater per pixel. Maximum temperature happens somewhere around 74 pixel. 


\subsubsection{Control experiment 2}

Heater was located at $2 \mathrm{~cm}$ at ambient temperature of $23{ }^{\circ} \mathrm{C}$ at $6 \mathrm{~V}(0.9 \mathrm{~W})$. This time, the difference of the maximum temperatures (analytical VS. experimental) is $0.3{ }^{\circ} \mathrm{C}$. The results are illustrated in figure 5-12 and figure 5-13. The maximum temperature was found to be $38{ }^{\circ} \mathrm{C}$ according to figure 5-12. However, the analytical solution yields a maximum temperature of 38.3 ${ }^{\circ} \mathrm{C}$.

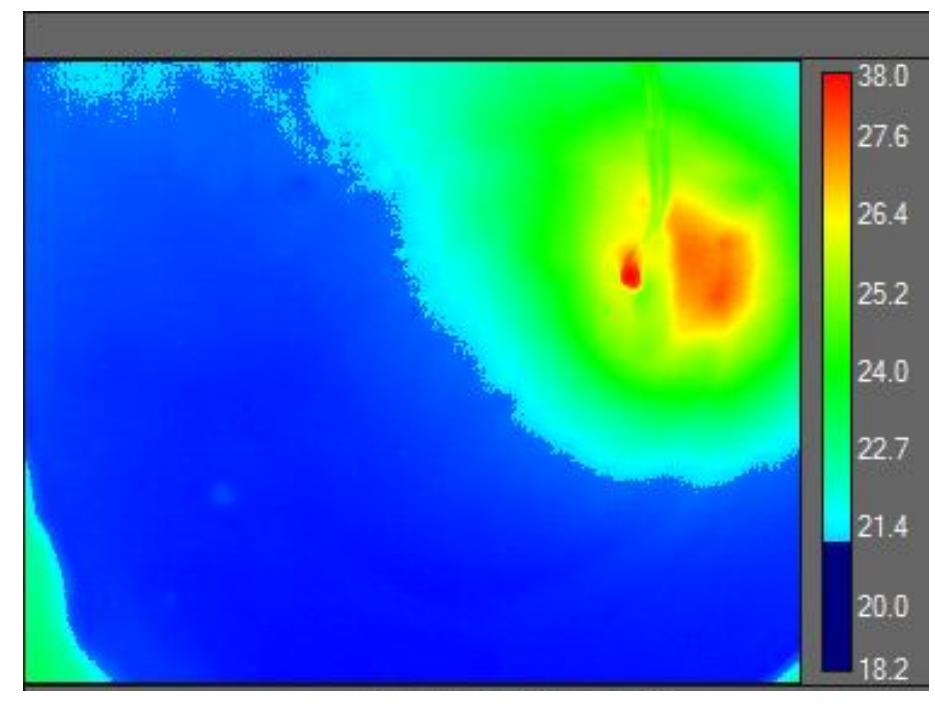

Figure 5-12 Thermal image of a heater located at $2 \mathrm{~cm}$ depth having diameter of $3.1 \mathrm{~mm}$. the heater was located at a random corner of the heater.

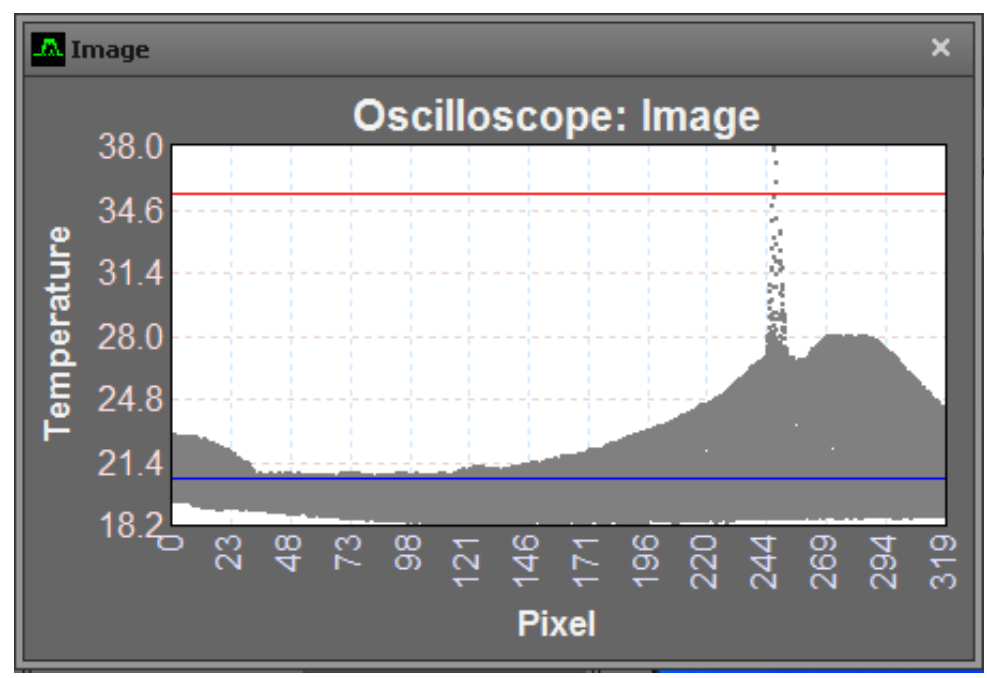

Figure 5-13 Temperature profile of the heater per pixel. Maximum temperature happens somewhere around 250 pixel. 


\subsubsection{Control experiment 3}

Finally, the heater was located at $3 \mathrm{~cm}$ again at ambient temperature of $22.9{ }^{\circ} \mathrm{C}$ at $6 \mathrm{~V}(0.9 \mathrm{~W})$. this time the difference of the maximum temperatures was found to be $0.95{ }^{\circ} \mathrm{C}$. This higher difference is due to the depth in which the heater is located. Phantom being at isolation also contribute to this error. However, the obtained results are again very similar to the results obtained from experiment 3. This would validate both our analytical and experimental model. Figures 5-14 and 5-15 show the thermal image of a heater located at $3 \mathrm{~cm}$ and temperature profile of the heater per pixel respectively.

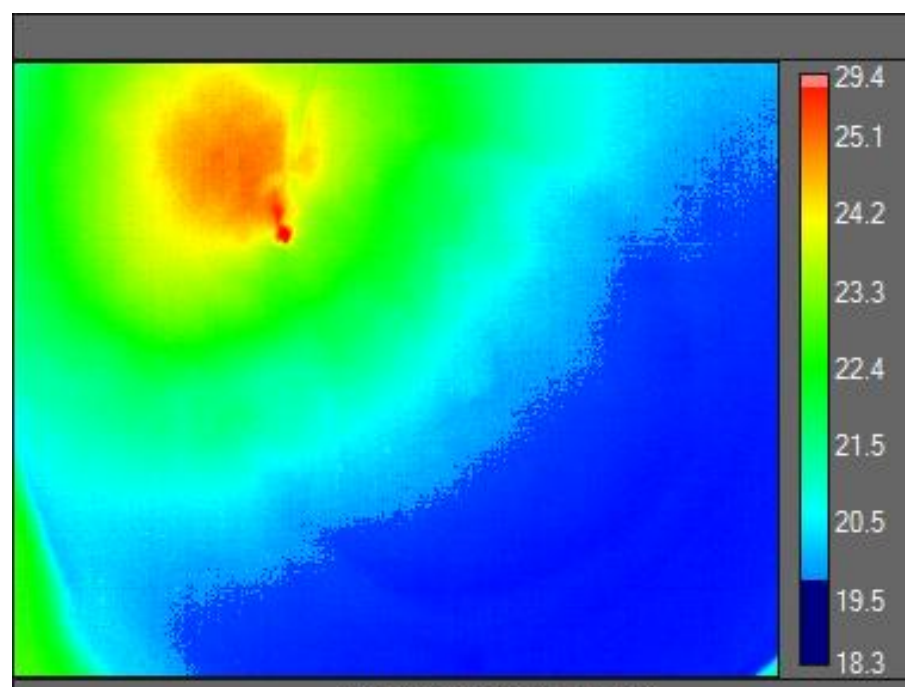

Figure 5-14 the thermal image of a heater located at $3 \mathrm{~cm}$ depth having diameter of $3.1 \mathrm{~mm}$. 


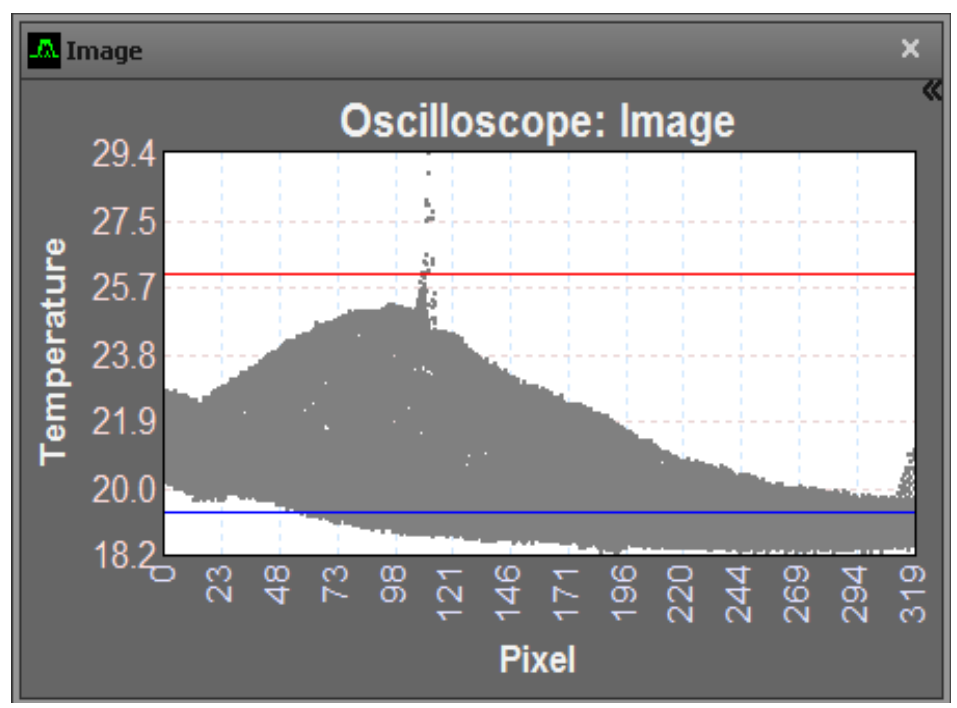

Figure 5-15 temperature profile of the heater per pixel. Maximum temperature happens somewhere around 98.

Table 5-3 comparison between the two different test sets.

\begin{tabular}{|c|l|l|l|l|} 
Depth & $\begin{array}{l}\text { Maximum } \\
\text { temperature (Test) } \\
\left({ }^{\circ} \mathrm{C}\right)\end{array}$ & $\begin{array}{l}\text { Maximum } \\
\text { temperature } \\
(\text { control test) } \\
\left({ }^{\circ} \mathrm{C}\right)\end{array}$ & $\begin{array}{l}\text { Error } \\
(\%)\end{array}$ & $\begin{array}{l}\text { Temperature } \\
\text { Difference }\end{array}$ \\
& & 47.6 & 1.6 & 0.8 \\
\hline 1.5 & 48.4 & 38 & 5.4 & 2.2 \\
\hline 2 & 40.2 & 29.4 & 2.6 & 0.8 \\
\hline 3 & 30.2 & & & \\
\hline
\end{tabular}

From Table 5-3, it can be seen that the maximum error happened when the heater was located at $2 \mathrm{~cm}$. This could be due to difference in ambient temperature. however, the errors are very small and negligible. 


\subsection{Summary}

Using the method developed in chapter 3, we have validated the analytical results by developing a laboratory experimental test set-up. During validation, a phantom of Agar solution was utilized to act as breast tissue. Additionally, to simulate tumor, a small cartridge heater was placed inside the phantom and heated up by $6 \mathrm{~V}(0.9 \mathrm{~W})$ input voltage.

The heater was heated at 6 volts for all test as well as control experiments. The results suggest that for a same heat source (at $6 \mathrm{~V}$ ) located at different depth, the experimental results are very close to the the analytical findings. The difference in maximum temperatures between the analytical results and their corresponding experimental results could be due to isolation of phantom, fluctuation in temperature, expansion of the metal heater, and any other environmental factors. 


\section{Chapter 6 \\ Experimental results of the chest model}

\section{Introduction}

This chapter like chapter 5, focuses on validation of analytical results obtained from chapter 4 . Again, the experimental test set up was composed of a 0-50 DC power source, an IR camera (FLIR SC 4000), a small cartridge heater of length $12.7 \mathrm{~mm}$ and diameter $3.1 \mathrm{~mm}$, a small cubical container designed by SolidWorks and printed Via 3D printer with dimensions of $9 \mathrm{~cm} \times 9 \mathrm{~cm} \times$ $4 \mathrm{~cm}$, a digital thermometer, a thermocouple (for calibration of camera), and solution of Noble Agar prepared and used as tissue phantom. Figure 6-1 illustrates the set up as a whole.
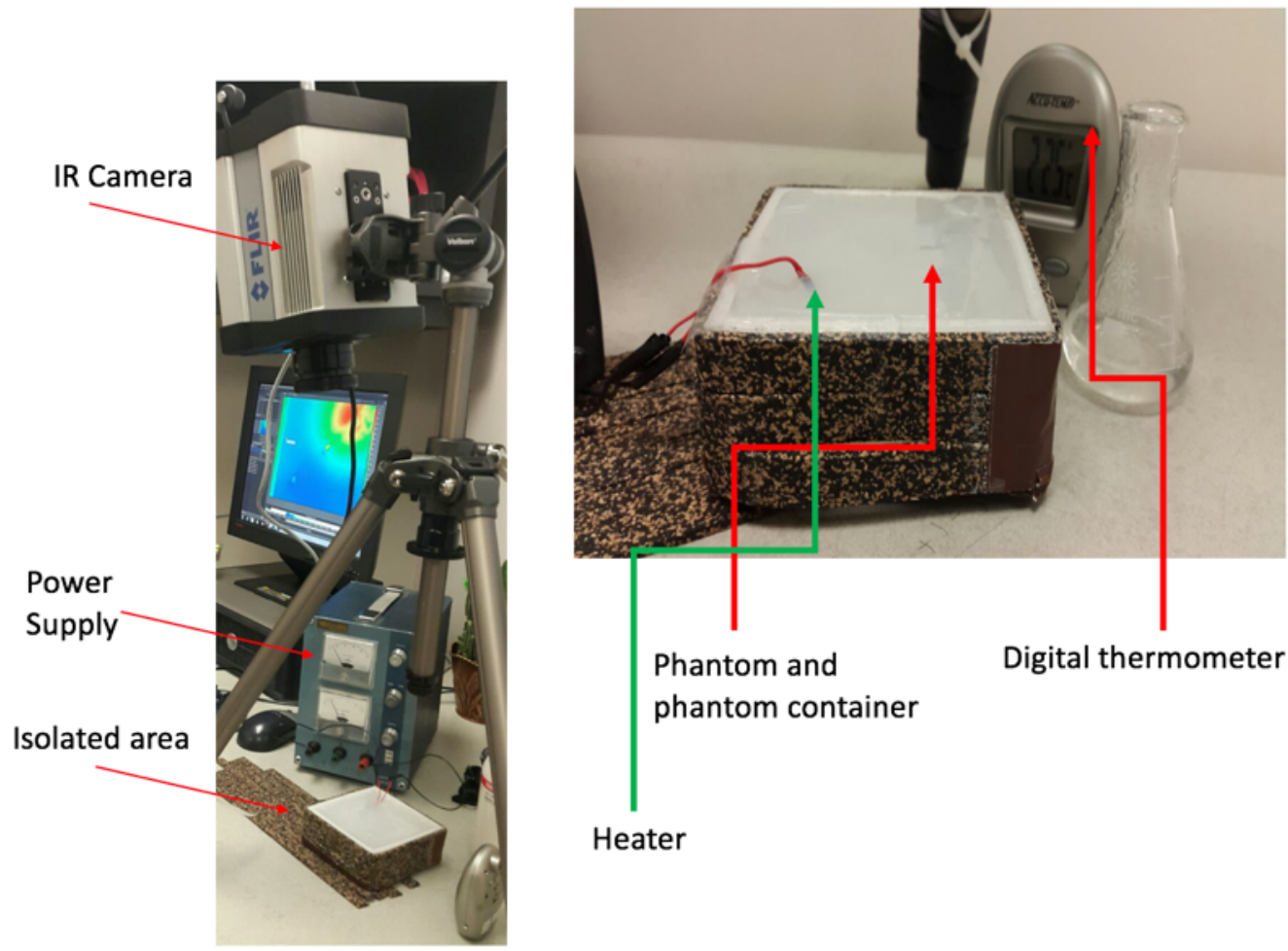

phantom container

Figure 6-1 Experimental set-up. 
The phantom is 1\% Noble Agar solution. Noble Agar was chosen since, it is not granulated and it hardens clear. Therefore, it is a better option for imaging purposes. 300ml of Agar solution was brought to boil and let to set for 24 hours. However, since the chest tissue is not totally homogenous, we have prepared $100 \mathrm{ml}$ of less dissolved and more concentrated (2.5\%) Agar solution (more granulated) and was poured on top of the harden clearer Agar and again let to set. This way the phantom is the same temperature as the room. Using two layers of Agar solution with different concentrations could be used to represent tissue layers (muscle and skin).

Thermal conductivity of the different gel materials at different temperatures (above zero and non-frozen) could be found in table 2 below. As it could be seen by comparing table 1 and table 2, at around $21{ }^{\circ} \mathrm{C}$, Agar solution of $1.5 \%$ has the closest thermal conductivity (k) to muscle tissue. Table 6-1sumerized the thermal conductivity of various gelatinous materials with Agar $1.5 \%$ being the closest to chest muscle in terms of thermal conductivity.

Table 6-1 Thermal conductivity of various gelatinous materials. Agar $1.5 \%$ at $21{ }^{\circ} \mathrm{C}$ has the closest thermal conductivity to chest muscle [36, 43-47].

\begin{tabular}{|c|c|c|c|}
\hline Gel type & T $\left({ }^{\mathbf{}} \mathbf{C}\right)$ & $\begin{array}{c}\text { Thermal conductivity } \\
\text { W/(m.K) }\end{array}$ & Reference \\
\hline Agar 1.5\% & & & \\
\hline Gelatin 2\% & 21 & $0.597 \pm 0.007$ & {$[44]$} \\
\hline Carrageenan 2\% & 20 & 0.619 & {$[36,43-45]$} \\
\hline Carrageenan 2\% & 10 & $0.592 \pm 0.031$ & {$[46]$} \\
\hline Carrageenan 2\% & 25 & $0.609 \pm 0.018$ & {$[36,46]$} \\
\hline Carrageenan 19\% & 30 & $0.645 \pm 0.022$ & {$[36,46]$} \\
\hline Carrageenan 28\% & 37 & 0.496 & {$[47]$} \\
\hline
\end{tabular}

Additionally, it was found through the experiment that the tip of the heater is the hottest point. Therefore, we have used the tip as the reference point. This points are sown in the figures by a small red arrow head. 
Before the phantom hardens 3 straws with different length were fixed at certain locations in the Agar solution to provide housing for the heater to be place in.

The length of the straws was measured accurately using a clipper. Figure 6-2 shows the test set up.

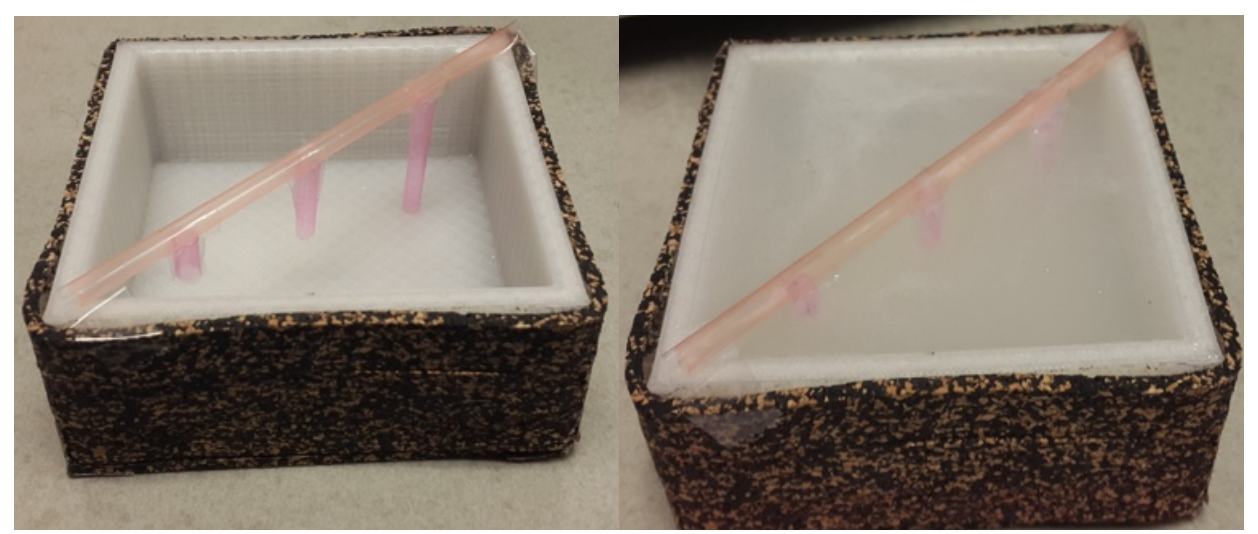

Figure 6-2 heater housing at different depth before and after pouring the Agar solution in the container.

Additionally, the container was isolated with crock strips so that the only temperature exchange is through the surface of the phantom.

The body temperature (core temperature) was assumed constant at $37{ }^{\circ} \mathrm{C}$. This parameter does not affect the study since, it is a constant and affects all points on the same layer the same. Also we have initially assumed that the tumor temperature is a separate heat source as the body core temperature.

\subsection{Experimental Tests}

We have started the experiment after making sure that the phantom is totally harden and has the same temperature as room temperature. The room was chosen somehow so there is minimum temperature fluctuation. Also, the surface that the container was placed on top of, was isolated with crock strips so there is no heat exchange through the bottom of the container. The 
experiment was conducted twice to provide more accuracy. the camera was running for minimum of 2.5 hours in each experiment to make sure that the system reaches steady state and the surface temperature stays at a constant value.

Figure 6-3 illustrates the phantom when the heater is off. As it can be seen, the maximum temperature is $23.1^{\circ} \mathrm{C}$ which is very close to the ambient temperature of $24^{\circ} \mathrm{C}$.

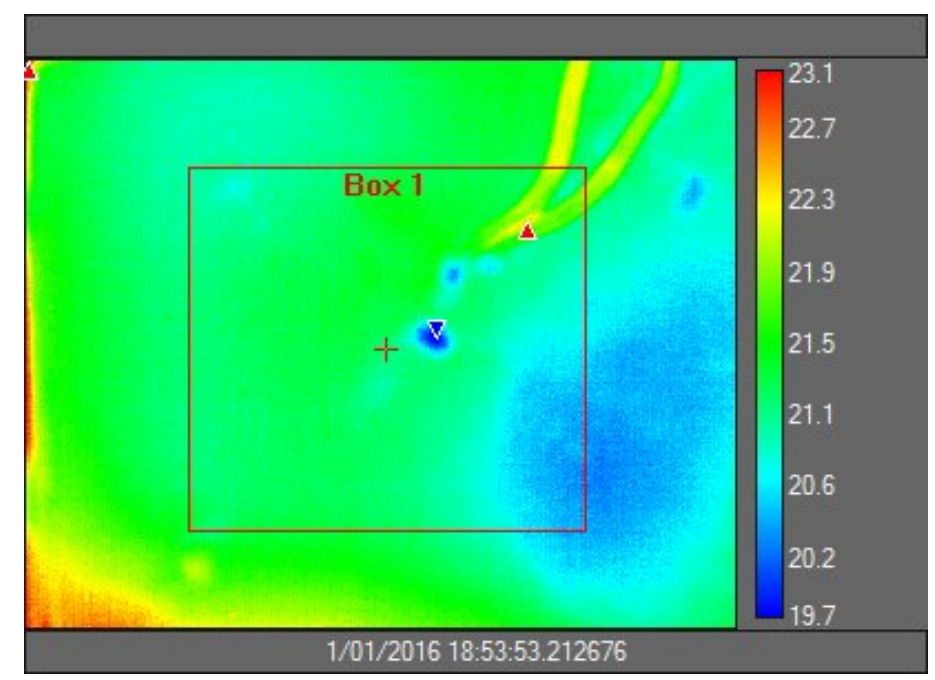

Figure 6-3 Thermal image of a phantom wit heater at off state. Maximum temperature is very close to ambient temperature.

\subsubsection{Experiment 1}

The heater was located at the $3.4 \mathrm{~cm}$ depth in the container. The housing was completely closed by pouring some $1 \%$ Agar solution on top of the heater and therefore, completely set the heater inside the phantom. In this experiment the room temperature was measured to be constant at 24.4 ${ }^{\circ} \mathrm{C}$. The heater diameter is $3.1 \mathrm{~mm}$. The experiment was conducted at $6 \mathrm{~V}(0.9 \mathrm{~W})$. The thermal image obtained from the camera is shown in Figure 6-4. 


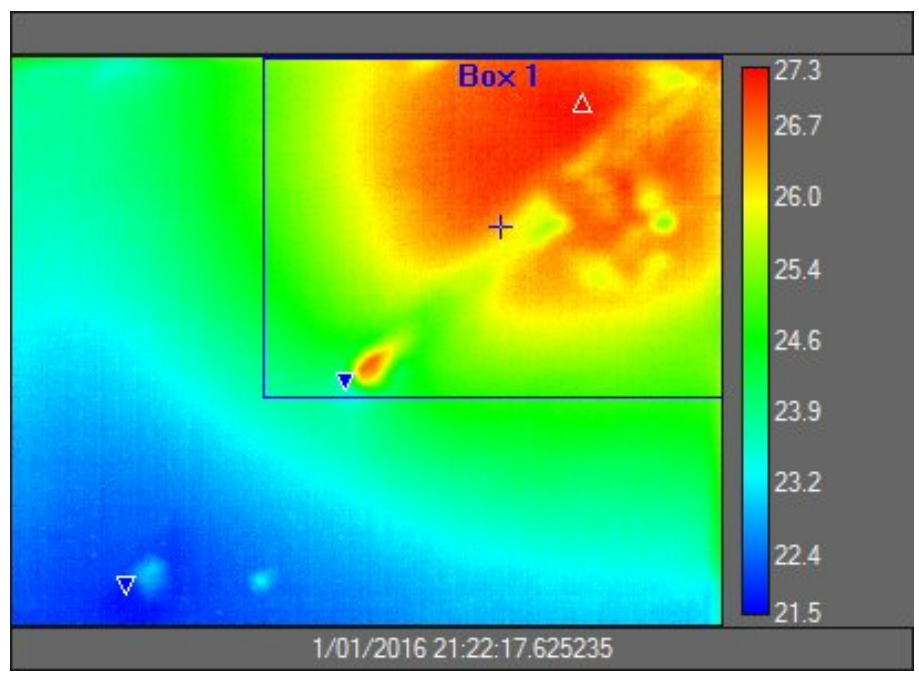

Figure 6-4 Thermal image of a heater located at $3.4 \mathrm{~cm}$ depth having diameter of $3.1 \mathrm{~mm}$. the red arrow illustrates the location of the maximum temperature and hence the tip of the heater.

According to the images, the maximum temperature is at $27.3^{\circ} \mathrm{C}$. Using the same depth and diameter in our analytical method, the maximum temperature is $27.94{ }^{\circ} \mathrm{C}$ as shown in figure $6-5$.

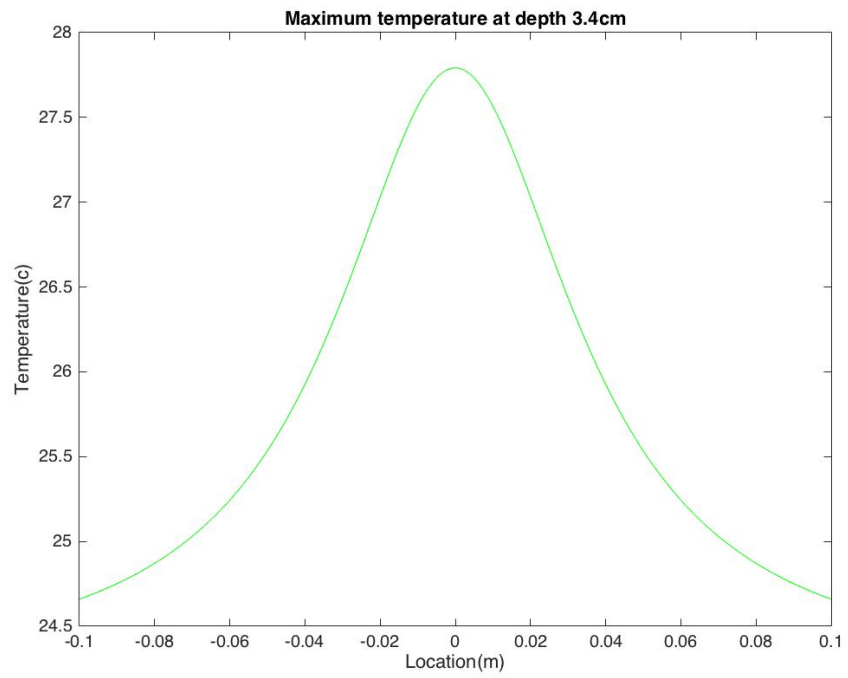

Figure 6-5 Analytical solution for a heater located at $3.4 \mathrm{~cm}$ depth having diameter of $3.1 \mathrm{~mm}$.

As it is illustrated above the maximum temperatures in figure 6-4 and 6-5 are very close to each other with a small difference of $0.76^{\circ} \mathrm{C}$. 
Additionally, from figure 6-5, it can be seen that the tip of the heater had tilted slightly but still is in the same depth.

\subsubsection{Experiment 2}

In this experiment we have taken the same steps as experiment 1 . The only difference in this case is that the heater was located at $2 \mathrm{~cm}$ depth from the surface of the Agar. The ambient temperature was fluctuating between $23.1{ }^{\circ} \mathrm{C}$ to $24^{\circ} \mathrm{C}$ which was negligible. At 6 volts figure 6-6 and 6-7 were obtained for maximum temperature of $31.9^{\circ} \mathrm{C}$ and $31.66^{\circ} \mathrm{C}$ respectively.

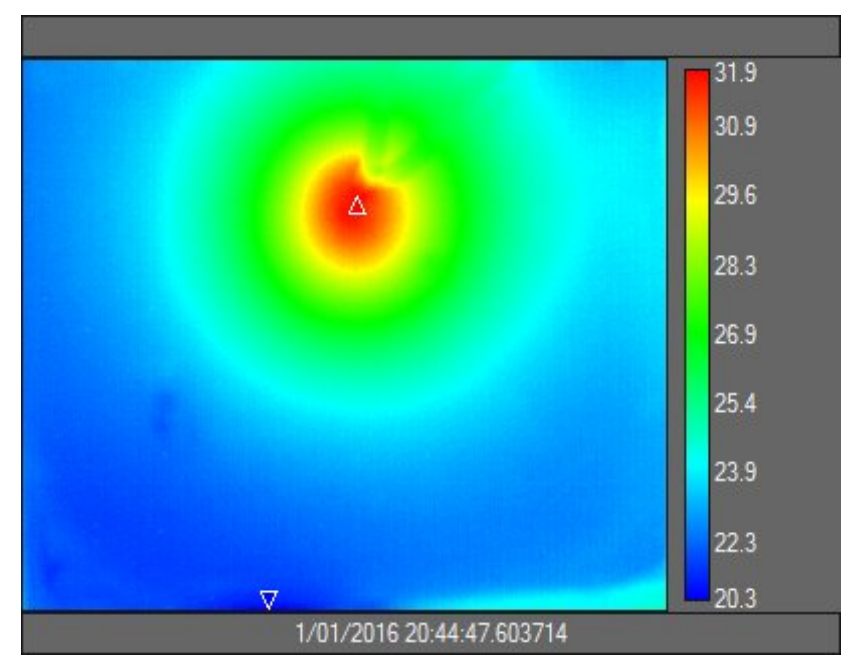

Figure 6-6 Thermal image of a heater located at $2 \mathrm{~cm}$ depth having diameter of $3.1 \mathrm{~mm}$. the red arrow illustrates the location of the maximum temperature and hence the tip of the heater. 


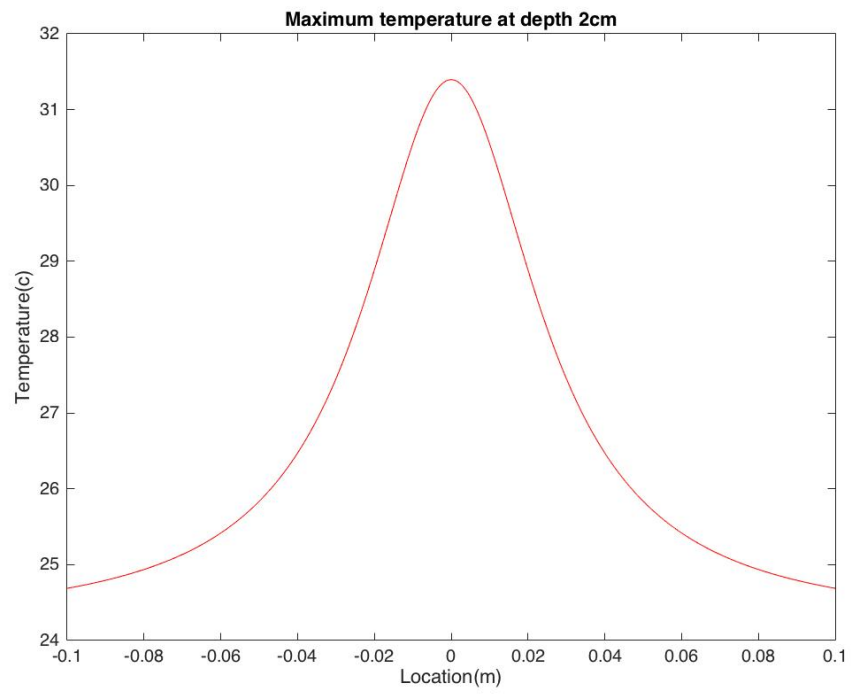

Figure 6-7 analytical solution for a heater located at $2 \mathrm{~cm}$ depth having diameter of $3.1 \mathrm{~mm}$.

As it is illustrated above the maximum temperatures in figure 6-6 and 6-7 are very close to each other with a small difference of $0.5^{\circ} \mathrm{C}$.

\subsubsection{Experiment 3}

The heater was located at $1 \mathrm{~cm}$ at fluctuating ambient temperature of $24.5^{\circ} \mathrm{C}$ to $24.9^{\circ} \mathrm{C}$ (the fluctuation is negligible). At $6 \mathrm{~V}(0.9 \mathrm{~W})$ voltage figure 6-8 and 6-9 was obtained from the camera and MATLAB.

As the figures 6-8 and 6-9 suggest, the maximum temperatures are very similar and there is a small difference of $0.11^{\circ} \mathrm{C}$ between the two. 


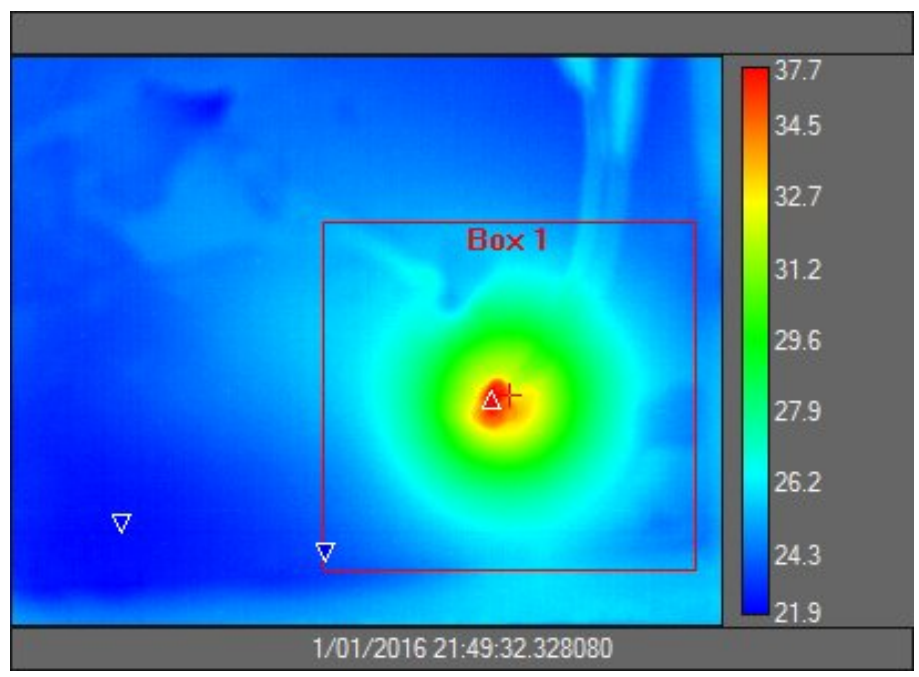

Figure 6-8 Thermal image of a heater located at $1 \mathrm{~cm}$ depth having diameter of $3.1 \mathrm{~mm}$. The red arrow illustrates the location of the maximum temperature and hence the tip of the heater.

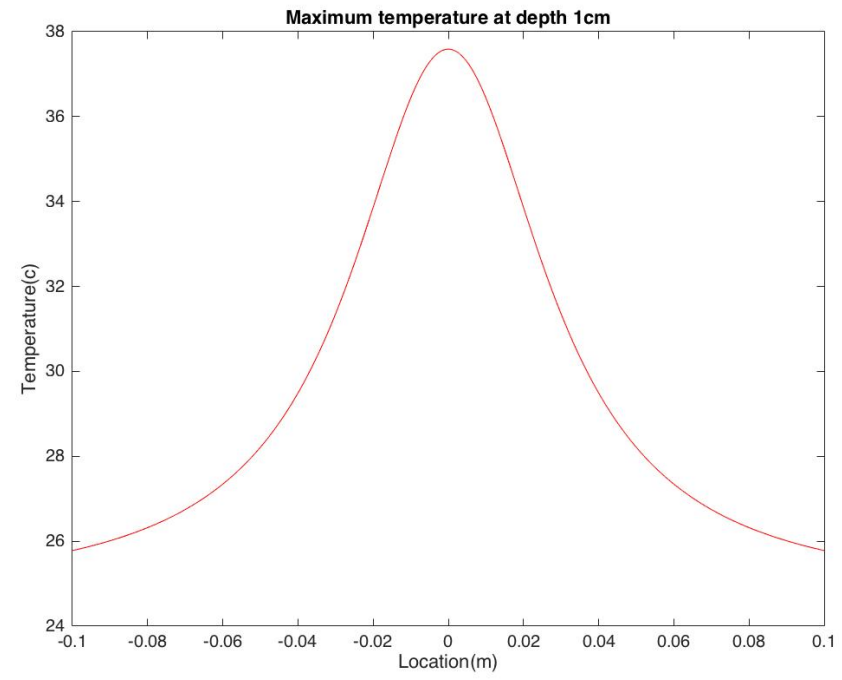

Figure 6-9 Analytical solution for a heater located at $1 \mathrm{~cm}$ depth having diameter of $3.1 \mathrm{~mm}$

Studying the thermal images above, there are regions of very low temperature at all the times. This is due to isolation of the phantom. The heat is only exchanged through the surface of the phantom and not trough any other sides. Table 6-2 summarizes the results obtained from experiments 1-3. It can be observed that by decreasing the tumor depth, the error of the method decrease. These results indicate that the proposed method for detection of superficial tumors is appropriate. 
Table 6-2 Results obtained through experiment 1-3.

\begin{tabular}{|l|l|l|l|l|}
$\begin{array}{l}\text { Experiment } \\
\text { Number }\end{array}$ & $\begin{array}{l}\text { Heat } \\
\text { source } \\
\text { Depth } \\
(\mathbf{c m})\end{array}$ & $\begin{array}{l}\text { Maximum } \\
\text { temperature from } \\
\text { Experimental } \\
\text { model }\left({ }^{\mathbf{0}} \mathbf{C}\right)\end{array}$ & $\begin{array}{l}\text { Maximum } \\
\text { temperature } \\
\text { from Analytical } \\
\text { model }\left({ }^{\mathbf{0}} \mathbf{C}\right)\end{array}$ & \multicolumn{2}{|l}{} \\
\hline $\mathbf{1}$ & 3.4 & 27.3 & 27.94 & 2.3 \\
\hline $\mathbf{2}$ & 2 & 31.9 & 31.66 & 0.75 \\
\hline $\mathbf{3}$ & 1 & 37.7 & 37.524 & 0.47 \\
\hline
\end{tabular}

\subsection{Control experimental tests}

The control experiments were conducted to increase the accuracy of the study. In this case, the top part of the phantom was shaved and a new layer of Agar solution was poured on the surface of the phantom. This time we allowed for even more inhomogeneity by creating lumps of harden Agar at the top of the surface. The phantom was let to cool down to room temperature and all three experiments were repeated again as below:

\subsubsection{Control experiment 1}

Heater was located at $3.4 \mathrm{~cm}$ at ambient temperature of $24.1^{\circ} \mathrm{C}$ at $6 \mathrm{~V}(0.9 \mathrm{~W})$. By the time that the system reached steady state, the ambient temperature was at $23.9^{\circ} \mathrm{C}$ (negligible fluctuation). The difference of the maximum temperatures is $1.23{ }^{\circ} \mathrm{C}$ with the red arrow locating the hottest point as shown in figure 6-10. This larger difference could be due to the lower voltage.

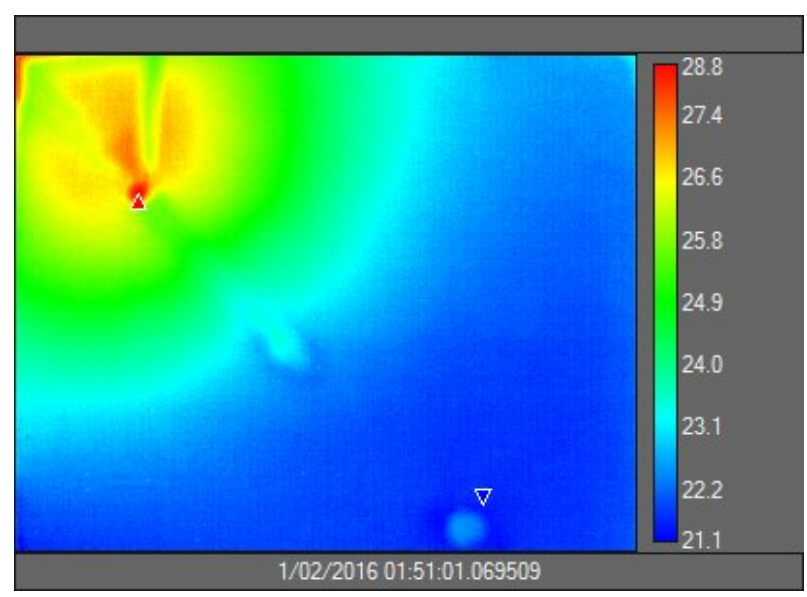

Figure 6-10 Thermal image of a heater located at $3.4 \mathrm{~cm}$ depth having diameter of $3.1 \mathrm{~mm}$. The red arrow illustrates the location of the maximum temperature and hence the tip of the heater. 
Figure 6-11 illustrates the heater thermal profile per camera pixel.

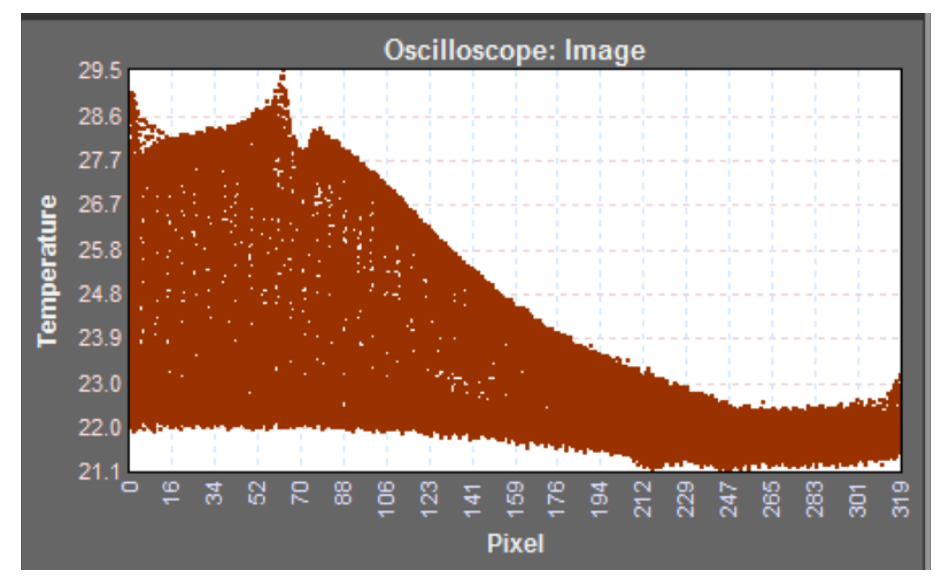

Figure 6-11 Temperature profile of the heater per pixel. Maximum temperature happens somewhere around 70.

\subsubsection{Control experiment 2}

Heater was located at $2 \mathrm{~cm}$ at ambient temperature of $23.9^{\circ} \mathrm{C}$ at $6 \mathrm{~V}$. The difference of the maximum temperatures is $0.6^{\circ} \mathrm{C}$ with the red arrow locating the hottest point as shown in figures 6-12 and 6-13.

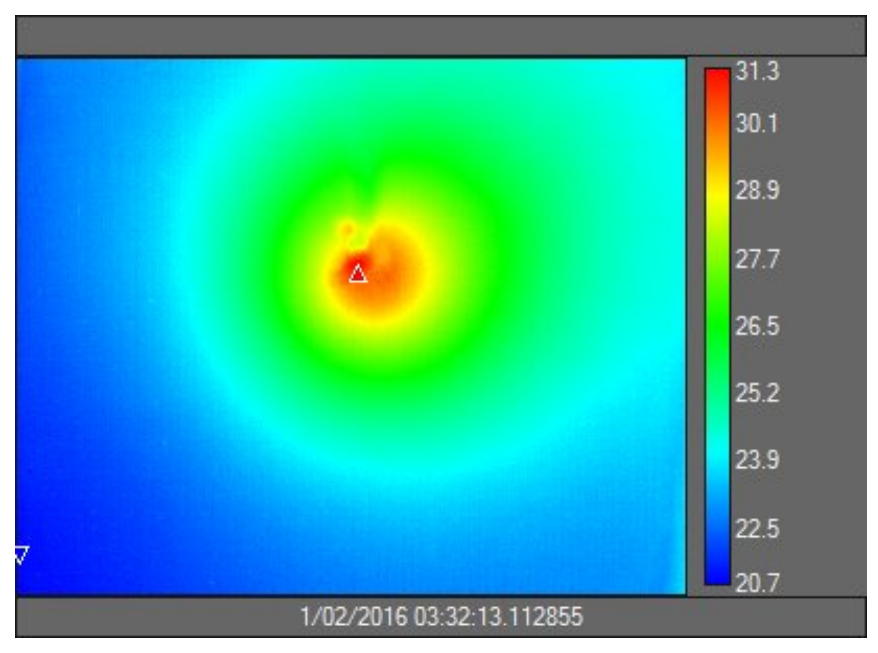

Figure 6-12 Thermal image of a heater located at $3.4 \mathrm{~cm}$ depth having diameter of $3.1 \mathrm{~mm}$. The red arrow illustrates the location of the maximum temperature and hence the tip of the heater. 


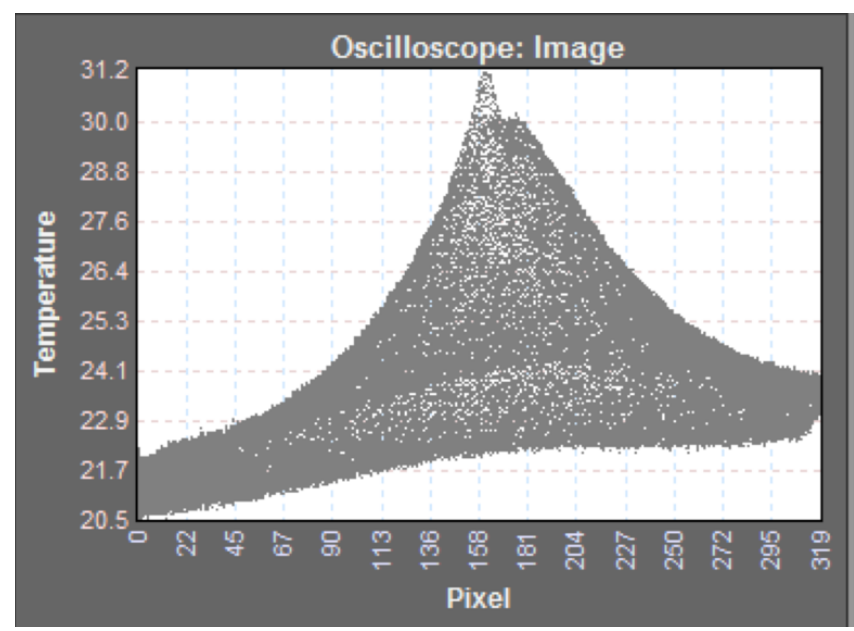

Figure 6-13 Temperature profile of the heater per pixel. Maximum temperature happens somewhere around 158.

\subsubsection{Control experiment 3}

Finally, the heater was located at $1 \mathrm{~cm}$ again at ambient temperature of $22{ }^{\circ} \mathrm{C}$ at $6 \mathrm{~V}(0.9 \mathrm{~W})$. This time the difference of the maximum temperatures was found to be $1.7^{\circ} \mathrm{C}$ with the red arrow locating the hottest point. This difference could be due to the lower voltage as well as lower ambient temperature (figures 6-14 and 6-15).

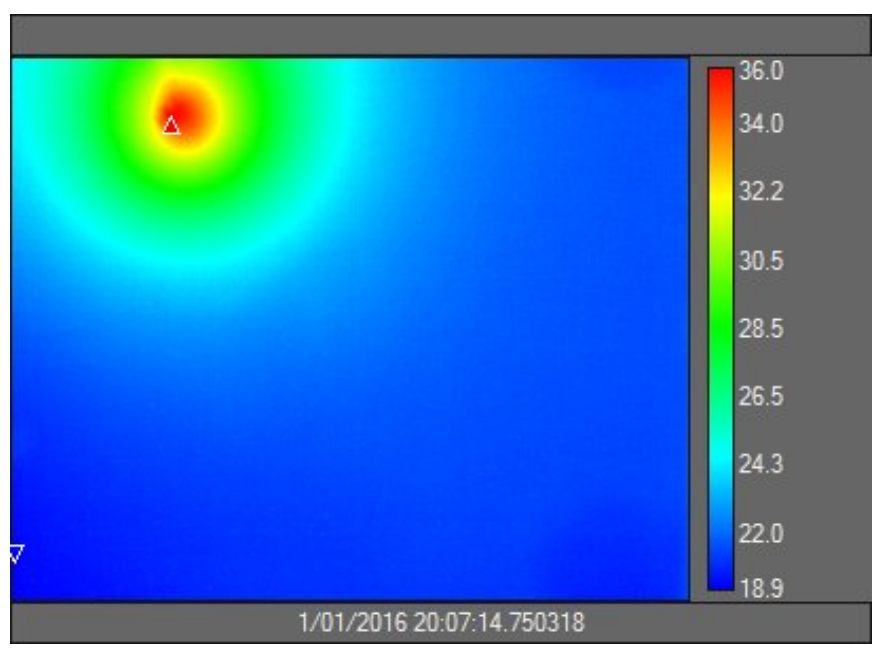


Figure 6-14 Thermal image of a heater located at $1 \mathrm{~cm}$ depth having diameter of $3.1 \mathrm{~mm}$. The red arrow illustrates the location of the maximum temperature and hence the tip of the heater.

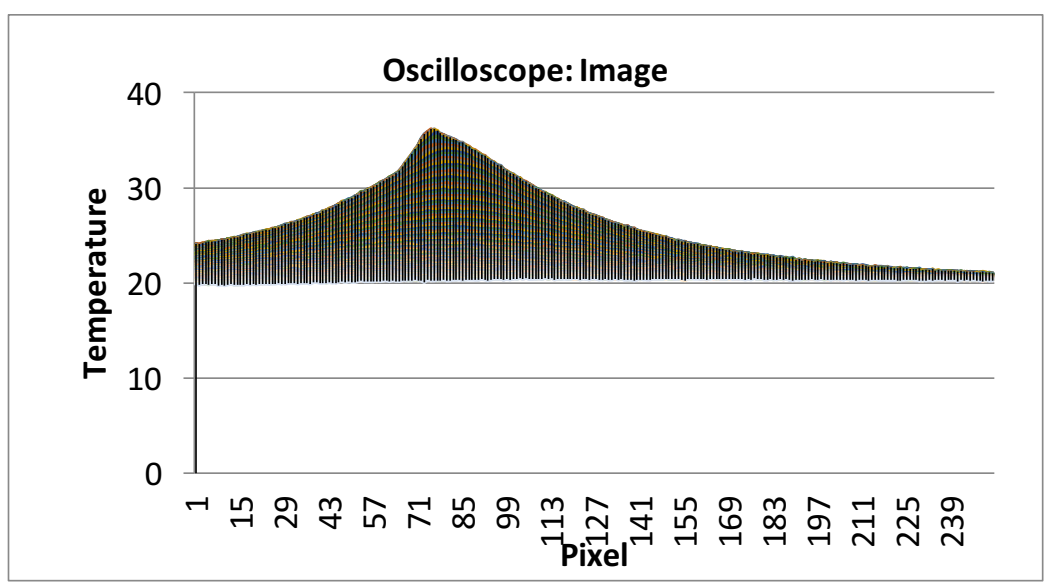

Figure 6-15 Temperature profile of the heater per pixel. Maximum temperature happens somewhere around 76.

A summary of obtained results are listed in Table 6-3.

Table 6-3 Results obtained through experiment 1-3 and control experiments 1- 3 .

\begin{tabular}{|c|c|c|c|c|c|}
\hline Exp.\# & $\begin{array}{c}\text { Voltage } \\
\text { (V) }\end{array}$ & $\begin{array}{l}\text { Heat } \\
\text { source } \\
\text { Depth } \\
\text { (cm) }\end{array}$ & $\begin{array}{c}\text { Maximum } \\
\text { temperature from } \\
\text { experimental } \\
\text { model }\left({ }^{\circ} \mathrm{C}\right)\end{array}$ & $\begin{array}{c}\text { Maximum } \\
\text { temperature from } \\
\text { Analytical model } \\
\left({ }^{\circ} \mathrm{C}\right)\end{array}$ & $\begin{array}{c}\text { Deviation } \\
\text { (\%) }\end{array}$ \\
\hline 1 & 6 & 3.4 & 27.3 & 27.94 & 2.3 \\
\hline 2 & 6 & 2 & 31.9 & 31.66 & 0.75 \\
\hline 3 & 6 & 1 & 37.7 & 37.524 & 0.47 \\
\hline C1 & 6 & 3.4 & 28.8 & 27.84 & 3.3 \\
\hline $\mathrm{C} 2$ & 6 & 2 & 31.3 & 31.60 & 0.95 \\
\hline C3 & 6 & 1 & 36.0 & 35.58 & 0.41 \\
\hline
\end{tabular}




\subsection{Heater with fixed temperature}

This part of the study was conducted for the $2 \mathrm{~cm}$ depth. The heater was allowed to reach a constant temperature of $45^{\circ} \mathrm{C}$ and placed at the desired depth while ambient temperature was constant at $22{ }^{\circ} \mathrm{C}$. Since the phantom is isolated, it includes regions of very low temperature. Also, heater has a very small surface area. Therefore, in this certain circumstances, it was found that the heater exchange heat with the environment faster than expected.

The heater was allowed to sit in the phantom for 5 hours until the temperature fluctuation has stopped. At this point the maximum temperature was reached to around $29{ }^{\circ} \mathrm{C}$ as as shown in Figure 6-16.

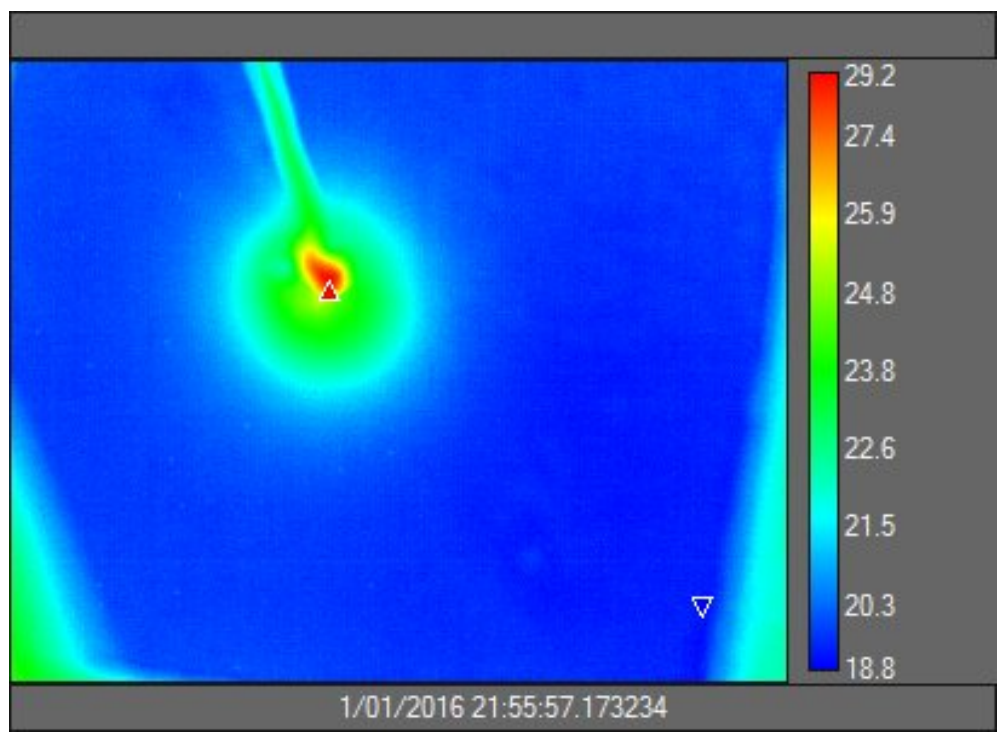

Figure 6-16 Thermal image of a heater located at $2 \mathrm{~cm}$ depth having diameter of $3.1 \mathrm{~mm}$.

Using the maximum temperature of $29.2^{\circ} \mathrm{C}$ in equation $4-7$ and employing thermal and physical properties listed in table $4-1$, the depth is found to be $2.326 \mathrm{~cm}$. This value is very close to the original depth that we have positioned the heater at. It is possible to optimize the location of the tumor by various optimization techniques. To do so, the same technique (artificial Neural Networks (ANN)) employed in our paper [REF]. 


\subsection{Summary}

In this chapter, we have used the laboratory setup in order to validate the developed analytical approach. The experimental test set up was composed of a 0-50 DC power source, an IR camera (FLIR SC 4000), a small cartridge heater of length $12.7 \mathrm{~mm}$ and diameter $3.1 \mathrm{~mm}$, a small cubical container designed by SolidWorks and printed Via 3D printer with dimensions of $9 \mathrm{~cm} \times 9 \mathrm{~cm} \times$ $4 \mathrm{~cm}$, a digital thermometer, a thermocouple (for calibration of camera), and solution of Noble Agar prepared and used as tissue phantom.

The heater was heated at 6 volts $(0.9 \mathrm{~W})$ for all the experiments and control sets, and data were recorded. As it could be found from the obtained results, for a same heat source (at $6 \mathrm{~V}$ ) located at different depth, the experimental results are very close to the analytical findings. This difference in maximum temperatures between the analytical results and their corresponding experimental results could be due to isolation of phantom, fluctuation in temperature, expansion of the metal heater, and any other environmental factors. 


\section{Chapter 7 \\ General conclusions and future work}

\section{Conclusion and future work}

\subsection{Conclusions}

The objective of this thesis was to develop an analytical method to diagnosis and parameterization of superficial tumors embedded in the human organ by measuring the surface temperature distribution utilizing thermography. Thermograms have a high incidence of false positive therefor; their clinical application was very limited during cancer detection. However, this study shows improved performance in earlier detection of cancer when thermal imaging was applied with the combination of analytical methods. The analytical method was used to train and ANN to optimize the model. Finally, the model was validated using a laboratory set up.

\subsection{Summary of Contribution of this thesis}

The analytical method was developed by using penne's bioheat equation for the estimation of thermophysical or geometrical parameters of a tumor region. This process has been optimized using artificial neural networks (ANN). Utilizing this self- learning algorithm, it was possible to optimize the location of the heat source embedded under the tissue. The study has developed physical models for the chest, and breast tissues. The cuboid model of the chest is built on four layers - the body core, muscle, fat, and skin where heat flows in the radial direction from the center toward the skin surface. The breast model is given a hemispherical shape overall with muscle, gland, fat, and skin tissues where axial heat flow takes place.

The heat flow problem at steady state has been addressed analytically for both tissues. It was also considered that the breast tissue is mainly composed of adipose tissue and chest was mainly composed of muscle. With the obtained analytical solutions, the effects of the thermal conductivity, the blood perfusion rate, the metabolic heat generation rate and the coefficient of heat transfer on the temperature distribution in living tissues were analyzed. An analytical model has provided a useful means to accurately study the temperature behavior of the biological 
system. Additionally, the sensitivity of each of the parameters was analyzed. It was found that surface temperature is the most sensitive in case of accurately measuring the tumor location.

To evaluate the developed analytical model, a laboratory set-up was designed. During the testing, a heat source was embedded in various depth of tissue phantom and was imaged with an infrared camera. Additionally, the analytical model was running at the same time. Given at a certain depth and diameter of heat source, the surface temperature found by the analytical model was carefully following the surface temperature measured with the camera.

Some of the main observations in this project are summarized below:

- Development of models of living organs such as chest, and breast by mimicking the organ's anatomy and shape.

- Solving bio-heat transfer problem numerically on the accurate anatomic models of the abovementioned organs in the presence of tumors to show how tumor's physical, thermal and biological parameters influence the surface temperature. The rate of change in surface temperature with respect to a particular parameter (element of the directional derivatives) provides a useful means for inverse source computation from a temperature distribution.

- Performing test for each of the models using tissue phantoms and validation of the analytical results.

\subsection{Future work}

The proposed methodology can estimate any tumors that are located superficially various organs. Combined with another active tomography it could be used to determine, for deep-seated benign tumors.

As this study was not validated with clinical data or biopsy results, the method could not be applied as the only diagnostic tool. One of the future works includes animal and clinical tastings. To validate the proposed methodology, the ongoing research in the Electro-thermal Laboratory at Ryerson University is trying to build collaboration with Canadian Breast Cancer Society to collect the surgical data and true thermogram. 


\section{Appendices}

\section{Cartridge Heater Data sheet.}

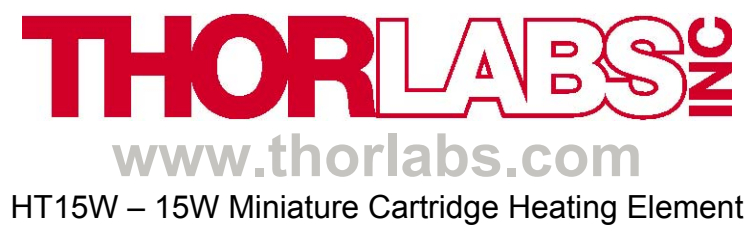

\section{Product Description:}

The HT15W is a $1 / 8$ " $\times 1 / 2$ ", $15 \mathrm{~W}$ heating element rod with 2.5 " leads compatible with Thorlabs TC200 general purpose heater controller.

\section{Specifications:}

Rated Heater Power: 15W @ 24V $\pm 20 \%$ (3.8W @ 12V and 0.90W @ 6V)

Diameter: $0.122 "$ nominal $\pm 0.002 "(3.1 \mathrm{~mm})$

Length: 0.5 " nomimal $\pm 0.015 "(12.7 \mathrm{~mm})$

Heater Resistance: $38.4 \Omega \pm 10 \%$

Lead Length: 2.5 " Typ. (63.5mm)

Maximum Block Temperature: $315^{\circ} \mathrm{C}\left(600^{\circ} \mathrm{F}\right)$ (when installed in a $0.125^{\prime \prime}$ diameter bore in a metal block)

\section{Application Information:}

Maximum Lead Exit Temperature: The lead exits of the heater are insulated with Teflon (PTFE) end caps. While the heater body may be operated at much higher temperatures, the Teflon caps should never exceed $260^{\circ} \mathrm{C}\left(500^{\circ} \mathrm{F}\right)$.

Use of Release Agents: The HT15W is guaranteed not to seize in any installation. Because of this the use of release agents is unnecessary and not recommended. However, these agents may still be applied if desired. In some cases the release agent may enter the heater and cause a temporary loss of insulation resistance. This can be restored by warming the heater to $120^{\circ} \mathrm{C}$ $\left(250^{\circ} \mathrm{F}\right)$ prior to application of full power.

Related Thorlabs Products:

TH10K - 10K $\Omega$ NTC Thermistor $\left(150^{\circ} \mathrm{C}\right.$ maximum)

TH100PT - $100 \Omega$ PTC Platinum Temperature Sensor $\left(750^{\circ} \mathrm{C}\right.$ maximum)

TC200 - General Purpose Heater Controller 
Cartridge heater. 


\section{Camera: FLIR SC4000 Data Sheet.}

\section{A FiLIRR}

The Global Leader in Infrared Cameras

THERMOVISION"

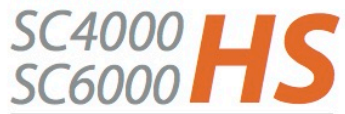

HIGH SPEED SERIES

The ThermoVision ${ }^{\circledR}$ HS Series is the premier infrared solution for advanced industrial, scientific and military applications.

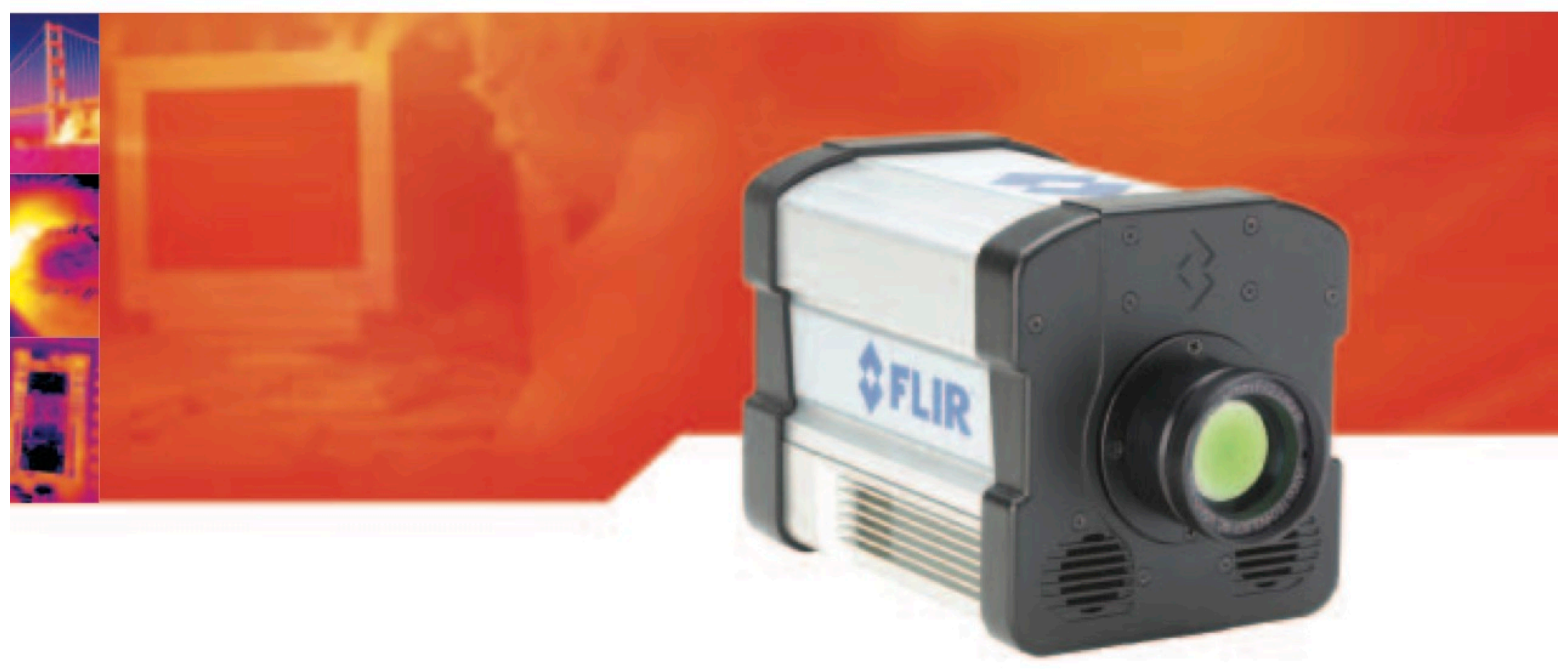

> Simultaneous Analog and Digital Data Output

> Adjustable and Triggered Integration Times

$>$ Gigabit Ethernet, Camera Link ${ }^{\mathrm{TM}}$ and USB

> Selectable Preset Sequencing

> Integrated IRIG-B Time Stamp

> Optimized for ThermaCAM ${ }^{\circledR}$ RTools and ThermaCAM ${ }^{\circledR}$ Researcher Software

> Compatible with ThermaCAM RTools HSDR and ThermaCAM Researcher HSDR

> On-Board Temperature Calibration Available 


\section{HS Series Specifications}

\begin{tabular}{|c|c|c|c|}
\hline & SC4000 HS-NIR / SC6000 HS-NIR & SC4000 HS-MWIR/SC6000 HS-MWIR & SC4000 HS-LWIR/SC6000 HS-LWIR \\
\hline \multicolumn{4}{|l|}{ Detector Specifications } \\
\hline Detector & Indium Gallium Arsenide (InGaAs) & Indium Antimonide (InSb) & $\begin{array}{l}\text { Gallium Arsenide (GaAs) } \\
\text { Quantum Well Infrared Photodetectors(QWIP) }\end{array}$ \\
\hline Spectral Range & $0.9-1.7 \mu \mathrm{m}$ & $3.0-5.0 \mu \mathrm{m}$ & $8.0-9.2 \mu \mathrm{m}$ \\
\hline Broadband Option & $0.4-1.7 \mu \mathrm{m}$ (VisGaAs) & $1.5 \cdot 5.0 \mu \mathrm{m}$ & NA \\
\hline Resolution & $320(\mathrm{H}) \times 256(\mathrm{~V}) / 640 \times 512$ & $320(\mathrm{H}) \times 256(\mathrm{~V}) / 640 \times 512$ & $320(\mathrm{H}) \times 256(\mathrm{~V}) / 640 \times 512$ \\
\hline Pixel Pitch & $30 \times 30 / 25 \times 25 \mu \mathrm{m}$ & $30 \times 30 / 25 \times 25 \mu \mathrm{m}$ & $30 \times 30 / 25 \times 25 \mu \mathrm{m}$ \\
\hline \multicolumn{4}{|l|}{ Electronics \& Data Rate } \\
\hline Integration Type & Snapshot & Snapshot & Snapshot \\
\hline $\begin{array}{l}\text { Integration Time } \\
\text { (Electronic Shutter Speed) }\end{array}$ & $3 \mu \mathrm{s}$ to full frame time & $9 \mu \mathrm{S}$ to full frame time & $9 \mu \mathrm{S}$ to full frame time \\
\hline Read-out Modes & $\begin{array}{l}\text { Asynchronous Integrate while read } \\
\text { Asynchronous Integrate then read } \\
\text { Special Integrate then read }\end{array}$ & $\begin{array}{l}\text { Asynchronous integrate while read } \\
\text { Asynchronous Integrate then read }\end{array}$ & $\begin{array}{l}\text { Asynchronous Integrate while read } \\
\text { Asynchronous Integrate then read }\end{array}$ \\
\hline Dynamic Range & 14 bits & 14 bits & 14 bits \\
\hline Data Rate & $50 \mathrm{MHz}$ & $50 \mathrm{MHz}$ & $50 \mathrm{MHz}$ \\
\hline Full Frame Rate & Programmable $1 \mathrm{~Hz}=420 \mathrm{~Hz} / 1 \mathrm{~Hz}=125 \mathrm{~Hz}$ & Programmable $1 \mathrm{~Hz}=42 \mathrm{~Hz} / 1 \mathrm{~Hz}=125 \mathrm{~Hz}$ & Programmable $1 \mathrm{~Hz}=420 \mathrm{~Hz} / 1 \mathrm{~Hz}=125 \mathrm{~Hz}$ \\
\hline Subwindowing & Yes - user defined & Yes - user defined & Yes - user defined \\
\hline \multicolumn{4}{|l|}{ Minimum Window Size } \\
\hline Superframing & Yes - up to 4 presets & Yes - up to 4 presets & Yes - up to 4 presets \\
\hline Preset Sequencing & Yes - up to 4 presets & Yes - up to 4 presets & Yes - up to 4 presets \\
\hline \multicolumn{4}{|l|}{ Performance Specifications } \\
\hline NEI / NETD & $\begin{array}{l}\text { Low Gain 3E-10W/cm² } \\
\text { High Gain: 1.5E-7W/cm }\end{array}$ & $<25 \mathrm{mk}(18 \mathrm{mK}$ typical) & $<35 \mathrm{mk}$ \\
\hline Well Capacity & $\begin{array}{l}\text { Low Gain: } x \text { M electrons / Low Gain: } 2.5 \mathrm{M} \text { electrons } \\
\text { High Gain: } 17 \text { Kelectrons / High Gain: } 93 \text { Kelectrons }\end{array}$ & $18 \mathrm{M}$ electrons / $11 \mathrm{M}$ electrons & $18 \mathrm{M}$ electrons $/ 11 \mathrm{M}$ electrons \\
\hline Operability & $\begin{array}{l}>99.5 \% \\
>99.896 \text { typical }\end{array}$ & $\begin{array}{l}>99.5 \% \\
>99.8 \% \text { typical }\end{array}$ & $\begin{array}{l}>99.5 \% \\
>99.8 \% \text { typical }\end{array}$ \\
\hline \multicolumn{4}{|l|}{ Camera Specifications } \\
\hline Sensor Assembly f/\# & Set by lens iris & $f / 2.5$ standard, $f / 4.1$ optional & f/2.5 standard, f/4.1 optional \\
\hline Sensor Cooling & Thermoelectric coolet & $\begin{array}{l}\text { Stirling closed cycle cooler; } \\
\text { optional Liquid Nitrogen (LN) }\end{array}$ & Stirling closed cycle cooler \\
\hline Lens Mount & C-Mount / Canon FD & Twist-lock Bayonet & Twist-lock Bayonet \\
\hline Power & $24 \mathrm{VOC}$ & $24 \mathrm{VDC}$ & $24 \mathrm{VDC}$ \\
\hline \multicolumn{4}{|c|}{ Advanced Communication and Data Transfer } \\
\hline Command and Control & USB, Gigabit Ethernet & & \\
\hline 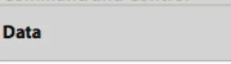 & $\begin{array}{l}\text { Gigabit Ethernet - Digital } \\
\text { Camera Link - Digital } \\
\text { Composite (BNC) - Analog }\end{array}$ & & \\
\hline
\end{tabular}

\begin{tabular}{|c|c|c|}
\hline \multicolumn{3}{|l|}{ Lenses - Optionally Available } \\
\hline \multicolumn{3}{|l|}{ InSb Camera Lenses - (3.0 - 5.0 microns) } \\
\hline Lens Focal Length & $320 \times 256$ Resolution & $640 \times 512$ Resolution \\
\hline $13 \mathrm{~mm}$ & $40.5^{\circ} \times 32.9^{\circ} \mathrm{FoV}$ & $63.2^{\circ} \times 52.4^{\circ} \mathrm{FoV}$ \\
\hline $25 \mathrm{~mm}$ & $21.7 \times 17.5^{\circ} \mathrm{FoV}$ & $35.5^{\circ} \times 28.7^{\circ} \mathrm{FoV}$ \\
\hline $50 \mathrm{~mm}$ & $11.0^{\circ} \times 8.8^{\circ} \mathrm{FoV}$ & $18.2^{\circ} \times 14.6^{\circ} \mathrm{FoV}$ \\
\hline $100 \mathrm{~mm}$ & $5.5^{\circ} \times 4.4^{\circ} \mathrm{FoV}$ & $9.1^{1} \times 73^{*} \mathrm{FoV}$ \\
\hline Dual Field of View 50/250 mmElectronics \& Data Rate & $\begin{array}{l}50 \mathrm{~mm}\left(11^{\circ} \times 8^{8} \mathrm{FoV}\right) \\
250 \mathrm{~mm}\left(2.2^{\circ} \times 1.8^{\prime \prime} \mathrm{FoV}\right)\end{array}$ & $\begin{array}{l}50 \mathrm{~mm}\left(18.2^{\circ} \times 14.6^{\circ} \mathrm{FoV}\right) \\
250 \mathrm{~mm}\left(3.7^{\circ} \times 2.9^{\circ} \mathrm{FoV}\right)\end{array}$ \\
\hline Triple Field of View $60 / 180 / 500 \mathrm{~mm}$ & $\begin{array}{l}60 \mathrm{~mm}\left(9.1^{\circ} \times 7.3^{\circ} \mathrm{FoV}\right. \\
180 \mathrm{~mm}\left(3.11^{*} \times 2.4^{*} \mathrm{FoV}\right) \\
500 \mathrm{~mm}\left(1.1^{*} \times 0.9^{\circ} \mathrm{FoV}\right)\end{array}$ & $\begin{array}{l}60 \mathrm{~mm}\left(15.2^{\circ} \times 12.2^{\circ} \mathrm{FoV}\right. \\
180 \mathrm{~mm}\left(5.11^{10} \times 4.1^{\circ} \mathrm{FoV}\right) \\
500 \mathrm{~mm}\left(1.8^{\circ} \times 1.5^{\circ} \mathrm{FoV}\right)\end{array}$ \\
\hline Microscope & $\begin{array}{l}1 x \\
2.5 x \\
4 x\end{array}$ & $\begin{array}{l}1 x \\
2.5 x \\
4 x\end{array}$ \\
\hline \multicolumn{3}{|c|}{ QWIP Camera Lenses - QWIP Cameras (8.0 - 9.2 microns) } \\
\hline Lens Focal Length & $320 \times 256$ Resolution & $640 \times 512$ Resolution \\
\hline $13 \mathrm{~mm}$ & $40.5^{\circ} \times 32.9^{\circ} \mathrm{FoV}$ & $63.2^{\circ} \times 52.4^{\circ} \mathrm{FoV}$ \\
\hline $25 \mathrm{~mm}$ & $21.7 \times 17.5^{\circ} \mathrm{FoV}$ & $35.5^{\circ} \times 28.7^{\circ} \mathrm{FoV}$ \\
\hline $50 \mathrm{~mm}$ & $11.0^{\circ} \times 8.8^{\circ} \mathrm{FoV}$ & $18.2^{\circ} \times 14.6^{\circ} \mathrm{FoV}$ \\
\hline $100 \mathrm{~mm}$ & $5.5^{\circ} \times 4.4^{\circ} \mathrm{FoV}$ & $9.1^{*} \times 73^{\circ} \mathrm{FoV}$ \\
\hline \multicolumn{3}{|c|}{ InGaAs Camera Lenses - InGaAs Cameras (0.9 - 1.7 microns) } \\
\hline Lens Focal Length & $320 \times 256$ Resolution & $640 \times 512$ Resolution \\
\hline $8 \mathrm{~mm}$ & $62^{\circ} \times 51^{\circ} \mathrm{FoV}$ & On request \\
\hline $16 \mathrm{~mm}$ & $33^{\circ} \times 27^{\circ} \mathrm{FoV}$ & On request \\
\hline $25 \mathrm{~mm}$ & $22^{\circ} \times 17^{\circ} \mathrm{FoV}$ & $25.5 \times 28.7$ \\
\hline $50 \mathrm{~mm}$ & $11^{\circ} \times 9^{\circ}$ FoV & $18.2 \times 14.6$ \\
\hline
\end{tabular}

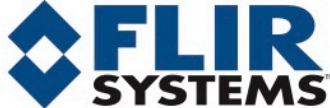

The Global Leader in Infrared Cameras

18004646372
View a SC4000/6000 Video at www.flirthermography.com/hsseries

Made in U.S.A.

Specifications subject to change. 0 Copyright 2006, FLIR Systems, Inc. All rights reserved. $1052406 \mathrm{PL}$ 
Noble Agar Data Sheet.

SIGMA-ALDRICH

sigma-aldrich.com

3050 Spruce Street, Saint Louis, MO 63103, USA

Website: www.sigmaaldrich.com

Email USA: techserv@sial.com

Outside USA: eurtechserv@sial.com

Product Name:

Noble agar

Product Number:

CAS Number:

MDL:

MFCD00081288

\section{Product Specification}

TEST

Appearance (Color)

Appearance (Form)

Residue on ignition (Ash)

Gel Temperature

Loss on Drying

Specification: PRD.0.ZQ5.10000037222

\section{Specification}

White to Light Yellow
Powder
$\leq 2 \%$
$32-39{ }^{\circ} \mathrm{C}$
$\leq 20 \%$

Sigma-Aldrich warrants, that at the time of the quality release or subsequent retest date this product conformed to the information contained in this publication. The current Specification sheet may be available at Sigma-Aldrich.com. For further inquiries, please contact Technical Service. Purchaser must determine the suitability of the product for its particular use. See reverse side of invoice or packing slip for additional terms and conditions of sale.

1 of 1 


\section{References}

[1] "Breast cancer: prevention and control", World Health Organization, 2017. [Online]. Available: http://www.who.int/cancer/detection/breastcancer/en/index1.html. [Accessed: 28Mar- 2017].

[2] "Breast cancer statistics - Canadian Cancer Society", www.cancer.ca, 2017. [Online]. Available: http://www.cancer.ca/en/cancer-information/cancer-type/breast/statistics/?region=bc. [Accessed: 28- Mar- 2017].

[3] M. J. Yaffe, "Mammography," in Biomedical Engineering Handbook, FL, CRC, Boca Raton, 1995.

[4] P. C. Pieters, M. W. J and J. H. DeMeo, "Evaluation of the portal venous system: complementary roles of invasive and noninvasive imaging strategies," RadioGraphics, vol. 17, no. 1, pp. 879-895, 1997.

[5] H. F. Bowman, "Estimtion of tissue blood flow," in Heat Transfer in Medicine and Biology, New York, Plenum Press, 1985, pp. 193-230.

[6] I. Laakso, and A. Hirata, "Dominant factors affecting temperature rise in simulations of human thermoregulation during RF exposure.”, Phys Med Biol. 2011 Dec 7, 56(23):7449-71.

[7] R. Habash, R. Bansal, D. Krewski and H. Alhafid, "Thermal Therapy, Part IV: Electromagnetic and Thermal Dosimetry", Critical Reviews ${ }^{\mathrm{TM}}$ in Biomedical Engineering, vol. 35, no. 1-2, pp. 123-182, 2007.

[8] E. Y. K. Ng, "Is thermal scanner lossing its bite in mass screening of fever due to SARS?," Medical Physics, vol. 32, pp. 93-97, 2005. 
[9] Md. S. Hossain, "development of methodology for detection of abnormal functioning region in human external organs using thermo-gram analysis," $\mathrm{PhD}$ thesis, electrical and computer engineering Dept., Ryerson Univ., Toronto, Ontario, 2015.

[10] P. Gamagami, "Indirect signs of breast cancer: Angiogenesis study," in Atlas of Mammography, Cambridge, Mass. Blackwell Science, 1996, pp. 231-326.

[11] "Mammogram Basics", Cancer.org, 2017. [Online]. Available: http://www.cancer.org/treatment/understandingyourdiagnosis/examsandtestdescriptions/mammo gramsandotherbreastimagingprocedures/mammograms-and-other-breast-imaging-procedureswhat-is-mammogram. [Accessed: 28- Mar- 2017].

[12] "physics", Physics.org, 2017. [Online]. Available: https://www.physics.org/explore-resultsall.asp?currentpage $=1 \& q=$ mri. [Accessed: 28 - Mar- 2017].

[13] 2017. [Online]. Available: http://www.mayoclinic.org/tests-procedures/breastmri/details/what-you-can-expect/rec-20239454. [Accessed: 28- Mar- 2017].

[14] "PET Scans | Breastcancer.org", Breastcancer.org, 2017. [Online]. Available: http://www.breastcancer.org/symptoms/testing/types/pet. [Accessed: 28- Mar- 2017].

[15] Lovrics, Peter J., "A prospective evaluation of positron emission tomography scanning,sentinellyph node biopsy and standard axillary dissection for axillary staging in patients with early stage breast cancer." Annals of surgical oncology 11.9 (2004): 846-853.

[16] E. Y. K. Ng, E. C. Kee (2008). Advanced integrated technique in breast cancer thermography. Journal of medical engineering \& technology, 32(2), 103-114. 
[17] D. Mostovoy, "About Thermography", Thermographyclinic.com, 2017. [Online]. Available: http://www.thermographyclinic.com/about-thermography. [Accessed: 28- Mar- 2017].

[18] P. Gamigami, M.D.; Atlas of Mammography: New Early Signs in Breast Cancer. Blackwell Science, 1996.

[19] P.Ahlgren, M.D., E. Yu, M.D., J. Keyserlingk, M.D.; Is it Time to Reassess the Value of Infrared Breast Imaging? Primary Care \& Cancer (NCI), 1998; V 18, No. 2.

[20] "Stefan-Boltzmann Law", Hyperphysics.phy-astr.gsu.edu, 2017. [Online]. Available: http://hyperphysics.phy-astr.gsu.edu/hbase/thermo/stefan.html. [Accessed: 28- Mar- 2017].

[21] R. N. Lawson, "Implications of surface temperatures in the diagnosis of breast cancer", Canadian Medical Association Journal, 1956, 75, 309-311.

[22] J. W Draper, and C. H. Jones, "Thermal patterns of the female breast." , British Journal of Radiology, 1969, 42, 401-410.

[23] C. M. Feasey, M. Davison, and W B James, "Effects of natural and forced cooling on the thermographic patterns of tumors", Physics in Medicine \& Biology, 1971 16, 213-220.

[24] M. Davison, "Skin temperature distributions over veins and tumors.", Physics in Medicine \& Biology, 1972, 17, 309-310.

[25] M. Gautherie, "Thermobiological Assessment of Benign and Malignant Breast Diseases," Am J Obstet Gynecol, vol. 147, no. 8, pp. 861-869, 1983.

[26] H. Spitalier and D. Giraud, "Does Infrared Thermography Truly Have a Role in Present-Day Breast Cancer Management" in Biomedical Thermology, New York, Alan R. Liss , 1982, pp. 269278. 
[27] J. Haberman, J. Francis and T. Love, "Screening a Rural Population for Breast Cancer Using Thermography and Physical Examination Techniques," Ann NY Acad Sci, vol. 335, pp. 492-500, 1980.

[28] M. Gautherie, "Thermography of breast cancer: measurement and analysis of IN-VIVO temperature and blood flow," Ann. N. Y. Acad. Sci., vol. 335, pp. 383-413, 1980.

[29] K. Louis, J. Walter and M. Gautherie, "Long-Term Assessment of Breast Cancer Risk by Thermal Imaging," in Biomedical Thermology, NY, Alan R. Liss Inc, 1982, pp. 279-301.

[30] C. H. Jones, "Thermography of the Female Breast.," in Diagnosis of Breast Disease, Baltimore, University Park Press, 1983, pp. 214-234.

[31] I. Nyirjesy and Y. Ayme, "Clinical Evaluation, Mammography, and Thermography in the Diagnosis of Breast Carcinoma," Thermology, vol. 1, pp. 170-173, 1986.

[32] L. Thomassin and D. Giraud, "Detection of Subclinical Breast Cancers by Infrared Thermography," in Recent Advances in Medical Thermology, New York, Plenum Press, 1984, pp. 575-579.

[33] H. H. Pennes, (1948). Analysis of tissue and arterial blood tem- peratures in the resting human forearm. Journal of Applied Physiology, 1, 93-122.

[34] F. Han, G. Shi, C.Liang, L. Wang, K. L , "A simple and efficient method for breast cancer diagnosis based on infrared thermal imaging", C Cell Biochemistry and Biophysics, 71 (1), January 2015, 491-498.

[35] S. Hossain and F. Mohammadi, "Tumor Parameter Estimation Considering the Body Geometry by Thermography" Computers in Biology and Medicine, 76 (2016) 80-93.

[36] F. Duck, "Physical Properties of Tissues", Google Books, 2016. [Online]. Available: https://books.google.ca/books/about/Physical_Properties_of_Tissues.html?id=UaXpAgAAQBAJ 
\&redir_esc=y. [Accessed: 22- Jun- 2016].

[37] "Male Breast Cancer: The National Breast Cancer Foundation", www.nationalbreastcancer.org, 2016. [Online]. Available: http://www.nationalbreastcancer.org/male-breast-cancer. [Accessed: 21- Jun- 2016].

[38] B. Stewart and C. Wild, "World Cancer Report 2014 | The Health Well", Thehealthwell.info, 2016. [Online]. Available: http://www.thehealthwell.info/node/725845. [Accessed: 21- Jun2016].

[39] "Male Breast Cancer Treatment", National Cancer Institute, 2016. [Online]. Available: http://www.cancer.gov/types/breast/patient/male-breast-treatment-pdq. [Accessed: 21Jun- 2016].

[40] Md. S. Hossain, F. Mohammadi, "Localization and parameterization of tumor using thermography", Canadian conference on electrical and computer engineering, Toronto, ON, 2014, pp. $1-5$.

[41] Xianwu, T., Haishu, D., Guangzhi, W., \& Zhongqi, L. (2004, September). Relationship between surface temperature distribution and internal heat source size of the in-vitro tissue. In Engineering in Medicine and Biology Society, 2004. IEMBS'04. 26th Annual International Conference of the IEEE (Vol. 1, pp. 873-878). IEEE.

[42] M. Mital and R. Pidaparti, "Breast Tumor Simulation and Parameters Estimation Using Evolutionary Algorithms", Modelling and Simulation in Engineering, vol. 2008, pp. 1-6, 2008.

[43] J. Valvano, "Tissue Thermal Properties and Perfusion", Optical-Thermal Response of LaserIrradiated Tissue, pp. 445-488, 1995.

[44] H. Bowman, E. Cravalho and M. Woods, "Theory, Measurement, and Application of Thermal Properties of Biomaterials", Annual Review of Biophysics and Bioengineering, vol. 4, pp. : 43-80 (Volume publication date June 1975), 1975. 
[45] H. HATFIELD and L. PUGH, "Thermal Conductivity of Human Fat and Muscle", Nature, vol. 168, no. 4282, pp. 918-919, 1951.

[46] M. Kent, K. Christiansen, I. van Haneghem, E. Holtz, M. Morley, P. Nesvadba and K. Poulsen, "Cost 90 collaborative measurements of thermal properties of foods", Journal of Food Engineering, vol. 3, no. 2, pp. 117-150, 1984.

[47] J. Grayson, "Internal calorimetry in the determination of thermal conductivity and blood flow", The Journal of Physiology, vol. 1181, pp. 54-72., 1952.

[48] M. Gautherie. 1980. "Thermopathology of breast cancer: Measurement and analysis of in vivo temperature and blood flow." Annals of the New York Academy of Sciences 335: 383-415.

[49] E. F. J. Ring, "Progress in the measurement of human body temperature," IEEE Eng. Med. Biol., vol. 17, no. 4, pp. 19-24, 1998.

[50] C. Gros and M. Gautherie, " Breast Thermography and Cancer Risk Prediction," Cancer, vol. 45 , pp. 51-56, 1980.

[51] M. Molls and P. Vanupel, Blood perfusion and microenvironment of human tumours: Implications for Clinical radiooncology, Berlin: Springer-Verlag press, 1998.

[52] M. Zhou and Q. Chen, "Estimation of Temperature Distribution in Biological Tissue by Analytic Solutions to Pennes' Equation," in 2nd International Conference on Biomedical Engineering and Informatics, BMEI, IEEE, Nanjing, 2009.

[53] K. Yue, X. Zhang and F. YU, "An Analytic Solution of One-dimensional Steady-state Pennes' Bioheat Transfer Equation in Cylindrical Coordinates.,", Journal of Thermal Science, Vols. 13, Issue 3, pp. 255-258., no. 3, pp. 255-258, 2004. 
[54] R. N. Lawson and M. S. Chugatai, "Breast cancer and body temperatures," Canadian Medical Association Journal, vol. 88, pp. 68-70, 1963.

[55] N. A. Diakides and J. D. Bronzino, Medical Infrared Imaging, Florida: CRC, Boca Raton, 2007.

[56] G. A. Santa Cruz, J. Bertotti, S. Marin, S. J. Gonzalez, S. Gossio, D. Alvarez, B. M. C. Roth, P. Menendez, M. D. Pereira, M. Albero, L. Cubau, P. Orellano and S. J. Liberman, "Dynamic infrared imaging of cutaneous melanoma and normal skin in patients treated with BNCT," Applied radiation and isotopes, vol. 67, pp. 54-58, 2009.

[57] J. P. Agnelli, A. A. Barrea and T. C. V, "Tumor location and parameter estimation by thermography," Mathematical and Computer Modelling, vol. 129, no. 1, pp. 1-4, 2010.

[58] E. Y. K. Ng and N. M. Sudharsan, "An improved three-dimensional direct numerical modeling and thermal analysis of a female breast with tumor," Intl. MechEngrs, vol. 215, pp. 25$37,2006$. 


\section{Glossary}

Parameter

Thermal conductivity

Metabolism

Blood perfusion rate

Heat exchange rate

Specific heat (blood)

Specific heat (tissue)

Density (blood)

Density (tissue)

Artier blood temperature

Body core temperature

Skin temperature

Environment temperature

Tumor doubling time

Tumor diameter

Tumor radius

Tissue thickness or radius

Tumor location

Heat source model constant

Heat rate ratio

\section{Symbol}

$k$

$Q m$

$\omega b$

ha

$c b$

c

$\rho b$

$\rho$

$T a$

Tc

TS

Te

$\tau$

D

$R$

$d$

h

\section{$\gamma$ \\ $n$}

\section{Unit}

$W /(m \cdot K)$
$W / m 3$
$1 / \mathrm{s}$
$W /(m 2 . K)$
$J /(k g . K)$
$J /(k g . K)$
$k g / m^{3}$
$k g / m^{3}$
$K$
$K$
$K$
$K$
day
$\mathrm{m}$
$\mathrm{m}$
$\mathrm{m}$
$\mathrm{m}$


